UNIVERSIDADE DE SÃO PAULO

FACULDADE DE ODONTOLOGIA DE RIBEIRÃO PRETO

ADRIANA CLÁUDIA LAPRIA FARIA

Avaliação de ligas experimentais de titânio para utilização em estruturas metálicas de próteses dentárias

Ribeirão Preto 


\section{Avaliação de ligas experimentais de titânio para utilização em estruturas metálicas de próteses dentárias}

Tese apresentada à Faculdade de Odontologia de Ribeirão Preto da Universidade de São Paulo para obtenção de título de Doutor em Reabilitação Oral.

Área de Concentração: Reabilitação Oral

Orientador: Prof. Dr. Ricardo Faria Ribeiro

Co-orientador: Prof. Dr. Adalberto Luiz Rosa

Ribeirão Preto 


\begin{abstract}
AUTORIZO A REPRODUÇÃO E DIVULGAÇÃO TOTAL OU PARCIAL DESTE TRABALHO, POR QUALQUER MEIO CONVENCIONAL OU ELETRÔNICO, PARA FINS DE ESTUDO E PESQUISA, DESDE QUE CITADA A FONTE.
\end{abstract}

FICHA CATALOGRÁFICA

Faria, Adriana Cláudia Lapria

Avaliação de ligas experimentais de titânio para utilização em estruturas metálicas de próteses dentárias. Ribeirão Preto, 2009. 128 p.: il.; $30 \mathrm{~cm}$

Tese de Doutorado, apresentada à Faculdade de Odontologia de Ribeirão Preto / USP - Depto. de Materiais Dentários e Prótese - Área de Concentração: Reabilitação Oral.

Orientador: Ribeiro, Ricardo Faria

Co-orientador: Rosa, Adalberto Luiz

1.Titânio; 2. Ligas dentárias; 3. Prótese dentária; 4. Biocompatibilidade; 5. Atrito dentário; 6. Resistência de materiais. 


\section{FOLHA DE APROVAÇÃO}

\section{Adriana Cláudia Lapria Faria}

Avaliação de ligas experimentais de titânio para utilização em estruturas metálicas de próteses dentárias

Tese apresentada à Faculdade de Odontologia de Ribeirão Preto da Universidade de São Paulo para obtenção do grau de Doutor.

Área de Concentração: Reabilitação Oral

Aprovado em: / 2009

Banca Examinadora

Prof. Dr.

Instituição: Assinatura:

Prof. Dr.

Instituição: Assinatura:

Prof. Dr.

Instituição: Assinatura:

Prof. Dr.

Instituição: Assinatura:

Prof. Dr.

Instituição: Assinatura: 


\section{A Deus}

Agradeço por tudo o que tenho e tudo o que sou! Entrego minha vida, para que seja feita a vontade do Pai e eu possa ser seu instrumento em minha vida e em meu trabalho.

"Há diversidade de dons, mas um só Espírito. Os ministérios são diversos, mas um só é o Senhor. Há também diversas operações, mas é o mesmo Deus que opera tudo em todos. A cada um é dada a manifestação do Espírito para proveito comum." (I Coríntios 12, 4-7) 


\section{Dedico este trabalho}

Aos meus pais João Batista e Deolinda Aparecida, por terem me impulsionado diante de cada obstáculo surgido, desde os meus primeiros passos, para que eu aprendesse que a vida se faz superando as dificuldades. Não existem palavras que possam traduzir meu amor e gratidão por cada gota de suor desprendida para que eu atingisse mais este objetivo em minha vida.

Aos meus avôs Cyro (in memorian) e Ondina, Elpídio (in memorian) e Estephânia (in memorian), por sempre me incentivarem diante de cada etapa cumprida, impulsionando minha chegada até aqui. À Maria (in memorian) e Antônia (in memorian), a quem aprendi amar como avós.

Aos meus irmãos André Eduardo, Ana Maria e Alexandre Vinícius, por todos os momentos, alegres ou tristes, embora mais alegres do que tristes, compartilhados desde a infância. Vocês são fundamentais para o meu aprendizado, pois com nossos acertos e erros, crescemos juntos e vencemos.

Ao Gustavo Henrique, por ter acreditado em meus ideais, ainda que para isso fosse preciso abdicar de suas vontades. Nos últimos quatro anos, você compartilhou minhas angústias e minhas conquistas diariamente, sendo verdadeiramente companheiro... companheiro para a vida inteira. 
Homenagem àqueles que me ensinaram, além da ciência, valores humanos...

Ao Prof. Dr. Ricardo Faria Ribeiro, por ter aceitado o desafio de minha orientação, ao conduzir este projeto de pesquisa. Sinto-me privilegiada ao perceber que, com estes anos de convivência, compartilhando dificuldades $e$ conquistas, tive a oportunidade de crescer... e principalmente amadurecer, ainda que eu ainda tenha muito a aprender.

Ao Prof. Dr. Adalberto Luiz Rosa, a quem devo a escolha deste caminho, por ter me conduzido em meus primeiros passos na pesquisa. Tenho a certeza de que sua serenidade e sinceridade despertaram em mim admiração e o desejo de seguir este caminho.

À Prof ${ }^{a}$. Dr ${ }^{a}$. Ana Paula Rosifini Alves Claro, por sua solicitude e paciência, sempre disposta a ajudar e esclarecer dúvidas, o que tornou possível este trabalho multidisciplinar. 


\section{Agradecimentos}

À Faculdade de Odontologia de Ribeirão Preto da Universidade de São Paulo, representada por seu diretor, Prof. Dr. Osvaldo Luiz Bezzon, pela acolhida durante o curso de graduação e pós-graduação.

Ao Prof. Dr. Edgar Graner da Faculdade de Odontologia de Piracicaba da Universidade de Campinas.

À Profa. Dra. Ana Paula Rosifini Alves Claro, aos graduandos Guilherme e Michel e aos pós-graduandos Ana Lúcia, Izabel e José Luiz Minatti, da Faculdade de Engenharia de Guaratinguetá da Universidade Estadual Paulista, pela colaboração durante o desenvolvimento deste trabalho.

Ao Prof. Dr. Paulo Atsushi Suzuki, da Escola de Engenharia de Lorena da Universidade de São Paulo, por ter conduzido as análises por difração de raios-X.

À Profa. Dra. Renata Cristina Silveira Rodrigues Ferracioli, por ter tornado meus dias de trabalho sempre agradáveis com sua presença serena e amiga. A minha gratidão pela sua disponibilidade constante e a minha admiração por esta pessoa tão especial.

Ao Prof. Dr. Márcio Mateus Beloti e ao pós-graduando Lucas Novaes Teixeira, pela colaboração na avaliação da morfologia celular e amizade.

Às Profa. Dra. Maria da Gloria Chiarello de Mattos e Profa. Dra. Rossana Pereira de Almeida Antunes, docentes do Departamento de Materiais Dentários e Prótese da Faculdade de Odontologia de Ribeirão Preto da Universidade de São Paulo, pelo convívio e ensinamentos transmitidos.

Aos docentes do Programa de Pós-Graduação em Reabilitação Oral.

À Ana Paula Macedo e ao Luis Sérgio Soares, pela prestatividade durante a realização deste trabalho e amizade.

Ao Paulo Donato Frighetto, por sua colaboração na fase experimental deste trabalho.

Ao Ricardo de Souza Antunes e Edson Volta.

Aos funcionários do Departamento de Materiais Dentários e Prótese da Faculdade de Odontologia de Ribeirão Preto da Universidade de São Paulo.

À Júnia Ramos, Roger Rodrigo Fernandes, Fabíola Singaretti de Oliveira e colegas do Laboratório de Cultura de Células.

Às amigas Ana Luiza de Carvalho Felippini, Ana Carolina Bernardes Azevedo, Laise Daniela Carrasco Guerisoli e Fernanda Socolowski, pela convivência e cumplicidade desde a graduação. 
À Elaine Risques Faria, à Nicole de Almeida Andrião e ao Milton Roberto Barbosa, pela amizade.

Ao Queiroz e à Dalva, por me acolherem como filha.

Ao Daniel e à Giovana, pela contribuição e paciência no transporte dos materiais.

Ao Rodrigo Tiossi, pela convivência e amizade.

Aos amigos e colegas do curso de Pós-Graduação.

A Regiane de Cássia Tirado Damasceno e Ana Paula Xavier, secretárias do Departamento de Materiais Dentários e Prótese e à Isabel Cristina Galino Sola e Regiane Cristina Mói Sacilotto, secretárias da Seção de Pós-Graduação da Faculdade de Odontologia de Ribeirão Preto-USP. pesquisa.

À FAPESP, pelo auxílio financeiro(Projeto 05/58363-5) para realização desta

Ao CNPq e à CAPES, pela bolsa de estudos concedida durante a pós-graduação.

A todos aqueles, que direta ou indiretamente, contribuíram para a realização deste trabalho e tornaram meus dias mais leves durante este período, fosse com um sorriso, um olhar, uma palavra... 


\section{RESUMO}

FARIA, A.C.L. Avaliação de ligas experimentais de titânio para utilização em estruturas metálicas de próteses dentárias. 2009. 128 f. Tese (Doutorado) - Faculdade de Odontologia de Ribeirão Preto, Universidade de São Paulo, Ribeirão Preto, 2009.

A utilização do titânio em odontologia tem aumentado devido suas propriedades mecânicas, biocompatibilidade, resistência à corrosão e baixo peso específico. Entretanto, o uso do titânio em próteses ainda não é rotineiro em virtude de dificuldades no processo de fundição. Uma das maneiras de superar estas dificuldades seria através do desenvolvimento de novas ligas cujo ponto de fusão fosse inferior ao do $\mathrm{Ti}$ cp. O objetivo deste estudo foi avaliar as propriedades mecânicas, biológicas e microestrutura de ligas experimentais de titânio para utilização em estruturas metálicas de próteses dentárias, após fundição odontológica, comparando-as ao Ti cp. As ligas experimentais avaliadas foram Ti-5Zr(\%p), Ti-5Ta(\%p) e Ti-5Ta-5Zr(\%p). Os corpos-de-prova foram fundidos por arco voltaico em atmosfera de argônio e injeção por vácuo-pressão. Para avaliação das propriedades mecânicas, corpos-deprova em forma de halteres foram submetidos a ensaios de tração, barras foram submetidas a ensaios de flexão para avaliação do módulo de elasticidade, e hemi-esferas e discos foram submetidos ao teste de desgaste de dois corpos, sendo o perfil das amostras avaliado antes e após o teste para cálculo da perda de altura vertical. Discos foram utilizados para avaliação da microdureza e para caracterização microestrutural. Para avaliação das propriedades biológicas, células SCC9 foram cultivadas em meio de cultura D-MEM/HF12 suplementado sobre discos e poços sem discos foram usados como controle. Após períodos de 1, 4, 7, 10 e 14 dias, foi avaliada a proliferação celular pelo método histoquímico MTT. Aos 7 dias foi avaliada a viabilidade celular após marcação com azul de Trypan e contagem em hemocitômetro. A morfologia celular foi avaliada às 2, 12 e 24 horas através da visualização, em microscópio de fluorescência por epiluminação, do citoesqueleto de actina e dos núcleos, usando, respectivamente, faloidina e DAPI. Os resultados foram submetidos a testes estatísticos e a liga Ti-5Ta apresentou resistência à tração menor que as demais e módulo de elasticidade significativamente menor do que o Ti cp, embora não diferente das demais ligas experimentais. Com relação à resistência à abrasão, as ligas experimentais apresentaram desgaste significativamente menor do que o $\mathrm{Ti}$ cp e a liga Ti-5Zr apresentou microdureza significativamente maior do que os demais materiais. Não houve diferença na proliferação e na viabilidade celular entre os materiais. A avaliação da morfologia celular mostrou diferença na proporção de células nos diferentes estágios de desenvolvimento nos períodos de 2 e 12 horas, mas não em 24 horas. $\mathrm{O}$ Ti cp apresentou microestrutura do tipo feather-like com fase $\alpha$, enquanto Ti-5Zr apresentou estrutura do tipo Widmanstätten com fase $\alpha$ e $\alpha$ '. As ligas Ti5Ta e Ti-5Ta-5Zr apresentaram as fases $\alpha, \alpha$ ', $\alpha$ '’ $\beta$, com arranjos lamelar e acicular, respectivamente. Os resultados deste estudo sugerem que as ligas estudadas apresentam potencial para aplicação em próteses dentárias, uma vez que suas propriedades biológicas foram semelhantes às do $\mathrm{Ti} \mathrm{cp}$, comprovado por proliferação, viabilidade e morfologia celular; e suas propriedades mecânicas, como resistência à abrasão, microdureza e resistência à tração foram satisfatórias, ainda que o módulo de elasticidade possa e deva ser melhorado.

Palavras-chave: Titânio, Ligas dentárias; Prótese dentária; Teste de materiais; Atrito dentário; Resistência de materiais. 


\section{ABSTRACT}

FARIA, A.C.L. Evaluation of experimental titanium alloys for prosthodontic frameworks. 2009.128 f. Thesis (Doctoral) - Dental School of Ribeirão Preto, University of São Paulo, Ribeirão Preto, 2009.

The use of titanium in dentistry have increased due to its mechanical properties, biocompatibility, corrosion resistance and density. However, titanium has not been routinely used because of the difficulties related to casting technique. One of the options to solve these difficulties would be to develop new titanium alloys whose melting point was lower than $\mathrm{cp}$ Ti. So, the aim of this study was to evaluate the mechanical and biological properties and microstructure of experimental titanium alloys for prosthesis frameworks, after dental casting, comparing to cp Ti. The experimental alloys evaluated were $\operatorname{Ti}-5 \mathrm{Zr}(\% \mathrm{w})$, $\mathrm{Ti}-5 \mathrm{Ta}(\% \mathrm{w})$ and Ti-5Ta-5Zr(\%w). The samples were cast by voltaic arc in argon atmosphere and vaccum/pressure injection. To evaluate the mechanical properties, dumbbell-shaped samples were submitted to tensile test, slab-shaped were submitted to flexure for modulus of elasticity evaluation, and stylus tips and disks were submitted to two-body wear test, evaluating the profile of the samples before and after the test to calculate vertical height loss. Disks were used for microhardness evaluation and microstructural observation. For the biological properties evaluation, SCC9 cells were cultured in D-MEM/HF12 supplemented on the disks and wells without disks were used as control. After 1, 4, 7, 10 and 14-day period, cell proliferation was measured by MTT method. After 7 days, cell viability was evaluated after Trypan blue marking and counting in a hemacytometer. Cell morphology was evaluated in 2, 12 and 24-hour periods examining, in fluorescence microscope under epifluorescence, actin cytoskeleton and cell nuclei, using, respectively, phalloidin and DAPI. The results were submitted to statistical analysis and Ti-5Ta alloy presented ultimate tensile strength lower than the others and modulus of elasticity statistically lower than cp $\mathrm{Ti}$, but no different to the other experimental alloys. In relation to wear resistance, the experimental alloys presented wear significantly lower than cp Ti and the Ti-5Zr alloy presented microhardness greater than other materials. Cell morphology evaluation showed difference in the proportion of cells in the different stages in 2 and 12-hour periods, but not in 24. The cp Ti presented feather-like structure with $\alpha$ phase while Ti-5Zr presented a Widmanstätten structure with $\alpha$ and $\alpha$ ' phases. The Ti-5Ta and Ti-5Ta-5Zr alloys presented $\alpha, \alpha$, $\alpha$ '” and $\beta$ phases with lamellar and acicular structures, respectively. The results of this study suggest that the studied alloys could be applied in dental prosthesis, once their biological properties were similar to cp Ti in cell proliferation, viability and morphology; and their mechanical properties, like wear resistance, microhardness and ultimate tensile strength were ideal, although the modulus of elasticity can and should be improved

Key-words: Titanium; Dental alloys; Dental prosthesis; Materials testing; Tooth attrition; Material resistance. 


\section{SUMÁRIO}

\section{RESUMO}

\section{ABSTRACT}

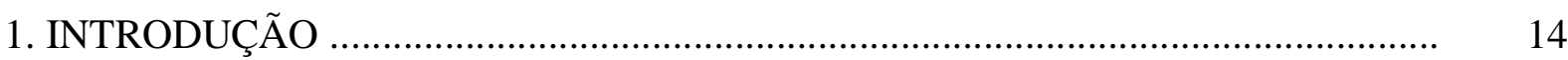

2. REVISÃO DA LITERATURA ……………………………………………....... 18

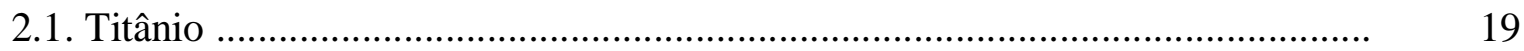

2.2. O titânio na Odontologia .................................................................................. 21

2.3. Ligas de titânio ............................................................................................

2.4. Propriedades das ligas de titânio ....................................................................... $\quad 30$

2.4.1. Propriedades mecânicas ............................................................................

2.4.2. Desgaste …………………………………………………………..

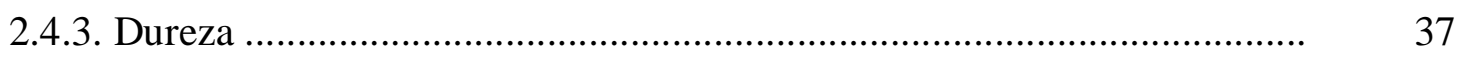

2.4.4. Biocompatibilidade …………………………………………………...

2.4.5. Microestrutura ...........................................................................................

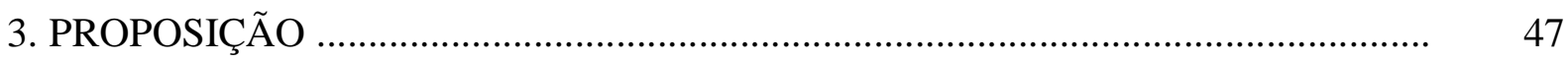

4. MATERIAIS E MÉTODOS ................................................................................ 49

4.1 Obtenção da liga ........................................................................................

4.2.Obtenção dos corpos-de-prova.......................................................................... 51

4.2.1. Ensaio de resistência à tração ..................................................................

4.2.2. Ensaio de flexão ...................................................................................

4.2.3. Ensaio de resistência à abrasão.................................................................... 52

4.2.4. Ensaios de biocompatibilidade, microdureza e caracterização ..................... 53 microestrutural

4.3. Inclusão e fundição ……………………………………………………………...

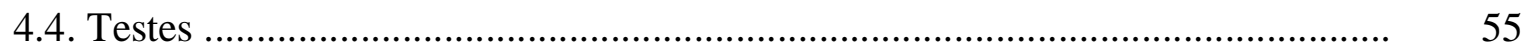

4.4.1. Ensaio de resistência à tração......................................................................

4.4.2. Ensaio de flexão....................................................................................

4.4.3. Ensaio de resistência à abrasão................................................................

4.4.4. Ensaio de microdureza ......................................................................... 59

4.4.5. Testes de biocompatibilidade..................................................................... 60

4.4.6. Caracterização microestrutural................................................................... 62

4.5. Análise Estatística............................................................................................ 


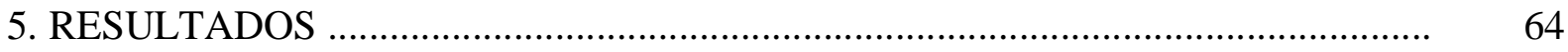

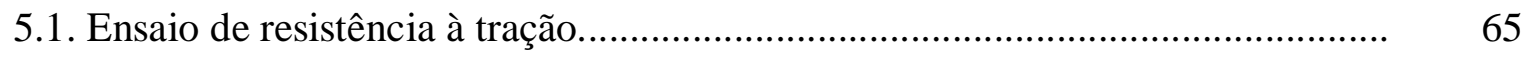

5.2. Ensaio de flexão......................................................................................... 66

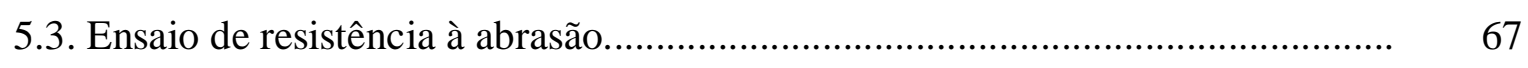

5.4. Ensaio de Microdureza.......................................................................................

5.5. Teste de biocompatibilidade..............................................................................

5.5.1. Avaliação da proliferação / viabilidade celular............................................. 74

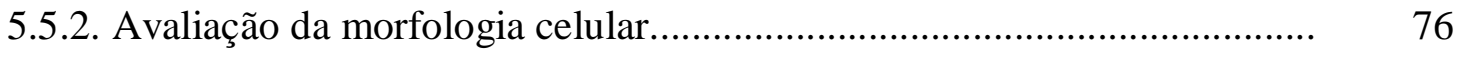

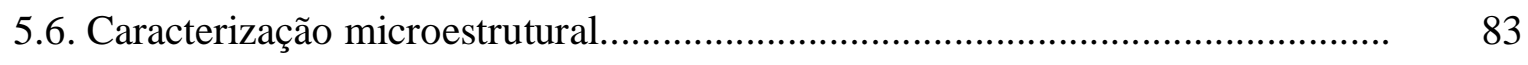

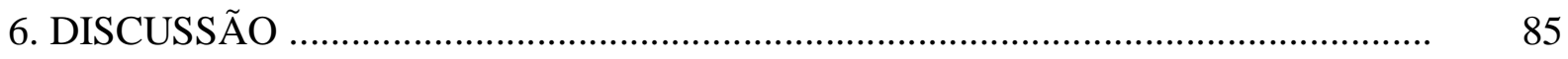

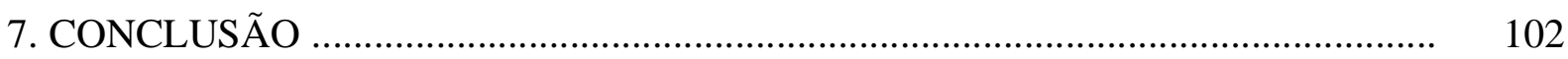

8. REFERÊNCIAS BIBLIOGRÁFICAS .................................................................... 104

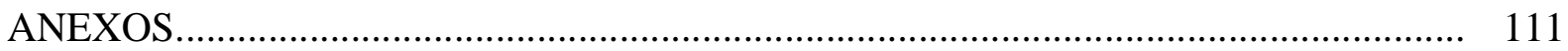


Até a década de 1970, quando o aumento do custo dos metais nobres levou a um maior uso das ligas de metais básicos, as ligas eram classificadas segundo sua aplicação, ou seja, havia ligas destinadas a restaurações totais metálicas, outras para restaurações metalocerâmicas, e outras para fundição de estruturas metálicas de próteses parciais removíveis, sendo que cada uma apresentava características específicas. Atualmente é possível observar que as mesmas ligas metálicas são utilizadas para as diferentes finalidades (WATAHA, 2002).

Embora o uso de metais fundidos tenha diminuído nos últimos anos em virtude do aumento da procura por materiais estéticos, eles ainda são utilizados na Odontologia como casquetes metálicos (copings) ou subestruturas de restaurações metalocerâmicas, comumente empregadas em prótese parcial fixa, especialmente quando usadas para restaurar dentes posteriores, por combinar resistência e biocompatibilidade para permanecer na boca por períodos mais longos (WATAHA; MESSER, 2004; ANUSAVICE, 2005). Além disso, estruturas metálicas de próteses parciais removíveis continuarão sendo fundidas com metais ou ligas metálicas biocompatíveis (SHIMPO, 2007). Como estes materiais desempenharão suas funções na cavidade bucal por períodos prolongados, a seleção do material a ser utilizado deve considerar as perspectivas técnicas, éticas e legais (WATAHA; MESSER, 2004).

O titânio e suas ligas surgiram como uma subclasse das ligas de metais básicos, sendo propostas para restaurações totais metálicas, metalocerâmicas e estruturas de próteses parciais removíveis (WATAHA, 2002). O titânio puro vem sendo cada vez mais utilizado na Odontologia na fabricação de próteses fixas e removíveis, devido à sua biocompatibilidade e baixo peso, comparado às ligas odontológicas convencionais (OHKUBO et al., 2000). Além disso, as propriedades mecânicas e excelente resistência à corrosão têm contribuído para sua aplicação em implantes e próteses fundidas (HENSTEN-PETTERSEN, 1992; 
LAUTENSCHLAGER; MONAGHAN, 1993; OKABE; HERO, 1995; WANG; FENTON, 1996; HAO et al., 2006).

Entretanto, o uso do titânio em próteses ainda não é rotineiro, pois a fundição deste metal para aplicação odontológica só se faz possível através de máquinas específicas que controlam a atmosfera de fundição e utilizam a indução ou o arco voltaico para fundição do metal (OKABE et al., 1998). Além disso, revestimentos específicos e laboratórios preparados para este processo de fundição são necessários (WATAHA, 2002).

As dificuldades pertinentes ao processo de fundição do titânio estão relacionadas, principalmente, ao seu alto ponto de fusão, alta reatividade química em altas temperaturas, e à baixa densidade do titânio que pode criar dificuldades no preenchimento do molde (LAUTENSCHLAGER; MONAGHAN, 1993; OKABE; HERO, 1995). Em virtude disso, pesquisas realizadas a partir da década de 1970 se direcionaram ao desenvolvimento de máquinas de fundição e revestimentos adequados, em busca de precisão na fundição de próteses em titânio, usando o arco voltaico em atmosfera de argônio e força centrífuga ou diferença de pressão para preenchimento do molde (LAUTENSCHLAGER; MONAGHAN, 1993).

As peças fundidas em titânio apresentam algumas limitações na qualidade da fundição, como, por exemplo, integridade marginal inferior e porosidades internas (CHAI; STEIN, 1995; SYVERUD; HERO, 1995; AOKI, 1996 apud AOKI et al., 2004; WATANABE et al., 1997). Outras limitações, tais como a grande variação nas propriedades mecânicas, dependendo da composição da liga; a dificuldade de soldagem devido à formação de óxidos de superfície; a alteração da estrutura de fase destas ligas decorrente do aquecimento no processo de soldagem; e a formação da camada $\alpha$-case, representam desvantagens para a sua utilização em próteses odontológicas (WATAHA et al., 1998; WATAHA; MESSER, 2004). 
O titânio pode se combinar com uma série de elementos para formar ligas metálicas; e esta seria uma das maneiras de superar suas limitações. Alguns autores relatam que o desenvolvimento de novas ligas binárias e ternárias, cujo ponto de fusão fosse inferior ao do titânio comercialmente puro e das ligas hoje disponíveis no mercado, possibilitaria obtenção de peças com menos problemas de fundição. Além disso, as ligas de titânio podem apresentar melhores propriedades mecânicas do que o titânio comercialmente puro (LAUTENSCHLAGER; MONAGHAN, 1993).

Uma prova disso está na liga Ti-6Al-4V, adaptada para utilização biomédica a partir de aplicações aeroespaciais. Embora apresente propriedades mecânicas superiores e excelente resistência à corrosão, esta liga tem sido questionada com relação à sua biocompatibilidade, uma vez que alguns autores relataram que o vanádio contido nessa liga está associado a efeitos citotóxicos e reações adversas em órgãos e tecidos; e o alumínio é reconhecido como um potencializador de distúrbios neurológicos associados a doenças como o Mal de Alzheimer (GEETHA et al., 2004). Da mesma forma, o uso das ligas Ti-6Al-7Nb e Ti-5Al2,5Fe é contestável, levando ao estudo de novas ligas alternativas que sejam biocompatíveis e apresentem boa resistência à corrosão (LAUTENSCHLAGER; MONAGHAN, 1993).

Sendo assim, a busca por novas ligas à base de titânio tem sido alvo de pesquisas; e, a caracterização destas ligas se faz necessária para sua aplicação, uma vez que o material utilizado para a fabricação de próteses odontológicas deve apresentar baixa deformação quando submetido aos esforços introduzidos durante o processo de mastigação; não deve se deformar ou causar quebra da cerâmica, nem alterar a sua cor, devendo permanecer unido à mesma. Além disso, outros fatores como precisão dimensional, resistência ao desgaste, biocompatibilidade, resistência à oxidação superficial e baixa deformação elástica (alto módulo de elasticidade) são importantes e devem ser considerados quando se pensa em propor novas ligas (McLEAN, 1983). 


\subsection{Titânio}

O titânio é um metal abundante, representando 0,6\% da crosta terrestre. Por ser um elemento alotrópico, ele é capaz de apresentar diferentes fases, com propriedades diferentes. Assim, o titânio pode se transformar de uma estrutura cristalina hexagonal compacta (hcc), denominada fase alfa $(\alpha)$, em estrutura cristalina cúbica de corpo centrado (ccc), denominada fase beta $(\beta)$ em temperaturas acima de $882,5^{\circ} \mathrm{C}$, não alterando mais sua estrutura cristalina até atingir a temperatura de aproximadamente $1670^{\circ} \mathrm{C}$, em que ele irá fundir. A menor temperatura em que o titânio apresenta $100 \%$ da fase $\beta$ é denominada por temperatura transus, ou seja, abaixo da temperatura transus a liga de titânio é uma mistura de fase $\alpha$ e fase $\beta$ ou somente fase $\beta$, se o metal contém $\beta$ estabilizadores; no entanto, ela pode ser totalmente constituída por fase $\alpha$, caso contenha limitada ou nenhuma quantidade de $\beta$ estabilizadores (LAUNTENSCHLAGER; MONAGHAN, 1993; SMITH, 1993; HAAG; NILNER, 2007). Existem divergências quanto à temperatura na qual ocorre a transformação alotrópica do titânio da fase $\alpha$ para fase $\beta$, sendo que Low et al. (2001) afirmam que essa transformação ocorre numa faixa de temperatura entre $882-885^{\circ} \mathrm{C}$.

Devido à alta reatividade, precisa ser processado usando gases inertes como argônio e hélio, uma vez que seu aquecimento em temperaturas acima de $500^{\circ} \mathrm{C}$, exposto ao ambiente, pode levar à difusão de oxigênio e nitrogênio em sua superfície, formando uma camada dura, friável e difícil de processar, denominada “alfa-case” (SJOGREN; ANDERSSON; BERGMAN, 1988 apud HAAG; NILNER, 2007).

É um metal de transição que possui uma camada eletrônica incompleta, o que possibilita a formação de solução sólida substitucional com a maioria dos elementos que apresentem um fator de tamanho de $\pm 20 \%$ em relação ao tamanho do seu átomo (LONG; RACK, 1998). A diferença entre os raios atômicos de dois elementos químicos para formação de solução sólida substitucional é de \pm 15\% (CALLISTER, 1994; ANUSAVICE, 2005). 
O titânio comercialmente puro (Ti cp) pode ser classificado em quatro diferentes categorias, podendo também ser tecnicamente considerado uma liga, uma vez que ferro e elementos intersticiais como carbono, oxigênio, nitrogênio e hidrogênio são permitidos, segundo as especificações da American Society for Testing and Materials (ASTM). Sendo assim, a composição química das diferentes categorias do Ti cp é apresentada na Tabela 1.

Tabela 1 - Classificação das ligas de titânio comercialmente puro (SMITH, 1993)

\begin{tabular}{ccccccc}
\hline \%p Ti & Grau & \%p C & \%p Fe & \%p N & \%p O & \%p H \\
\hline 99,5 & 1 & 0,08 & 0,20 & 0,03 & 0,18 & 0,015 \\
\hline 99,2 & 2 & 0,08 & 0,25 & 0,03 & 0,20 & 0,015 \\
\hline 99,1 & 3 & 0,08 & 0,25 & 0,05 & 0,30 & 0,015 \\
\hline 99,0 & 4 & 0,08 & 0,50 & 0,05 & 0,40 & 0,015 \\
\hline
\end{tabular}

Dentre os elementos intersticiais (oxigênio, nitrogênio e carbono), o oxigênio é o mais importante, pois é uma impureza encontrada na maioria das ligas comerciais de titânio. Segundo Ouchi et al. (1998), seu teor é de aproximadamente 0,06\%p e em alguns casos é utilizado para controlar as propriedades mecânicas. O limite de resistência e a dureza são diretamente proporcionais à porcentagem de oxigênio, ou seja, para o titânio puro uma redução de seu teor de 830 para 36ppm (partes por milhão) diminuiu o limite de resistência em 200MPa (aproximadamente 50\% do seu valor original), entretanto a ductilidade (medida em redução de área e alongamento) é inversamente proporcional ao teor de oxigênio.

Assim, o teor de oxigênio do Ti cp determina o seu grau e resistência mecânica, podendo em princípio ser considerado como uma liga Ti-O, em que o oxigênio e nitrogênio presentes nos interstícios produzem o endurecimento por solução sólida (WEISS; SEMIATIN, 1999). Sendo assim, essas ligas possuem baixa resistência mecânica (240 e 550MPa para titânio grau 1 e grau 4, respectivamente) embora possuam excelente resistência 
à corrosão. Por outro lado, o hidrogênio possui baixa solubilidade, sendo sua presença indesejada por causar fragilidade.

\subsection{O titânio na Odontologia}

Na década de 1950, quando o titânio era citado nos trabalhos relacionados à indústria aeroespacial como um metal fantástico, não se poderia imaginar que quarenta anos mais tarde ele seria um metal importante para aplicações médicas e biológicas. A sua baixa densidade $\left(4,5 \mathrm{~g} / \mathrm{cm}^{3}\right)$ em relação ao ouro $\left(19,3 \mathrm{~g} / \mathrm{cm}^{3}\right)$ associada à alta resistência possibilitaram a construção de próteses quatro vezes mais leves do que peças semelhantes confeccionadas em ouro (LAUNTENSCHLAGER; MONAGHAN, 1993; HAAG; NILNER, 2007).

Segundo Canay et al. (1998), o Ti cp possibilita confecção de estruturas mais finas e mais leves e com resistência compatível às das estruturas de Co-Cr, sendo uma alternativa de uso em caso de pacientes alérgicos. Sendo assim, estes autores compararam a resistência à corrosão de estruturas de próteses parciais removíveis confeccionadas em Ti cp (recémfundidas e utilizadas durante seis meses por pacientes) e estruturas de Co-Cr. Os autores relataram que as estruturas de Ti cp recém-fundidas eram mais resistentes à corrosão do que as utilizadas durante seis meses e as de Co-Cr; e relacionaram tais resultados ao fato de que as fundições em Ti cp apresentam mais porosidades superficiais do que as de Co-Cr, pois por ser mais dura, dificulta o polimento e possibilita a corrosão localizada, principalmente se for considerado que estes poros criam áreas retentivas para resíduos alimentares.

Uma pesquisa realizada com dentistas da Noruega em 1995 oferecendo peças fundidas em titânio para confecção de coroas e próteses parciais fixas revelou que, de 89\% dos dentistas que se propuseram a participar da pesquisa, $88 \%$ responderam favoravelmente ao uso do titânio, relatando como vantagens o baixo custo comparado aos metais nobres, a biocompatibilidade e o peso. No entanto, foram relatadas limitações relacionadas à estética e à 
técnica, sendo que a adaptação marginal do titânio não demonstrou ser tão boa como a das demais ligas convencionais, indicando que o titânio não substituiria as ligas convencionais, mas seria uma alternativa para as situações em que as ligas convencionais não pudessem ser utilizadas (BERG, 1997 apud WHITTERS et al., 1999). Mori et al. (1997 apud WHITTERS et al., 1999) relataram uma taxa de rejeição de aproximadamente $40 \%$ das estruturas metálicas para próteses parciais removíveis fundidas em titânio devido à presença de poros maiores do que 0,5mm em regiões flexíveis da estrutura. Com relação à adaptação marginal, embora pesquisas tenham revelado valores de desadaptação em torno de $47 \mu \mathrm{m}$ (BESIMO; JEGER; GUGGENHEIM, 1997 apud WHITTERS et al., 1999), a pesquisa citada anteriormente que coletou a opinião de dentistas acerca do titânio revelou que a adaptação marginal era clinicamente satisfatória (BERG, 1997 apud WHITTERS et al., 1999).

Haag e Nilner (2007) relataram que os valores aceitáveis de adaptação marginal variam de 50 a $100 \mu \mathrm{m}$, embora maiores valores de desadaptação tenham sido identificados no titânio em virtude da contração ocorrida durante o resfriamento. Além disso, estes autores afirmam que os problemas relacionados à fundição como contração e porosidade tem impedido o uso do titânio em próteses odontológicas, ainda que suas propriedades físicas sejam satisfatórias para aplicação em próteses parciais fixas e removíveis.

De acordo com Chan, Koike e Okabe (2007), o uso clínico de próteses em titânio começou há aproximadamente 15 anos na Europa e no Japão; no entanto, problemas práticos como a deformação permanente e fratura de grampos de titânio, descoloração e deslocamento da resina da base da prótese, e desgaste aumentado em comparação às ligas odontológicas convencionais foram observados.

Como nos últimos 20 anos o titânio passou a ser utilizado em próteses parciais removíveis devido à biocompatibilidade, resistência à corrosão e propriedades mecânicas, Ohkubo, Hanatani e Hosoi (2008) fizeram um levantamento de pesquisas sobre a aplicação do 
titânio em próteses parciais removíveis e verificaram aumento, ainda que os problemas laboratoriais não tenham sido completamente solucionados, pois não há relatos de alergias ou falhas catastróficas de estruturas confeccionadas em titânio e os problemas clínicos vêm sendo gradualmente solucionados. Dentre as suas vantagens, são citadas a biocompatibilidade, a resistência à corrosão, não provocar reações alérgicas, gosto neutro, e translucidez aos raios$\mathrm{X}$, que permite diagnosticar defeitos de fundição.

Segundo Hero, Syverud e Waarli. (1993), o aumento da pressão de argônio (de 50 para 400Torr) aumentou consideravelmente a porosidade interna, uma vez que ao entrar no molde, o argônio se expande forçando o titânio fundido em direção às paredes do molde, copiando a forma externa; no entanto, os gases não escapam através do revestimento aquecido e são incorporados ao metal, ainda que a forma externa das estruturas tenha sido adequada.

O titânio é um material que disponibiliza menos tempo de trabalho do que outras ligas, o que requer maior proximidade entre o forno e o equipamento utilizado para fundição, para que a perda de calor seja minimizada. Além disso, sua baixa condutividade térmica associada ao alto gradiente de temperatura entre o metal fundido e o molde pode resultar em peças com pobre qualidade de superfície, fendas que podem surgir com o desgaste e alto estresse residual, que levaria às distorções dimensionais (SEAGLE; YU; GIANGIORDANO, 1999).

Nas fundições de titânio, forma-se uma camada frágil devido à reação da superfície do metal fundido com componentes do revestimento, e esta camada deve ser removida porque reduz a ductilidade e a resistência à fadiga de estruturas metálicas e grampos de próteses parciais removíveis (VALLITTU; KOKKONEN, 1995 apud OHKUBO et al. 2000). Takahashi, Miyazaki e Kawawa (1994) afirmam que esta camada superficial é mais rugosa e afeta diretamente a adaptação das margens das coroas e próteses parciais fixas.

Watanabe et al. (2004) afirmam que, embora a camada $\alpha$-case seja removida em fundições industriais, é preciso considerar a dificuldade em removê-la em aplicações 
odontológicas como coroas, próteses parciais fixas e próteses parciais removíveis, em que a remoção desta camada superficial poderia comprometer a adaptação destas peças.

Com relação às suas propriedades mecânicas, o baixo módulo de elasticidade do titânio exige estruturas metálicas para próteses parciais removíveis de maior espessura, para prevenir a deformação permanente dos componentes em função; no entanto, este módulo de elasticidade também permite o posicionamento dos braços retentivos dos grampos em áreas mais retentivas do dente, sem que sejam transmitidas cargas laterais ao dente pilar nos movimentos de inserção e remoção da prótese. Já nos casos de próteses parciais fixas, este baixo módulo de elasticidade contra-indica a aplicação deste metal em próteses extensas bilaterais (LAUTENSCHLAGER; MONAGHAN, 1993).

\subsection{Ligas de titânio}

Com exceção do Ti cp, os metais utilizados em Odontologia para estruturas de próteses parciais são ligas metálicas, uma vez que dois ou mais elementos metálicos são misturados a um ou mais metais ou não-metais para melhorar as propriedades físicas, sendo em geral produzidos pela fusão de elementos acima de seus pontos de fusão (ANUSAVICE, 2005). Ao se pensar em novas ligas, é preciso considerar a dificuldade de fundição, a adaptação marginal, a dificuldade de soldar e polir, além dos desafios estéticos (CRAIG; POWERS, 2004).

Além disso, as novas ligas devem ter como vantagem a transformação martensítica em temperaturas inferiores, o que possibilita melhor resistência (LAUTENSCHLAGER; MONAGHAN, 1993). Dentre os elementos propostos para serem utilizados em ligas de Ti estão Zr, Nb, W e Ta, metais que são geralmente cobertos por uma fina camada de óxido que constitui uma barreira entre o metal e o meio, melhorando sua resistência à corrosão e, conseqüentemente, a biocompatibilidade. 
Okazaki et al. (1998) avaliaram a biocompatibilidade de extratos preparados a partir do pó de elementos como $\mathrm{Ti}, \mathrm{Zr}, \mathrm{Sn}, \mathrm{Nb}, \mathrm{Ta}, \mathrm{Al}$ e $\mathrm{V}$, propostos na literatura para utilização em ligas de Ti; e concluíram que Ti, $\mathrm{Zr}, \mathrm{Sn}, \mathrm{Nb}$ e Ta não interferiram na taxa de crescimento das células em cultura, enquanto $\mathrm{Al}$ e $\mathrm{V}$ causaram diminuição significativa.

Outro estudo realizado por Oliveira et al. (2005) avaliou a resistência à corrosão de ligas contendo $\mathrm{Ti}, \mathrm{Zr}$ e $\mathrm{Nb}$ em diferentes concentrações. Os autores relataram que a liga Ti50Zr pode ser utilizada como biomaterial por ter apresentado a melhor resistência à corrosão e ser reconhecidamente superior do ponto de vista mecânico.

Os elementos químicos utilizados nas ligas de titânio são classificados em três tipos: $\alpha$ estabilizadores (alfagênicos), $\beta$ estabilizadores (betagênicos) e neutros (LOW et al., 2001).

Os elementos $\alpha$ estabilizadores (alfagênicos) são elementos químicos que estabilizam a fase $\alpha$ através do aumento da temperatura na qual essa fase é estável, isto é, eles são mais solúveis nessa fase e deslocam a temperatura transus para cima. Conforme indicado por Smith (1993), os elementos a estabilizadores são classificados em substitucionais e intersticiais. Os elementos substitucionais são: Al, Ga e Ge, sendo o Al o mais utilizado. Sua presença aumenta a ductilidade e favorece a redução de peso, sendo empregado com teores variando de 2 a $6 \%$ p.

Já os elementos $\beta$ estabilizadores (betagênicos), ao contrário dos $\alpha$ estabilizadores, diminuem a temperatura transus da liga estabilizando a fase $\beta$ a baixas temperaturas. Esses elementos são divididos em dois grupos: os isomorfos - Mo, $\mathrm{V}$, Ta e $\mathrm{Nb}$ - que não formam componentes intermetálicos (DONACHIE, 1989); e os eutetóides - Cr, Mn, Fe, Co, Ni, Cu (ANKEM; GREENE, 1999). Normalmente, em ligas $\beta$ os teores encontrados para V e Mo variam de 2 a $20 \%$ p, de 2 a $12 \%$ p para o $\mathrm{Cr}$ e de 2 a $6 \%$ p para o $\mathrm{Cu}$. O Fe, além de $\beta$ estabilizador, também é utilizado como refinador de grão, conforme relatado por Yamada (1996) e Lin et al. (2002). A presença do Nb reduz o módulo de elasticidade (GEETHA et al., 
2004), tornando o seu uso indicado para aplicações ortopédicas, uma vez que neste caso busca-se módulo de elasticidade próximo ao do osso humano (35GPa).

$\mathrm{O} \mathrm{Zr}$ e o $\mathrm{Sn}$ são considerados elementos neutros. Eles provocam o endurecimento por solução sólida da liga de titânio sem afetar a temperatura de transformação, isto é, eles são isomorfos para as fases $\alpha$ e $\beta$. Os teores de $\mathrm{Zr}$ utilizados nas ligas de titânio variam de 2 a $8 \%$ p. Esses elementos possuem extensa solubilidade tanto na fase $\alpha$ como na fase $\beta$, não promovem a estabilidade de fase, porém retardam a velocidade de transformação e são utilizados como agentes endurecedores. Kobayashi et al. (1998), mencionaram a utilização do Zr na liga Ti-5Al-3Mo-4Zr utilizada como biomaterial, devido ao efeito de endurecimento por solução sólida desse elemento químico.

As ligas de titânio são classificadas de acordo com a estrutura cristalográfica favorecida pela composição química das mesmas. Segundo Weiss e Semiatin (1999) elas são divididas em cinco categorias: alfa $(\alpha)$; pseudo alfa (pseudo- $\alpha$ ); alfa mais beta $(\alpha+\beta)$; pseudo beta (pseudo- $\beta$ ), e beta ( $\beta$ ). Low et al. (2001), utilizaram a seguinte classificação: alfa $(\alpha)$; pseudo alfa (pseudo- $\alpha)$; alfa mais beta $(\alpha+\beta)$; beta metaestável ( $\beta$ metaestável), e beta estável ( $\beta$ estável) enquanto Kikuchi et al. (2003), definem três classes, que são as mais aceitas: alfa $(\alpha)$; alfa mais beta $(\alpha+\beta)$, e beta $(\beta)$.

As ligas $\alpha$ são materiais com fase única e estrutura cristalina hexagonal compacta. Al, Sn e Zr são os principais elementos utilizados nessas ligas, favorecendo o endurecimento por solução sólida e aumentando o limite de resistência em incrementos de 35-70MPa por porcentagem de elemento adicionado. Diferentemente das ligas $\alpha+\beta$ e $\beta$, não podem ser endurecidas por tratamento térmico, o que lhes confere boa soldabilidade (WEISS; SEMIATIN, 1999). Ligas binárias Ti-Zr foram propostas para aplicação biomédica, pois além do $\mathrm{Ti}$ e do $\mathrm{Zr}$ apresentarem propriedades químicas semelhantes, eles são completamente 
solúveis em altas temperaturas e propiciam a obtenção de ligas com dureza e resistência à tração superior ao metal puro (KOBAYASHI et al., 1995).

As ligas pseudo- $\alpha$ contém até $2 \%$ p de $\beta$ estabilizadores, geralmente o Mo e/ou V. Mesmo contendo uma pequena quantidade de fase $\beta$ na microestrutura, comportam-se mais como uma liga $\alpha$ do que uma liga $\alpha+\beta$. A adição dessas quantidades de elementos $\beta$ estabilizadores aumenta a faixa de temperatura $\alpha+\beta$ permitindo que as mesmas sejam trabalhadas mecanicamente a quente. Estas ligas possuem boa soldabilidade, boa resistência à fluência, elevada resistência mecânica (900MPa), baixa ductilidade e alto módulo de elasticidade. $\mathrm{O}$ maior limite de resistência é devido à presença da martensita $\left(\alpha^{\prime}\right)$ ou uma mistura das fases $\alpha$ e $\alpha^{\prime}$ (WEISS; SEMIATIN, 1999).

As ligas $\alpha+\beta$ contêm um ou mais elementos $\beta$ estabilizadores em quantidade suficiente para permitir a retenção de apreciável quantidade de fase $\beta$ à temperatura ambiente, resultando em uma microestrutura $\alpha+\beta$. As ligas $\alpha+\beta$ são solubilizadas e envelhecidas para aumentar suas propriedades mecânicas. A microestrutura dessas ligas é função da composição química, histórico de processamento e tratamento térmico. Quando essas ligas são solubilizadas e resfriadas em água (velocidade de resfriamento superior a $525^{\circ} \mathrm{C} / \mathrm{s}$ ), a microestrutura obtida é a martensita hexagonal ( $\left.\alpha^{\prime}\right)$, sendo composta de longas placas de martensita orientadas ortogonalmente, possuindo uma morfologia acicular. O envelhecimento da martensita produz aumento na resistência mecânica devido à precipitação da fase $\beta$ a partir da martensita instável $\left(\alpha^{\prime}\right)$. Quando uma amostra dessa liga é solubilizada e resfriada ao ar, é produzida uma microestrutura acicular de $\alpha$ que é transformada a partir da fase $\beta$ por nucleação e crescimento. Em situações de baixa velocidade de resfriamento é observada a ocorrência de uma pequena quantidade de fase $\beta$ nos contornos de grão. As ligas de titânio $\alpha$ $+\beta$ são caracterizadas microestruturalmente pela presença da fase $\alpha$ em contorno de grão da 
fase $\beta$ original. Dentro do grão é observada a fase $\alpha$, formando uma textura lamelar com a fase $\beta$ presente (CHRAPONSKI; SZKLINIARZ, 2001).

Ligas $\alpha+\beta$, livres de V e Al (Ti-15Sn-2Ta-0,2Pd e Ti-15Zr-4Nb-4Ta-0,2Pd), compostas de elementos não tóxicos estão em desenvolvimento. As ligas de titânio utilizadas em aplicações odontológicas são similares às utilizadas como material para implante cirúrgico e são produzidas por fundição (NIINOMI, 1998).

As ligas pseudo- $\beta$ e $\beta$ possuem menos $\alpha$ estabilizadores do que as ligas $\alpha$ e $\alpha+\beta$ e quantidade suficiente de $\beta$ estabilizadores que evitam, no resfriamento, a formação da martensita. Nas ligas $\beta$ metaestáveis ocorre precipitação da fase $\alpha$ durante o envelhecimento abaixo da temperatura transus; por outro lado as ligas $\beta$ estáveis não podem ser endurecidas através de envelhecimento (WEISS; SEMIATIN, 1999). Os principais elementos utilizados nessas ligas são o V, Mo, Cr e Fe; e possuem estrutura cúbica de corpo centrado (ccc) que facilita o seu trabalho a frio. A fase $\beta$ usualmente é metaestável e possui a tendência de transformar-se em $\alpha+\beta$ na condição de equilíbrio. Após o tratamento de solubilização, a fase $\beta$ metaestável é envelhecida para transformar parcialmente a fase $\beta$ em fase $\alpha$. A fase $\alpha$ apresenta-se finamente dispersa na fase $\beta$ retida, obtendo-se valores de resistência mecânica comparáveis ou superiores às ligas $\alpha+\beta$ envelhecidas. A desvantagem das ligas $\beta$ em comparação com as ligas $\alpha+\beta$ é sua maior densidade. Na condição solubilizada $(100 \%$ de fase $\beta$ retida), essas ligas possuem boa ductilidade e tenacidade (DONACHIE, 1989). Segundo Anken e Greene (1999), a precipitação homogênea da fase $\alpha$ na fase $\beta$ metaestável aumenta o limite de resistência e a ductilidade da liga. Conforme relatado por esses autores, o envelhecimento duplo para controlar a precipitação da fase $\alpha$ melhora o limite de resistência e a tenacidade das ligas titânio $\beta$.

Estas ligas pseudo- $\beta$ e $\beta$ são caracterizadas pela alta temperabilidade e elevada resistência à fadiga. As ligas $\beta$ podem ser processadas de modo a se obter melhor resistência 
mecânica e apresentar melhor tenacidade do que a ligas $\alpha+\beta$, além de apresentar melhor conformabilidade (LIN et al., 2002). A liga $\beta$ metaestável Ti-12Mo-6Zr-2Fe, após resfriamento a temperaturas acima da transus $\left(754^{\circ} \mathrm{C}\right)$ é composta somente de fase $\beta$ e após o envelhecimento ocorre a precipitação de finas partículas de fase $\alpha$.

O resfriamento rápido da liga metaestável $\beta$ Ti-15Mo resultou em estrutura cúbica de corpo centrado com grão fino e baixo módulo de elasticidade (77,7MPa). Uma quantidade de $10 \% \mathrm{p}$ de molibdênio é necessário para estabilizar a fase $\beta$ à temperatura ambiente das ligas binárias Ti-Mo (HO et al., 1999).

Segundo Kuroda et al. (1998) as recentes pesquisas com biomateriais à base de titânio têm focado as ligas tipo $\beta$, pois as variáveis de processamento dessas ligas podem ser melhor controladas para se produzir o resultado desejado. Esses autores indicam que as ligas $\beta$ utilizadas para biomateriais são compostas por elementos não tóxicos como o $\mathrm{Nb}, \mathrm{Ta}, \mathrm{Zr}$, Mo e Sn. Outros autores relataram que a adição de elementos $\beta$ estabilizadores possibilita diminuir o ponto de fusão e a reatividade do titânio, facilitando desta maneira o processo de fundição (KIKUCHI et al., 2003).

Seagle, Yu e Giangiordano (1999) relataram que a presença de elementos $\beta$ estabilizadores torna a liga menos susceptível à formação de porosidades enquanto os $\alpha$ estabilizadores aumentam esta susceptibilidade. Além disso, os elementos $\beta$ estabilizadores aumentam a ductilidade da liga, possibilitando que ela tenha maior deformação antes de se fraturar. 


\subsection{Propriedades das ligas de titânio}

\subsubsection{Propriedades mecânicas}

Com relação às propriedades mecânicas do titânio, estas irão variar de acordo com a composição das ligas de titânio (WATAHA, 2002). O módulo de elasticidade é a medida de rigidez de uma liga, sendo que as ligas a serem utilizadas em próteses precisam apresentar módulo de elasticidade alto a ponto de resistir à flexão, principalmente em restaurações metalocerâmicas cuja fratura da porcelana pode ser causada pela flexão do metal. Segundo alguns autores, módulo de elasticidade variando de 90 a 120GPa é suficiente para a maioria das situações clínicas; no entanto, estes valores podem não ser suficiente em próteses parciais fixas extensas ou próteses parciais removíveis, em que ligas à base de níquel ou cobalto, cujo módulo de elasticidade varia de 180 a 230GPa, são mais apropriadas (MOFFA et al., 1973 apud WATAHA, 2002). Wataha e Messer (2004) relatam que uma liga com alto módulo de elasticidade é aconselhável para aplicação em próteses extensas, particularmente as metalocerâmicas.

Além disso, uma reabilitação extensa envolvendo conectores curtos gengivooclusalmente em decorrência de coroas clínicas curtas, questões periodontais ou requisitos estéticos requer ligas com alta resistência à tração. A resistência à tração de uma liga deve ser suficiente a ponto de não causar distorção permanente da restauração, sendo o ponto mais susceptível a estas falhas a região entre os pônticos em próteses múltiplas. Ligas com resistência à tração superior a 300MPa são capazes de resistir à deformação permanente intrabucal na maioria das situações clínicas (CRAIG; POWERS, 2004).

Segundo Wataha (2002), as ligas de ouro tipo IV foram substituídas pelas ligas de metais básicos na confecção de estruturas metálicas de próteses parciais removíveis porque as últimas apresentam alto módulo de elasticidade e baixa densidade, o que permite a confecção 
de estruturas metálicas mais finas, leves e rígidas e de menor custo. Além disso, a necessidade de melhores propriedades físicas tem afetado a evolução das ligas odontológicas, uma vez que ligas com maior módulo de elasticidade são requeridas em estruturas metálicas de próteses parciais removíveis por não se flexionarem muito ao receberem cargas oclusais, transmitindo melhor estas cargas aos dentes e tecidos remanescentes; e em próteses parciais fixas metalocerâmicas, quando a flexão da infra-estrutura metálica poderia causar fratura da porcelana, por ser este material de natureza friável. Sendo assim, segundo Moffa et al. (1973 apud WATAHA, 2002), em próteses parciais fixas extensas, a utilização de uma liga metálica com módulo de elasticidade de 90GPa não é suficiente para prevenir problemas clínicos de flexão e suas conseqüências, principalmente se a infra-estrutura metálica for fina ou os conectores estreitos por necessidades anatômicas ou estéticas.

Lewis (1977) relatou que o tipo de revestimento é um dos fatores associados à quantidade e tipo de porosidade desenvolvida em estruturas fundidas, o que irá influenciar o comportamento mecânico desta liga.

As propriedades mecânicas do Ti cp foram estudadas por Ferenczi et al.(1998), que avaliaram o efeito da camada $\alpha$-case. Estes autores relataram que há uma variação de aproximadamente 50GPa no módulo de Young quando são testados corpos-de-prova jateados e polidos mecanicamente, afirmando que a presença desta camada, que segundo os mesmos autores é formada pela interação com o hidrogênio e não com componentes do revestimento, demonstrou diminuir os valores encontrados para o módulo de Young.

Ho et al. (1999) avaliaram o efeito da adição de Mo ao Ti cp, em concentrações de 6 a $20 \%$ p e observaram que todas as concentrações testadas, exceto a de $10 \%$, apresentaram menor módulo de elasticidade do que o Ti cp, enquanto a resistência à flexão nas ligas Ti-Mo foi superior ao Ti cp, principalmente na concentração de $10 \%$. 
Em 2002, Lee, Ju e Chern Lin relataram que as ligas contendo 10 e 27,5\%p de Nb em sua composição apresentaram maior resistência à flexão enquanto as ligas contendo 17,5\%, $20 \%$ e mais do que $30 \%$, cuja microestrutura apresenta respectivamente as fases $\alpha$ ”' e $\beta$, apresentaram os valores mais baixos de módulo de elasticidade.

Um estudo realizado por Kikuchi et al. (2003) relatou que a adição de $\mathrm{Cu}$ ao $\mathrm{Ti}$ cp afetou suas propriedades mecânicas, de forma que a resistência à tração aumentou significativamente quando mais de 5\%p de $\mathrm{Cu}$ foi adicionado à liga enquanto o módulo de elasticidade não foi afetado por nenhuma das concentrações. Em 2004, Aoki et al. estudaram as propriedades mecânicas de ligas de Ti-6Al-4V quando $\mathrm{Cu}$ era adicionado em concentrações variando de 1 a 10\%p; e concluíram que as propriedades mecânicas da liga eram alteradas na medida em que $\mathrm{Cu}$ era adicionado ao sistema, sendo que a microdureza aumentava com o conteúdo de Cu e a porcentagem de alongamento diminuía, além do que adição de $1 \%$ de $\mathrm{Cu}$ ocasionava fraturas dúcteis enquanto 4 e 10\% ocasionavam fraturas friáveis, indicando as ligas com concentrações de 1 e 4\% de Cu para estruturas metálicas de próteses.

Em estudo realizado por Gordin et al. (2004), a liga Ti-12Mo-5Ta apresentou valores de módulo de elasticidade semelhante a outras ligas de $\mathrm{Ti}$ do tipo $\beta$ desenvolvidas recentemente. Sato et al. (2005) avaliaram as propriedades mecânicas da liga Ti-Hf em concentrações de Hf (Háfnio) de 10 a 40\%p e observaram aumento da resistência à tração e ao escoamento na medida em que o conteúdo de Hf aumentou, enquanto a porcentagem de alongamento diminuiu. Com relação ao módulo de elasticidade, este não foi afetado pela adição de Hf.

Em 2004, Zhou, Niinomi e Akahori avaliaram o módulo de elasticidade e a resistência à tração em ligas binárias Ti-Ta solubilizadas quando Ta foi adicionado em concentrações de 10 a 80\%. Estes autores concluíram que a microestrutura destas ligas foi sensível ao conteúdo 
de Ta, exibindo estrutura lamelar ( $\alpha$ ') em concentrações abaixo de 20\%, martensita acicular ortorrômbica ( $\alpha$ ’’) em concentrações entre 30 e 50\%, fase $\beta$ metaestável e $\alpha$ ”' em concentrações de $60 \%$, e apenas estrutura $\beta$ metaestável em concentrações acima de $60 \%$, sendo que nas concentrações de 30 e $70 \%$ as ligas apresentaram o menor módulo de elasticidade e a maior resistência, o que, segundo os autores, as tornava candidatas para aplicações biomédicas. Posteriormente, Zhou, Niinomi e Akahori (2004) avaliaram as propriedades mecânicas e a microestrutura das ligas Ti-30Ta, Ti-40Ta e Ti-50Ta após envelhecimento, e concluíram que a decomposição da martensita $\alpha$ ”’ identificada nas ligas de Ti-Ta é sensível ao conteúdo de Ta e à temperatura de envelhecimento. Desta forma, houve aumento dos valores de resistência à tração destas ligas quando as mesmas foram envelhecidas em $773 \mathrm{~K}\left(499,85^{\circ} \mathrm{C}\right)$, e diminuição em temperaturas de $873 \mathrm{~K}\left(599,85^{\circ} \mathrm{C}\right)$. No entanto, o módulo de elasticidade aumentou progressivamente na liga Ti-30Ta com o aumento da temperatura de envelhecimento, enquanto nas outras duas ligas foi observado aumento do módulo de elasticidade quando o envelhecimento foi realizado em $773 \mathrm{~K}\left(499,85^{\circ} \mathrm{C}\right)$ e posterior diminuição quando o tratamento foi feito em temperaturas de $873 \mathrm{~K}\left(599,85^{\circ} \mathrm{C}\right)$.

Em 2005, Lin, Ju e Chern Lin compararam a resistência à fadiga do Ti cp, Ti-6Al-4V, Ti-7,5Mo e Ti-13Nb-13Zr e relataram que Ti-7,5Mo e Ti-13Nb-13Zr apresentaram maior resistência à fadiga do que as demais ligas convencionais, e relacionaram a resistência à fadiga a fatores como porosidades superficiais e subsuperficiais, a localização destas porosidades e propriedades mecânicas dos materiais, já que as ligas Ti-7,5Mo e Ti-13Nb-13Zr apresentaram maior resistência à tração e ao escoamento do que o Ti cp e menor do que o Ti6Al-4V. Com relação ao módulo de elasticidade, Ti-7,5Mo e Ti-13Nb-13Zr foram inferiores às demais embora a porcentagem de alongamento tenha sido comparável ao Ti cp.

Em 2006, o módulo de elasticidade de ligas binárias de Ti contendo Au, Ag ou Cu em concentrações variando de 5 a 30\%p das ligas foi avaliado por alguns autores e os resultados 
demonstraram que o módulo de elasticidade da liga $\mathrm{Ti}-\mathrm{Cu}$ aumenta na medida em que aumenta a concentração de $\mathrm{Cu}$, enquanto nas ligas Ti-Au e Ti-Ag, houve diminuição do módulo quando as concentrações eram inferiores a 20\% em decorrência da fase $\alpha$ imperfeita e em concentrações a partir de $20 \%$ houve aumento do módulo de elasticidade devido à presença de componentes intermetálicos (KIKUCHI; TAKAHASHI; OKUNO, 2006).

Hao et al. (2006) avaliaram o efeito do conteúdo de Zr e Sn no módulo de elasticidade de ligas Ti-Nb e relataram que a liga Ti-24Nb-4Zr-7,5Sn apresentou o menor módulo de Young em virtude de microestrutura caracterizada por fase $\beta$, já que o conteúdo dos elementos Zr e Sn interferiu na microestrutura da liga.

O estudo de Ho et al. (2008) que avaliou a liga Ti-Zr em diferentes concentrações de Zr, relatou que a resistência à flexão destas ligas aumentava na medida em que aumentou o conteúdo de Zr, sendo que todas apresentavam valores superiores ao Ti cp. Com relação ao módulo de elasticidade, embora Ti-Zr tenha apresentado valores superiores ao $\mathrm{Ti}$ cp, foi notada diminuição na medida em que aumentou o conteúdo de Zr.

A avaliação de ligas experimentais Ti-Ag-Cu demonstrou que Ti-3Ag-1Cu e Ti-3Ag2Cu apresentaram maior resistência à tração e ao escoamento do que Ti cp, Ti-1Ag-2Cu e Ti1Cu-2Ag, embora não houvesse diferença no módulo de elasticidade destas ligas avaliadas (KANG et al., 2009).

\subsubsection{Desgaste}

O fenômeno de desgaste acontece na cavidade bucal como resultado de interações complexas e é afetado por uma série de fatores, como pH e natureza da saliva, temperatura, sexo, idade, etnia, hábitos nutricionais e parafuncionais, tipo de oclusão, força neuromuscular, espessura e dureza do esmalte, material e forma dos dentes antagonistas e a localização da restauração. Além disso, o desgaste dos dentes é um termo que abrange a atrição resultante do 
contato das superfícies dos dentes entre si, abrasão resultante do contato com outros meios físicos que sejam diferentes dos dentes antagonistas, e erosão que é a perda de substância química dos dentes. Desta forma, a simulação da condição bucal é impossível e não se pode prever o desgaste clínico a partir de resultados de testes in vitro (SMITH; KNIGHT, 1984 apud OHLMANN et al. 2007; SUZUKI et al., 2002; WATAHA; MESSER, 2004).

Khan, Williams e Williams (1996), ao estudarem a resistência ao desgaste de ligas de titânio, associada ou não a corrosão em meio biológico, relataram que ligas $\beta$ (Ti-15Mo) e pseudo $\beta$ (Ti-13Nb-13Zr) apresentam resistência à corrosão superior; e que a comparação do desgaste e do desgaste associado à corrosão demonstrou que o desgaste associado à corrosão afetou mais as ligas $\alpha+\beta$ do que as demais, embora todas tenham apresentado a corrosão associada ao desgaste mais severa do que a corrosão isolada.

Abe et al. (2001), ao estudarem o desgaste de dentes artificiais para próteses frente ao esmalte humano, afirmaram que a medida da dureza de um material pode não ser um dado confiável para o desgaste do material, mas pode ser um parâmetro possível para se prever o desgaste. Além disso, estes autores alertam para o fato de que os debris liberados a partir da superfície desgastada podem transformar os testes de desgaste abrasivo de dois corpos em testes de três corpos.

Em 2003, a resistência ao desgaste de ligas experimentais Ti-Cu foi avaliada em um estudo em que diferentes concentrações de $\mathrm{Cu}$ foram adicionadas ao $\mathrm{Ti}$ cp e Ti-6Al-4V e concluíram que a inclusão da fase eutetóide $\alpha \mathrm{Ti} / \mathrm{Ti}_{2} \mathrm{Cu}$ em titânio $\alpha$ aumenta a resistência à deformação plástica, melhorando a resistência ao desgaste destas ligas, aliado ao fato de que na liga Ti-6Al-4V, o cobre aumenta a resistência ao desgaste pelo benefício de uma microestrutura de duas fases $\alpha+\beta$ (OHKUBO et al., 2003).

Zhou et al. (2005) relataram maior resistência ao desgaste de ligas binárias Ti-10Ta, Ti-30Ta e Ti-70Ta, comparadas à liga Ti-6Al-4V, sendo que os resultados de desgaste não 
estavam relacionados às propriedades mecânicas como a dureza e a resistência à tração destas ligas.

Um estudo realizado por Zeng et al. (2005) que avaliou a resistência ao desgaste de dentes artificiais para próteses, encontrou correlação entre a resistência ao desgaste e a microdureza, atribuindo à perda das partículas de carga a razão para a menor resistência ao desgaste.

Lambrechts et al. (2006) apresentaram os diferentes métodos in vitro para simulação de desgaste e o efeito de uma série de fatores, tais como a padronização do material antagonista testado, o número de ciclos, a freqüência e a velocidade do contato com a superfície antagonista, a presença de lubrificantes, o pH, a presença de enzimas e debris, que poderiam interferir nos resultados in vitro e acabariam por tornar impossível a simulação das condições em meio oral. Outros autores (ELMARIA et al., 2006) relataram a correlação existente entre a rugosidade superficial e o desgaste do esmalte, quando este é testado com diferentes antagonistas, como materiais cerâmicos e ouro.

Kadokawa et al. (2006) avaliaram a resistência ao desgaste da porcelana quando ouro, resina composta e esmalte foram usados como antagonistas, utilizando testes abrasivos de 2 e 3 corpos. Estes autores relataram que os valores de desgaste foram menores tanto para a porcelana como para os elementos usados como antagonistas, em testes de desgaste de 3 corpos apesar da superfície da porcelana ter sido mais alterada nesses mesmos testes.

Heintze et al. (2006) avaliaram três diferentes métodos para quantificar o desgaste, como a perda de altura e de volume em um perfilômetro, em um dispositivo escaner a laser associado a um software, e um sensor óptico que avalia o ponto mais profundo da faceta desgastada e calcula a perda vertical e de volume. Segundo estes autores, não houve diferença estatística entre os três métodos e houve correlação entre perda vertical e de volume nos três 
métodos testados, o que demonstra não haver necessidade de quantificar as duas variáveis ao se avaliar o desgaste.

Chan, Koike e Okabe (2007) propuseram um modelo matemático que permitisse estimar a resistência ao desgaste em ligas de titânio $\alpha, \beta$ e $\alpha+\beta$, considerando a ductilidade e a dureza, e observaram que o modelo deveria ser usado com mais cautela em ligas $\alpha+\beta$ que apresentaram valor de $r^{2}$ mais baixo. No entanto, os resultados demonstraram que maior resistência ao desgaste é alcançada quando a liga apresenta alta dureza e baixa ductilidade.

Em 2007, Ohlmann et al. apresentaram um método que possibilitou avaliar o desgaste de coroas metal-free clinicamente através da obtenção de réplicas de gesso e uso de um escaner a laser 3D.

\subsubsection{Dureza}

A dureza de uma liga deve ser suficiente a ponto de não ser desgastada nem desgastar dentes e restaurações antagonistas, esmalte ou outros materiais como a porcelana (WATAHA, 2002). Ligas com dureza Vickers inferior a $125 \mathrm{Kg} / \mathrm{mm}^{2}$ são susceptíveis ao desgaste, e com dureza superior a $340 \mathrm{~kg} / \mathrm{mm}^{2}$ podem desgastar os dentes antagonistas (CRAIG; POWERS, 2004).

Segundo Lautenschlager e Monaghan (1993), nas fundições de titânio pode haver contaminação da superfície com oxigênio e com o revestimento, que pode triplicar os valores de dureza na superfície em relação aos valores de dureza em camadas mais profundas da amostra. Ohkubo et al (2000) avaliaram a usinabilidade e a microdureza do Ti cp e Ti-6Al-4V quando a camada superficial $\alpha$-case foi ou não removida e encontraram maiores valores de microdureza quando esta camada não era removida e os valores de microdureza estavam correlacionados à usinabilidade quando pontas de SiC foram utilizadas. 
Um estudo que avaliou o efeito da adição de Mo ao Ti cp, em concentrações de 6 a 20\%p, encontrou os menores valores de microdureza nas concentrações de 6 e 7,5\%, em que foi observada microestrutura com a fase $\alpha$ '”- martensita ortorrômbica (HO et al., 1999).

Kikuchi et al. (2003) encontraram maiores valores de microdureza da liga, principalmente nas maiores concentrações de $\mathrm{Cu}$ ao variarem a concentração de $\mathrm{Cu}$ de 0,5 a 10\%p em ligas Ti-Cu,. Outro estudo avaliou o efeito da adição de $\mathrm{Cu}$ na liga Ti-6Al-4V, em concentrações variando de 1 a 10\%p, e os resultados demonstraram que a microdureza das ligas aumentou na medida em que maiores concentrações de $\mathrm{Cu}$ foram adicionadas ao sistema (AOKI et al., 2004).

A avaliação da liga Ti-12Mo-5Ta apresentou melhores resultados de microdureza, comparada aos valores apresentados na literatura para o Ti cp e outras ligas de Ti, sendo este aumento na microdureza atribuído à presença de menores grãos em sua microestrutura (GORDIN et al., 2004).

Um estudo que avaliou a microdureza de ligas Ti-Ag em função da concentração de Ag, que variou de 0,5 a 4,5\%p, demonstrou que a microdureza aumentou na medida em que a concentração de Ag aumenta, sendo este aumento significativo em concentrações superiores a 3,5\% (OH; SHIM; KIM, 2005). A avaliação da microdureza de ligas binárias Ti-Hf com concentrações de Hf variando de 10 a 40\%p demonstrou que a microdureza aumentou proporcionalmente ao conteúdo de Hf e que diminuiu gradualmente das camadas mais superficiais para as mais profundas (SATO et al., 2005).

Rocha et al. (2006) avaliaram o efeito de diferentes tratamentos térmicos $\left(750^{\circ} \mathrm{C}-2 \mathrm{~h}\right.$ e $\left.955^{\circ} \mathrm{C}-1 \mathrm{~h}+620^{\circ} \mathrm{C}-2 \mathrm{~h}\right)$ na microdureza Vickers do Ti cp e Ti-6Al-4V, e relataram que Ti-6Al-4V foi afetada por ambos os tratamentos enquanto $\mathrm{Ti}$ cp foi afetado somente pelo segundo. Os autores atribuíram estes resultados a uma possível transformação de fase decorrente do aquecimento dos materiais a temperatura superior a $883^{\circ} \mathrm{C}$, justificando os 
melhores resultados no segundo tratamento térmico em que a temperatura atingida foi superior.

Outros autores relataram aumento na microdureza de ligas do sistema Ti-Ag-Cu na medida em que aumentaram os elementos da liga, sendo que as ligas apresentaram microdureza estatisticamente superior ao Ti cp (KANG et al., 2009)

\subsubsection{Biocompatibilidade}

A biocompatibilidade é mais bem descrita como a forma com que uma liga ou metal interage ou afeta os sistemas biológicos, sendo que a liberação de elementos de uma liga na cavidade bucal pode levar a efeitos adversos como alergia ou inflamação (WATAHA; MESSER, 2004). Teoricamente, a biocompatibilidade de uma liga poderia estar diretamente relacionada às propriedades de corrosão; no entanto, na prática esta relação tem se mostrado inviável diante da dinâmica complexa de liberação de elementos e da interação de tais elementos, uma vez que a resposta biológica aos elementos liberados está relacionada ao elemento que foi liberado, à quantidade liberada, à duração da exposição dos tecidos e outros fatores. No entanto, a liberação de elementos metálicos é condição quase essencial para a ocorrência de efeitos adversos como toxicidade, alergia e mutagenicidade; sendo que alguns elementos são mais liberados do que outros, e o meio em que estas ligas estão inseridas irá interferir nesta liberação de íons metálicos (WATAHA, 2000; WATAHA; MESSER, 2004).

Em 1986, Stanford estabeleceu uma série de testes a serem realizados para utilização segura de ligas de níquel-cromo com mínimo custo. Assim, foram recomendados testes in vitro, para o material na forma sólida e para os produtos que se solubilizavam; e testes in vivo, em que o material era colocado em contato com o tecido por determinado tempo e as reações eram observadas, também podendo ser chamado de teste secundário ou de uso, alertando para 
a necessidade de realização de testes padronizados para determinação da biocompatibilidade, prévios ao uso clínico.

Testes de biocompatibilidade prévios ao uso clínico são realizados em três estágios, englobando testes in vitro, utilizando cultura de células; testes in vivo e testes de uso, realizados em humanos (SCHMALZ, 1997). Assim, vários testes são recomendados para introduzir novas ligas odontológicas no mercado, avaliando a citotoxicidade dos materiais, na forma sólida ou de elementos que se solubilizam, para avaliar o risco de irritação tecidual destes materiais que estarão temporariamente ou permanentemente adjacentes à mucosa oral. A avaliação da biocompatibilidade in vitro de um material exige muita cautela por estar sujeita a uma série de variáveis como, por exemplo, a linhagem de células a ser utilizada na avaliação. Desta forma, é preciso selecionar a linhagem de células mais relevante para a aplicação clínica apesar de se saber que o mecanismo in vivo é muito mais complexo (STANFORD, 1986; SCHMALZ, 1997). Em 2008, Faria et al. avaliaram a biocompatibilidade de ligas de metais básico utilizadas em próteses, em cultura de células epiteliais SCC9, cultivando-as diretamente sobre discos das ligas testadas. No ano seguinte, os mesmos autores avaliaram a biocompatibilidade destas ligas através de extratos, sendo que os extratos foram obtidos a partir da submissão dos metais imersos em saliva a ciclos térmicos que simulavam o meio bucal ${ }^{1}$ (em fase de elaboração). Embora a queixa de pacientes em relação à biocompatibilidade seja rara, ela geralmente está relacionada a queixas como gosto, inflamação ou infecção decorrente dos elementos liberados das ligas (WATAHA, 2000).

Dentre os estudos relatados na literatura avaliando a biocompatibilidade de ligas de titânio, está o de Prigent et al. (1998) que comparou a biocompatibilidade de ligas de Ti-5Ta ao Ti cp em cultura de células epiteliais e fibroblastos, concluindo que a liga Ti-5Ta apresenta

\footnotetext{
${ }^{1}$ FARIA, A.C.L. et al. Effect of temperature variation on the citotoxicity of dental alloys and titanium obtained by casting. Journal of Applied Oral Science. Aceito, a ser publicado em 2009.
} 
biocompatibilidade semelhante ao titânio, sendo sugerida pelos autores para aplicações futuras em implantologia oral.

Okazaki et al. (1998) propuseram as novas ligas Ti-15Zr-4Nb-4Ta, Ti-15Sn-4Nb-2Ta para aplicação cirúrgica, comparando-as ao Ti cp, Ti-6Al-4V, Ti-15Mo-5Zr-3Al e Ti-6Al2Nb-1Ta, em cultura de osteoblastos e fibroblastos. Os autores formularam o estudo por questionarem a neurocitotoxicidade do $\mathrm{Al}$ e toxicidade do $\mathrm{V}$ e concluíram que as ligas propostas propiciaram crescimento das células em cultura superior ao do Ti cp e Ti-6Al-4V.

Niinomi (2003) relatou em seu estudo, em que foi avaliada a biocompatibilidade da liga Ti-29Nb-13Ta-4,6Zr, que este material apresenta biocompatibilidade semelhante ao Ti cp e superior ao Ti-6Al-4V, sendo que a viabilidade celular era diminuída quando os extratos não eram filtrados e comparados aos resultados dos experimentos com extratos filtrados. Além disso, os autores alertam para o fato de que, não apenas íons metálicos dissolvidos, mas também os debris do material afetam sua citotoxicidade, ressaltando a necessidade de se evitar o desgaste de materiais metálicos, evitando a formação dos debris.

Watanabe et al. (2004) avaliaram a citotoxicidade de ligas comerciais e experimentais com e sem a presença da camada superficial $\alpha$-case e não encontraram diferenças na biocompatibilidade das ligas Ti-20Cr, Ti-5Cu, Ti-10Cu, Ti-25Pd, Ti-10Mn, Ti-6Al-7Nb, Ti-6Al-4V e Ti cp, apresentando ou não a camada de reação superficial.

Em 2004, Eisenbarth et al. avaliaram a biocompatibilidade de elementos $\beta$ estabilizadores utilizados em ligas de titânio em culturas de células endoteliais e osteoblásticas e encontraram bons resultados de biocompatibilidade para Ti, Ta, Nb e Zr, embora o último tenha apresentado pobre resistência à corrosão. Dentre os metais testados, a seqüência decrescente de biocompatibilidade foi: Nb, Ta, Ti, Zr, Al, 316L, Mo.

A biocompatibilidade de uma nova liga Ti-12Mo-5Ta, testada em duas diferentes rugosidades, foi demonstrada através dos resultados de adesão e migração celular, que não 
foram diferentes do material controle (Thermanox ${ }^{\circledR}$ ); e da densidade celular, que foi significativamente maior nas ligas de Ti. Além disso, os resultados demonstraram que a topografia da superfície influenciou a biocompatibilidade, de forma que as superfícies mais polidas apresentaram melhores resultados (GORDIN et al., 2004).

Zhou et al. (2005) avaliaram a resistência à corrosão e a biocompatibilidade de ligas binárias Ti-Ta em concentrações de 10, 20 e 30\% de Ta. Estes autores concluíram que estas ligas binárias apresentavam resistência à corrosão superior pelo fato do filme passivo $\mathrm{Ta}_{2} \mathrm{O}_{5}$, formado na superfície destas ligas, ser mais resistente do que o $\mathrm{TiO}_{2}$, identificado na superfície do Ti cp e outras ligas de titânio. Além disso, as ligas estudadas apresentaram biocompatibilidade semelhante ao $\mathrm{Ti} \mathrm{cp}$, sendo que os autores relataram que a estrutura cristalina, que variou de acordo com a concentração de Ta na liga, não alterou a resistência à corrosão e a citotoxicidade destas ligas.

A citotoxicidade das ligas Ti-Ag foi avaliada por Oh, Shim e Kim (2005), que relataram citotoxicidade das ligas $\mathrm{Ti}$-Ag semelhante ao $\mathrm{Ti} \mathrm{cp}$, atribuindo estes resultados ao baixo conteúdo de Ag ou à fina camada de óxido de titânio, que inibiu a resposta citotóxica da liga, embora a Ag seja reconhecida como um agente citotóxico.

A avaliação da biocompatibilidade de quatro ligas de titânio comercializadas e três experimentais demonstrou a biocompatibilidade destas ligas em cultura de fibroblastos, atribuindo estes resultados a excelente resistência à corrosão destes materiais em condições estáticas, mesmo sendo um meio biológico (KOIKE et al., 2007).

Em 2008, um estudo clínico relatado por Berg et al. comparou coroas fabricadas em liga de Au-Pd e Ti-15Zr, avaliando a ocorrência de placa, sangramento à sondagem e satisfação do paciente; e concluíram não haver diferença no desempenho clínico das coroas confeccionadas com as duas diferentes ligas. 
Ligas experimentais Ti-Ag-Cu, testadas em quatro diferentes concentrações de Ag e $\mathrm{Cu}$, apresentaram citotoxicidade semelhante ao Ti cp em cultura de fibroblastos (KANG et al., 2009).

\subsubsection{Microestrutura}

Uma das formas de se descrever uma liga é através de sua estrutura de fase, sendo que as fases são áreas em que uma liga apresenta a mesma composição e estrutura cristalina. De acordo com Wataha (2000), a estrutura de fase de uma liga é crítica para suas propriedades de corrosão e biocompatibilidade, uma vez que a interação entre o meio biológico e a estrutura de fase determinará os elementos liberados pela liga, e a resposta do organismo a estes elementos. Além disso, os tamanhos dos grãos são importantes para as propriedades físicas das ligas, afetando outras propriedades clínicas (WATAHA, 2002). Um exemplo é que pequenos grãos têm demonstrado melhorar a porcentagem de alongamento e resistência à tensão nas ligas de ouro, embora a dureza e resistência ao escoamento não tenham sido afetadas (NIELSEN; TUCCILO, 1966 apud WATAHA, 2002). Segundo Craig e Powers (2004), a forma como a estrutura da fase interfere na resistência da liga é mais complexa, e apesar de ligas de múltiplas-fase serem reconhecidas como mais resistentes, esta resistência dependerá da natureza da segunda fase, sua composição e dispersão através de outras fases, enquanto as ligas de fase única são mais fáceis de manipular, apresentam propriedades mais consistentes e são menos sensíveis à técnica.

Ahmed e Rack (1998) avaliaram a transformação de fase em ligas de titânio $\alpha+\beta$ diante de diferentes ciclos de resfriamento e observaram que maiores taxas de resfriamento resultaram em microestrutura martensítica e na medida em que a taxa de resfriamento era diminuída, a transformação foi substituída por microestrutura do tipo Widmanstätten. 
Em 1999, Ho et al. adicionaram Mo em concentrações de 6 a 20\%p ao Ti cp e observaram que a adição de 6\% e 7,5\% de Mo levava à formação de uma microestrutura martensítica acicular de fase $\alpha$ ”’ ortorrômbica e que em concentrações iguais ou superiores a $10 \%$, a fase $\beta$ se tornava predominante.

Em 2002, Lee et al. estudaram ligas binárias Ti-Nb avaliando a microestrutura, as propriedades mecânicas e o comportamento corrosivo e concluíram que a estrutura cristalina era sensível às diferentes concentrações de $\mathrm{Nb}$, sendo que quando o $\mathrm{Nb}$ foi utilizado em concentrações de até $15 \%$, a liga apresentou estrutura martensítica acicular com fase $\alpha$ ' hexagonal, enquanto concentrações de 17,5 a 25\% levaram à formação de estrutura ortorômbica com fase $\alpha$ ”' e em concentrações de $\mathrm{Nb}$ superiores a 27,5\% foi encontrada estrutura equiaxial com fase $\beta$, sendo que pequenas quantidades de fase $\omega$ também foram detectadas nas últimas.

Embora as ligas Ti-Cu tenham sido propostas para diminuir a temperatura de fusão da liga na tentativa de melhor preencher o molde, no estudo realizado por Watanabe et al. (2003) os resultados destas ligas foram semelhantes ao $\mathrm{Ti}$ сp, sendo que ambas falharam na extremidade final do molde. Segundo os autores, este resultado do Ti-Cu pode ser atribuído à redução na fluidez no final da solidificação devido à precipitação da fase sólida no metal fundido, enquanto do Ti cp se deve ao seu padrão de solidificação da extremidade para o centro do molde devido à diferença de temperatura entre o metal fundido e o molde.

Kikuchi et al. (2003) avaliaram a microestrutura do titânio quando concentrações de Cu de 0,5 a 10\%p foram adicionadas e compararam ao Ti cp e Ti-6Al-4V. O Ti cp apresentou microestrutura do tipo Widmanstätten, com estrutura basket-wave de Ti fase $\alpha$ enquanto Ti6Al-4V apresentou microestrutura Widmanstätten de $\alpha$-Ti que se separaram de $\beta$-Ti durante o resfriamento. Já nas ligas $\mathrm{Ti}-\mathrm{Cu}$, em concentrações de 1 e $2 \%$ foi identificada fase $\alpha$, 
enquanto na de $5 \%$ foi observada estrutura hipoeutetóide com $\alpha$-Ti e $\mathrm{Ti}_{2} \mathrm{Cu}$ e na de $10 \%$ foi observada basicamente estrutura eutetóide com $\mathrm{Ti}_{2} \mathrm{Cu}$.

Gordin et al. (2004) relataram em estudo de caracterização, que a liga Ti-12Mo-5Ta apresentou a fase $\beta$ em sua microestrutura em decorrência de elementos $\beta$ estabilizadores como o Mo e o Ta. Alves et al. (2004) avaliaram a microestrutura e a resistência à corrosão da liga Ti-10Mo em diferentes condições e relataram que as ligas recém-fundidas apresentaram estrutura dendrítica com fase $\beta$, enquanto ligas que passaram por tratamento térmico apresentaram estrutura com grãos equiaxiais com fase $\beta$ e fase $\alpha$; enquanto as ligas que passaram por processo de refundição odontológica apresentaram diferente morfologia de microestrutura com as fases $\alpha$ e $\beta$, demonstrando não ser possível obter microestrutura com fase $\beta$ após fundição odontológica.

Um estudo realizado por Oh, Shim e Kim (2005) avaliou a microestrutura de ligas TiAg para aplicação odontológica quando diferentes concentrações de Ag (0,5 a 4,5\%p) foram utilizadas. Quando o conteúdo de Ag não ultrapassava 2,5\%, a fase $\alpha$ era a única encontrada enquanto em concentrações acima, as fases $\alpha$ e $\beta$ foram identificadas. Além disso, em concentrações de 3,5 e 4,0\% foram identificados componentes intermetálicos.

A caracterização microestrutural de ligas binárias Ti-Hf não identificou fase $\beta$ para estas ligas, ainda que a concentração do elemento $\beta$ estabilizador Hf tenha sido utilizado em concentrações de até $40 \%$. Sendo assim, esta liga apresentou somente fase $\alpha$ (SATO et al., 2005).

Lin et al. (2005) relataram que a liga Ti-13Nb-13Zr foi dominada por uma morfologia martensítica fina acicular com a fase $\alpha$ ' enquanto Ti-7,5Mo apresentou a mesma morfologia, porém com fase $\alpha$ ’’ 
Em 2008, Ho et al. caracterizaram a liga binária Ti-Zr variando a concentração de Zr de 10 a 40\%p, e observaram que o aumento do conteúdo de $\mathrm{Zr}$ levava a um aumento do número de estruturas acicular martensítica, provavelmente devido à diminuição da temperatura de início da transformação martensítica. Sendo assim, a liga Ti-40Zr apresentou uma microestrutura mais fina acicular enquanto Ti-10Zr e Ti-20Zr apresentaram microestrutura do tipo lamelar.

A avaliação da microestrutura de ligas do sistema Ti-Ag-Cu foi caracterizada pela presença da fase $\alpha$, independente das concentrações de Ag e Cu testadas, embora a espessura e extensão da fase $\alpha$ tenham diminuído com o aumento do conteúdo de Cu e Ag. Não foram identificadas fase $\beta$ e precipitados (KANG et al., 2009). 
O objetivo deste estudo foi avaliar as propriedades mecânicas, biológicas e microestrutura de ligas experimentais de titânio para utilização em estruturas metálicas de próteses dentárias, após fundição odontológica, comparando-as ao Ti cp. Para isso, foram avaliados os parâmetros abaixo:

Propriedades mecânicas:

- resistência à tração;

- módulo de elasticidade;

- resistência à abrasão;

- microdureza;

Propriedades biológicas:

- proliferação celular;

- viabilidade celular;

- morfologia celular;

Microestrutura. 


\subsection{OBTENÇÃO DA LIGA}

Para este estudo, foram preparadas ligas experimentais adicionando os metais tântalo (Ta, 99,9\% de pureza) (SIGMA-ALDRICH, Estados Unidos) e zircônio (Zr, 99,5\% de pureza, MULLER METAIS Indústria e Com. Ltda., São Paulo, Brasil) ao titânio comercialmente puro grau I (Ti cp, 99,9\% de pureza) (MULLER METAIS Indústria e Com. Ltda.). Para isto, chapas dos metais utilizados foram preparadas através de corte com disco diamantado; limpeza em solução formada por $50 \mathrm{ml}$ de ácido sulfúrico $\left(\mathrm{H}_{2} \mathrm{SO}_{4}\right), 20 \mathrm{ml}$ de ácido fluorídrico (HF), $20 \mathrm{ml}$ de ácido nítrico $\left(\mathrm{HNO}_{3}\right)$ e $10 \mathrm{ml}$ de água destilada, sendo este processo chamado de decapagem química; e pesagem dos elementos puros em balança de precisão $(0,001 \mathrm{~g}$ de resolução, Bel Engineering, Monza, Itália) (Alves 1998), de acordo com a composição apresentada na Tabela 2:

\begin{tabular}{c}
$\frac{\text { Tabela } 2 \text { - Materiais avaliados }}{\text { Ti cp grau II (controle) }}$ \\
\hline Ti-5Ta \%p \\
\hline Ti-5Zr \%p \\
\hline Ti-5Ta-5Zr \%p
\end{tabular}

O equipamento empregado para a fundição das ligas foi um forno a arco voltaico, com atmosfera inerte (gás argônio) e cadinho de cobre refrigerado à água, da Faculdade de Engenharia de Guaratinguetá da Universidade Estadual Paulista - UNESP (Figura 1). Os metais pesados foram levados ao forno e colocados em um cadinho de cobre existente no interior da câmara de fundição. Após o fechamento do forno, a bomba de vácuo foi acionada para realizar o vácuo $\left(10^{-2} \mathrm{mbar}\right)$, e posteriormente foi injetado argônio no interior da câmara de fundição. Este procedimento, conhecido como lavagem, foi repetido por pelo menos dez vezes e na última injeção de argônio, para fusão das amostras, a pressão foi mantida em 1atm. 


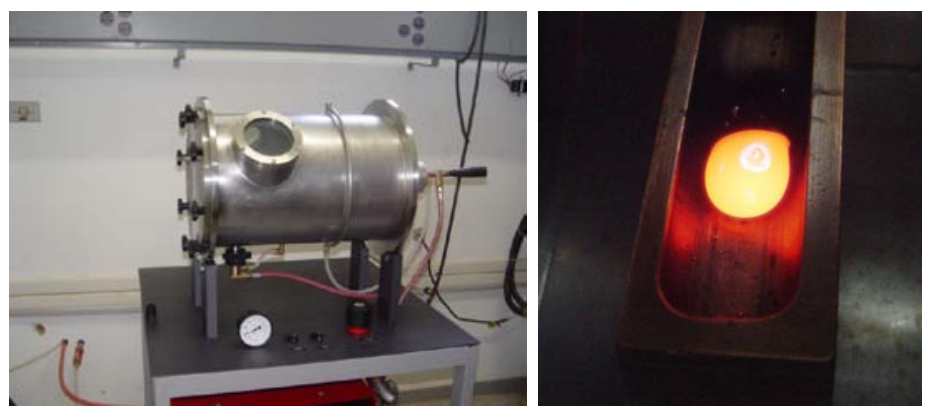

Figura 1 - Forno de arco voltaico para obtenção das ligas.

\subsection{OBTENÇÃO DOS CORPOS-DE-PROVA}

Foram obtidos diferentes corpos-de-prova de acordo com os ensaios a serem realizados. Segue a descrição de cada corpo-de-prova abaixo.

\subsubsection{Ensaio de resistência à tração}

Para a confecção dos padrões de cera, foi utilizada uma matriz bipartida contendo três cavidades padronizadas (Figura 2), em forma de halteres, sem ângulos vivos, com dimensões em conformidade com a norma E-8M da ASTM (American Society for Testing and Materials) apresentadas na Figura 3.
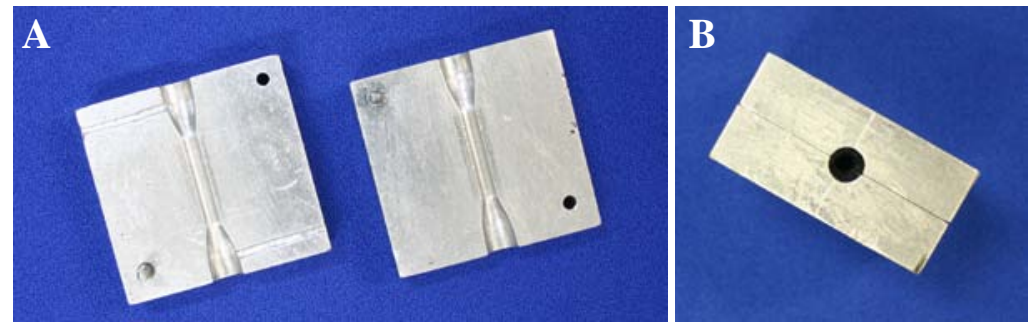

Figura 2 - Matriz bipartida utilizada para enceramento dos corpos-de-prova para ensaio de tração - A: aberta; B: montada.

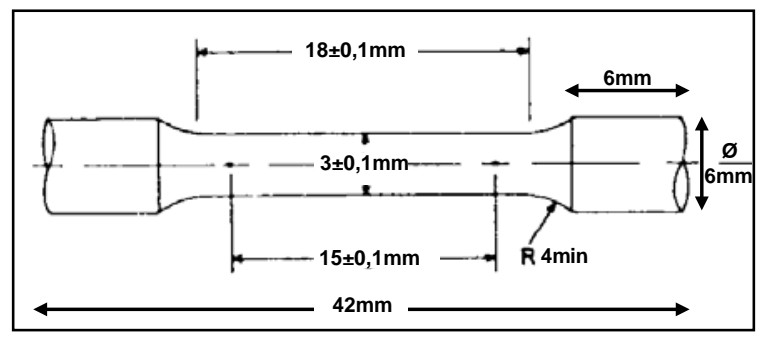

Figura 3 - Dimensões do corpo-de-prova utilizado no ensaio de tração de acordo com a norma ASTM E8M (ASTM 2001). 
Os padrões foram confeccionados utilizando cera Pico dip (Renfert, Alemanha), liquefeita em aparelho digital Hotty Led (Renfert, Alemanha) e vertida na matriz levemente isolada com vaselina sólida e aquecida. Após o resfriamento da cera, a matriz foi aberta e os padrões foram removidos (Figura 4).

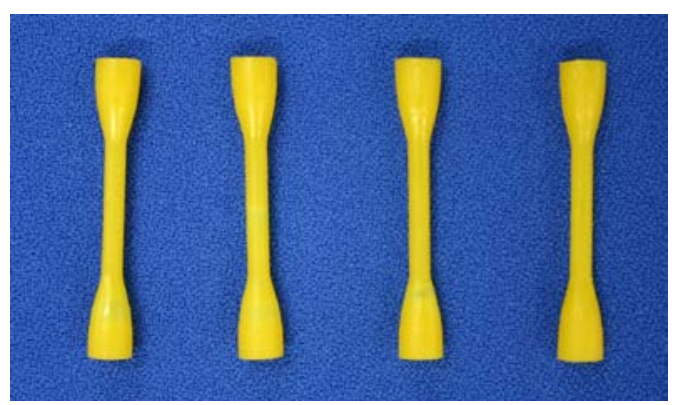

Figura 4 - Padrões de cera para os corpos-de-prova dos ensaios de resistência à tração

\subsubsection{Ensaio de resistência à flexão}

Para a realização do ensaio de flexão, foram cortadas placas acrílicas nas dimensões de 1,0mm de espessura, 5,0mm de largura e 40,0 mm de comprimento (Figura 5).
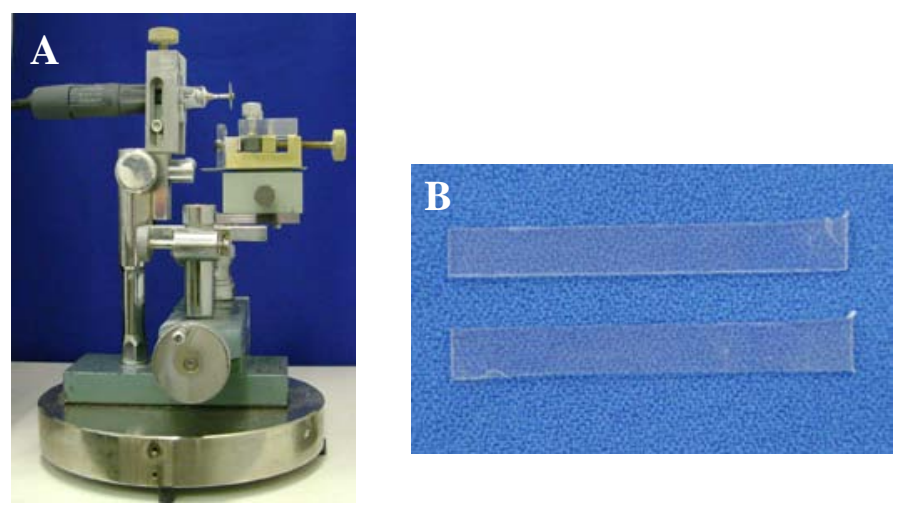

Figura 5 - A: Dispositivo para corte das placas acrílicas nas dimensões especificadas; B: Placas acrílicas para obtenção dos corpos-de-prova dos ensaios de flexão.

\subsubsection{Ensaio de resistência à abrasão}

Para a realização dos testes de resistência à abrasão, foram confeccionados dois tipos de corpos-de-prova: o primeiro de forma semi-esférica, cujo raio é de 5,0mm; e o segundo em forma de discos, apresentando 13,0mm de diâmetro e 2,0 mm de espessura. Os dois tipos de 
corpos-de-prova foram obtidos vertendo cera liquefeita em suas respectivas matrizes de teflon (Figura 6), confeccionadas na Oficina do Departamento de Materiais Dentários e Prótese da Faculdade de Odontologia de Ribeirão Preto da Universidade de São Paulo (FORP-USP). Após o resfriamento da cera, a superfície posterior do padrão foi aplainada com espátula aquecida e os padrões (Figura 7) foram removidos de suas respectivas matrizes.
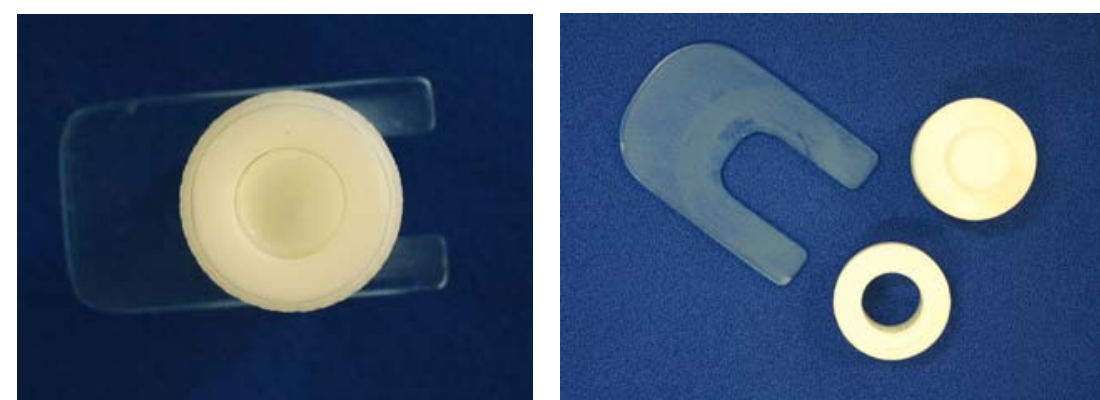

Figura 6 - Matriz de teflon para enceramento dos corpos-de-prova - A: hemi-esfera; B: discos.
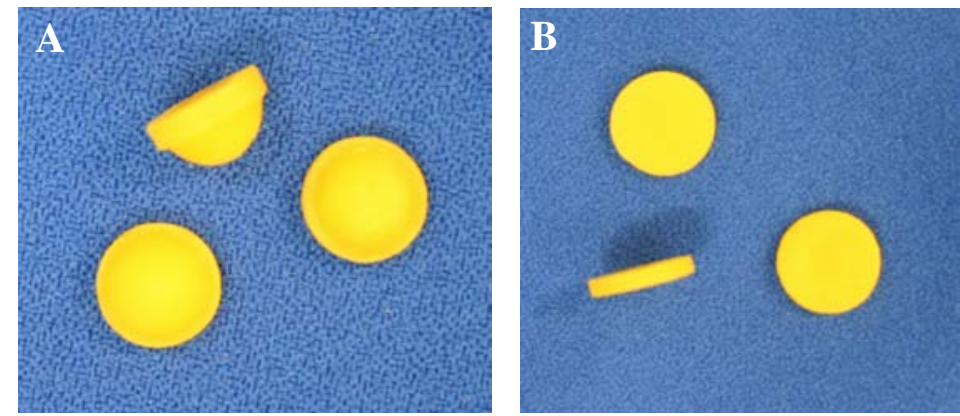

Figura 7 - Padrões de cera dos corpos-de-prova para ensaio de resistência à abrasão - A: hemi-esfera; B: discos.

\subsubsection{Ensaios de biocompatibilidade, microdureza e caracterização microestrutural}

Para a realização dos testes de biocompatibilidade, microdureza e caracterização microestrutural, foram utilizados padrões-de-cera em forma de discos (13,0mm de diâmetro e 2,0mm de espessura), semelhantes aos corpos-de-prova em forma de discos utilizados nos testes de resistência à abrasão. 


\subsection{INCLUSÃO E FUNDIÇÃO}

Todos os padrões obtidos para cada ensaio foram posicionados em base conformadora de cadinho e incluídos em revestimento fosfatado Rematitan Plus (Dentaurum, Pforzhein, Alemanha), seguindo as instruções fornecidas pelo fabricante. A seguir, os anéis foram submetidos ao ciclo térmico recomendado para expansão do revestimento e eliminação do padrão de cera.

A fundição de todos os corpos-de-prova foi realizada na máquina Discovery Plasma (EDG Equipamentos e Controles Ltda., Brasil), que faz a fundição por arco voltaico, sob vácuo e atmosfera inerte de argônio, com injeção da liga/metal no molde por vácuo-pressão (Figura 8).
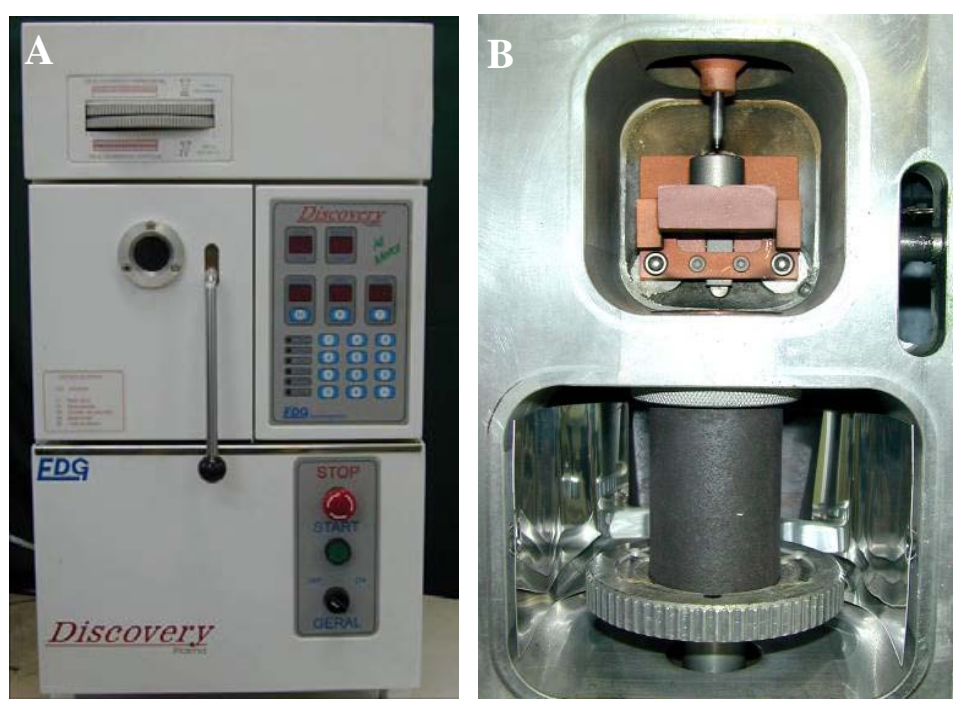

Figura 8 - Máquina Discovery Plasma - A: Painel Externo; B: Câmaras Internas.

Após a fundição, todas as peças foram desincluídas e jateadas com óxido de alumínio $\left(80 \mathrm{psi}=5,62 \mathrm{kgf} / \mathrm{cm}^{2}\right)$ para remoção dos resíduos de revestimento. Em seguida foram cortadas dos lastros de fundição e foram realizados os polimentos de acordo com as indicações para cada teste. 


\subsection{TESTES}

Antes da realização dos testes, os corpos-de-prova foram submetidos a exame radiográfico para detecção de possíveis defeitos de fundição que inviabilizassem o uso posterior. Para a tomada radiográfica, foi utilizada a unidade laboratorial X-Control (Dentaurum, Ispringen, Alemanha), com tensão de $70 \mathrm{kV}$, corrente de $8 \mathrm{~mA}$, distância focofilme de 200mm e tempo de exposição de 1,5 segundos (Figura 9A). O filme utilizado foi Polapan 57 high speed panchromatic black and white film (Polaroid Corp., Cambridge, EUA), com área de exposição de 9,0 x 12,0cm, auto-processado por 20 segundos (Figura 9B). Após o processamento, foi aplicado fluido para fixação da imagem. Cada tomada radiográfica foi feita juntamente com um dispositivo escalonado de raios $\mathrm{X}$ para radiografias de titânio cp (Dentaurum, Ispringen, Alemanha). Os corpos-de-prova que apresentaram defeitos internos e/ou externos não foram considerados para os ensaios.
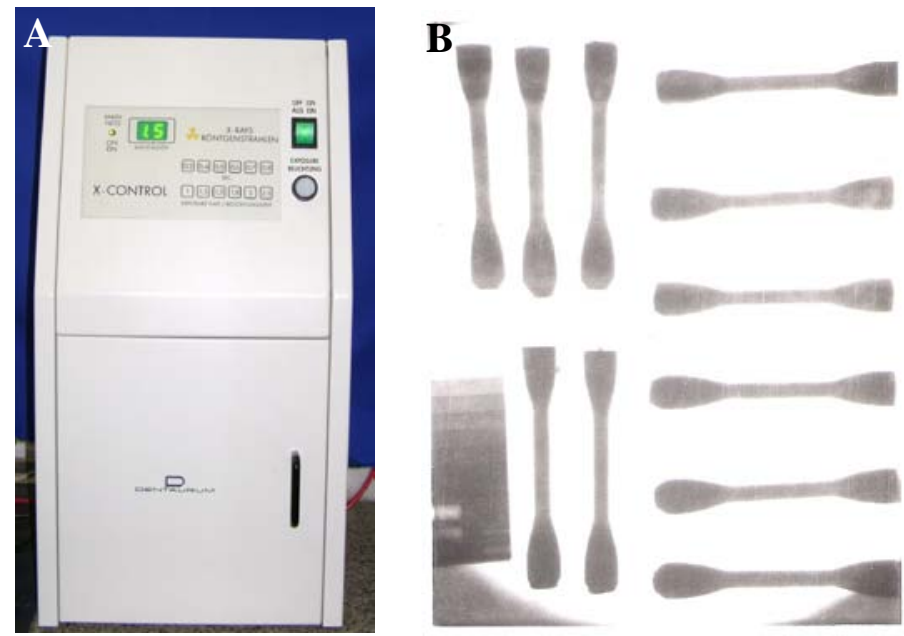

Figure 9 - A: Unidade laboratorial X-Control; B: Radiografia dos corpos-de-prova

\subsubsection{Ensaio de resistência à tração}

As amostras obtidas para o ensaio de resistência à tração foram jateadas com partículas de óxido de alumínio $100 \mu \mathrm{m}\left(80 \mathrm{psi}=5,62 \mathrm{kgf} / \mathrm{cm}^{2}\right)$. O diâmetro de cada amostra foi aferido com paquímetro digital (Mitutoyo, Japão) com precisão de 0,01mm. Os ensaios foram realizados em uma máquina universal EMIC MEM 2000 (EMIC, São José dos Pinhais, SP) 
com uma velocidade de $1 \mathrm{~mm} /$ minuto (Figura 10). No momento da ruptura o programa fornece os valores de tensão máxima (MPa), bem como o gráfico tensão $\mathrm{X}$ deformação, calculados automaticamente. Foram preparados seis corpos-de-prova para cada grupo experimental.

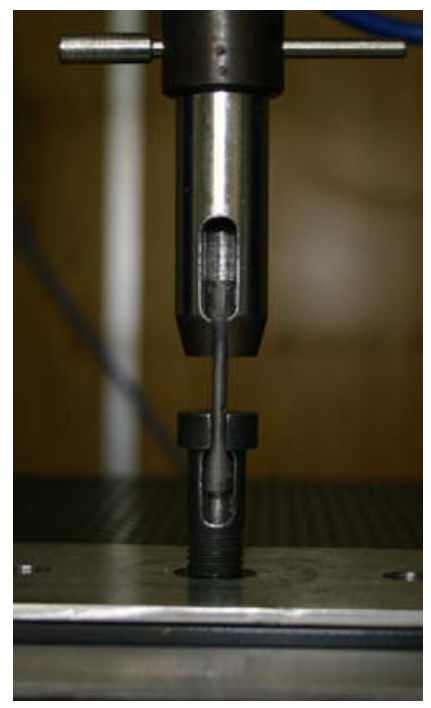

Figura 10 - Corpo-de-prova posicionado na máquina universal EMIC MEM 2000 para ensaio de resistência à tração.

\subsubsection{Ensaio de flexão}

Para eliminar a camada contaminada (" $\alpha$-case") nas placas fundidas, os corpos-deprova foram jateados com partículas de óxido de alumínio $100 \mu \mathrm{m}\left(80 \mathrm{psi}=5,62 \mathrm{kgf} / \mathrm{cm}^{2}\right)$. Posteriormente, as dimensões dos corpos-de-prova foram aferidas com o auxílio de um paquímetro digital (Mitutoyo, Japão). Os ensaios foram realizados em uma máquina universal SHIMADZU AG-X (Shimadzu do Brasil, São Paulo, SP) na Faculdade de Engenharia de Guaratinguetá da Universidade Estadual Paulista - UNESP (Figura 11), com uma velocidade de 0,5mm/minuto. Os corpos-de-prova foram apoiados em um dispositivo com uma distância entre centros dos apoios de 21mm (L), sendo a carga aplicada no centro dos apoios (L/2) utilizando-se um punção cilíndrico, conectado a uma célula de carga de $10 \mathrm{kN}$. 


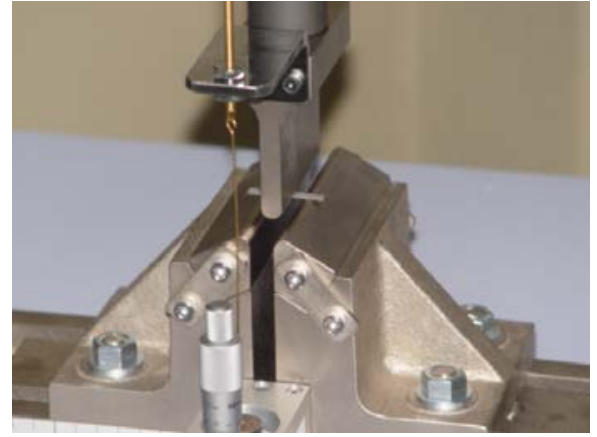

Figura 11 - Corpo-de-prova posicionado na máquina para ensaio de resistência à flexão.

O módulo de elasticidade à flexão foi calculado de acordo com a equação proposta por Ho, Ju e Chern Lin (1999):

$$
E=\frac{L^{3} \Delta P}{4 b h^{3} \Delta \delta}
$$

onde E é o módulo de elasticidade à flexão, L é a distância dos apoios (21mm), h é a espessura dos corpos-de-prova (1,03-1,13mm), b é largura do corpo de prova $(5,01-5,25 \mathrm{~mm})$, $\Delta \mathrm{P}$ é o incremento de carga $(\mathrm{N})$ medido a partir da pré-carga $(1,5 \mathrm{~kg})$, e $\Delta \delta$ é a deflexão medida na distância L/2 após a aplicação da pré-carga. A deflexão foi medida utilizando relógio apalpador, com resolução de $0,01 \mathrm{~mm}$. Foram preparados 10 corpos-de-prova para cada grupo experimental.

\subsubsection{Ensaio de resistência à abrasão}

Os corpos-de-prova em forma de pastilhas foram embutidos em anéis de PVC (Tigre, Brasil), com 2,0cm de diâmetro X 1,5cm de altura, utilizando resina acrílica autopolimerizável (Clássico, Brasil), e posteriormente polidos em lixadeira-politriz mecânica EF-30 (Fortel, Brasil), sob refrigeração abundante, utilizando seqüencialmente lixas 180, 320, 400 e 600. Os corpos-de-prova semi-esféricos, da mesma forma, também foram incluídos em anéis de PVC, com as dimensões acima descritas, utilizando o mesmo método; e polidos utilizando um kit específico para polimento de titânio (Dentaurum, Alemanha), simulando o 
polimento de uma peça clínica (Figura 12 A). Os corpos-de-prova em forma de discos foram ainda jateados com partículas de óxido de alumínio $100 \mu \mathrm{m}\left(80 \mathrm{psi}=5,62 \mathrm{kgf} / \mathrm{cm}^{2}\right)$ e tiveram a rugosidade superficial ajustada em $0,75 \mu \mathrm{m}$.
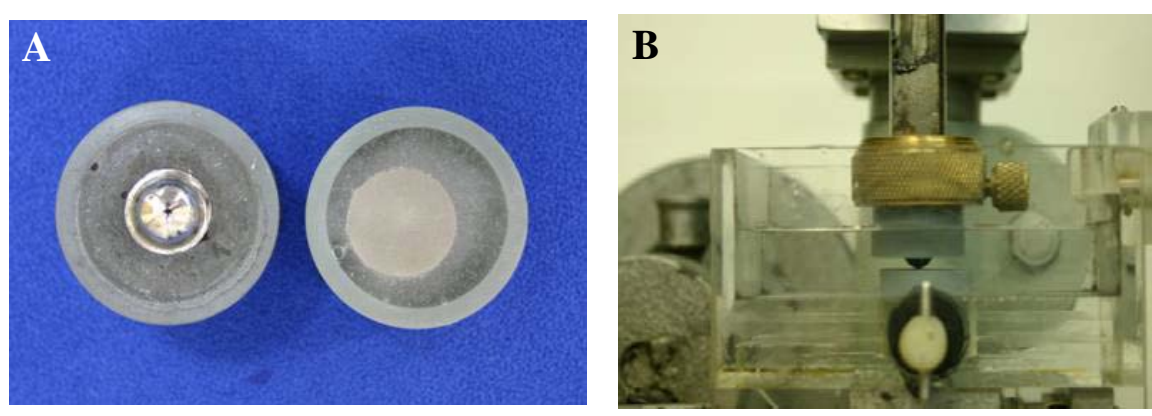

Figura 12 - A- Corpos-de-prova embutidos para ensaio de resistência à abrasão ; B- Corpos-de-prova posicionados em máquina de desgaste.

Os corpos-de-prova foram submetidos a teste de desgaste de 2 corpos usando uma máquina de desgaste confeccionada na Faculdade de Odontologia de Ribeirão Preto-USP (Figura 12B). O teste de desgaste foi realizado pela repetição do movimento de deslizamento entre as amostras, sob carga de aproximadamente $5 \mathrm{~N}$ e freqüência de $4.4 \mathrm{~Hz}$ (265 ciclos/minuto; distância de deslizamento: $10 \mathrm{~mm}$ ). O ensaio foi realizado em água deionizada e o número de ciclos foi de 40.000 (RICCIARDI COPPEDÊ et al., 2009).

Antes do teste de desgaste, os corpos-de-prova foram levados a um projetor de perfil (Nikon Profile Projector, 6C, Nikon, Tokyo) com aumento de 20X (Figura 13), e o perfil das amostras era traçado em papel vegetal. Após o teste, as amostras eram levadas novamente ao projetor de perfil, e a diferença entre o perfil traçado antes do teste e o perfil após o teste foi medida com auxílio de um paquímetro digital (Mitutoyo, Japão) e a resistência ao desgaste foi medida como perda de altura vertical. Foram obtidos seis pares de corpos-de-prova (hemiesférico e disco) para cada grupo experimental. Para avaliar a condição da superfície dos corpos-de-prova hemi-esféricos submetidos a teste de desgaste, um corpo-de-prova de cada grupo experimental foi analisado por microscopia eletrônica de varredura. 

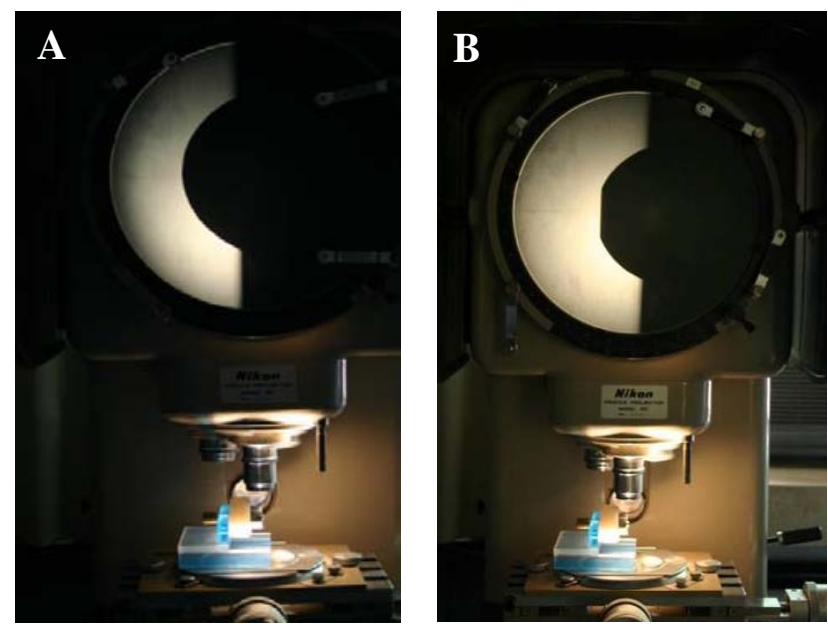

Figura 13 - Perfil do corpo-de-prova projetado no perfilômetro Nikon : A-Antes do teste; B-Após o teste

\subsubsection{Ensaio de microdureza}

O ensaio de microdureza foi realizado utilizando microdurômetro da série HMV-2 (Shimadzu Corp., Kyoto, Japão) (Figura 14), sendo realizadas 03 mossas por quadrante, totalizando 12 mossas por corpo-de-prova, utilizando penetrador com diamante Vickers, piramidal de base quadrada com ângulo de $136^{\circ}$ entre planos. A carga aplicada foi de 19,614N, por 20 segundos. Os resultados foram fornecidos pelo próprio aparelho, após medição das diagonais das mossas produzidas para cada corpo-de-prova. Foi feita a média aritmética das leituras, obtendo-se a microdureza Vickers (VHN). Foram utilizadas doze amostras para cada grupo experimental.

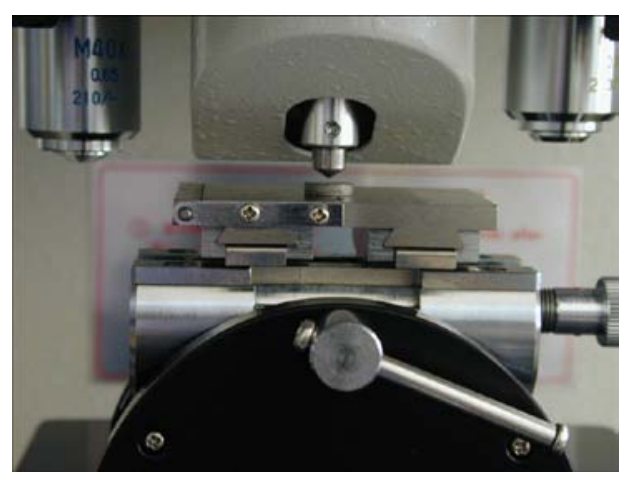

Figura 14 - Microdurômetro 


\subsubsection{Teste de biocompatibilidade}

Para avaliar a biocompatibilidade destas ligas experimentais, foram realizados testes in vitro utilizando cultura de células da mucosa bucal, pensando na utilização destas ligas para próteses e implantes odontológicos. A avaliação da biocompatibilidade in vitro com células da mucosa bucal foi feita com uma linhagem de queratinócitos de carcinomas espinocelulares da cavidade bucal (SCC9 $35^{\mathrm{a}}-38^{\mathrm{a}}$ passagem) da American Type Culture Collection (ATCC, EUA), gentilmente cedidas pelo Prof. Dr. Edgard Graner da Faculdade de Odontologia de Piracicaba, UNICAMP. Estas células foram cultivadas em meio de cultura DMEM/Ham`s F12 (Gibco/Life Technologies, EUA), suplementado com 10\% de soro fetal bovino (FBS, Gibco), $50 \mu \mathrm{g} / \mathrm{mL}$ de gentamicina (Gibco), $0,3 \mu \mathrm{g} / \mathrm{mL}$ de fungizone (Gibco) e 0,4 $\mu \mathrm{g} / \mathrm{mL}$ de hidrocortisona (Sigma, EUA).

As células foram cultivadas em frascos de $75 \mathrm{~cm}^{2}$ a $37^{\circ} \mathrm{C}$ em atmosfera contendo $5 \%$ de $\mathrm{CO}_{2}$ e 95\% de umidade. Ao atingirem a subconfluência, o meio de cultura foi removido dos frascos de $75 \mathrm{~cm}^{2}$ e estes foram lavados três vezes com solução salina tamponada com fosfato $\mathrm{pH} 7,4$ (PBS, Gibco) e então incubadas a $37^{\circ} \mathrm{C}$ com tripsina 0,25\% / EDTA 1mM (Gibco, EUA), durante 10 minutos. Os frascos foram então observados em microscópio de contraste de fase, e estando as células soltas, a suspensão de células foi transferida para tubos de centrífuga estéreis, contendo DMEM/Ham's F12 com 10\% de FBS, para interromper a ação da tripsina. Após centrifugação, o sobrenadante foi removido e os "pellets” foram ressuspendidos em DMEM/Ham's F12 para serem plaqueados nas concentrações desejadas.

Para se avaliar a biocompatibilidade do material com células epiteliais, foram avaliados os seguintes parâmetros: proliferação/viabilidade celular e morfologia celular.

Para avaliação da proliferação/viabilidade celular, foram plaqueadas 2,0x10 ${ }^{4}$ células/poço em placas de 24 poços, sobre discos previamente polidos, lavados, secos, embalados e autoclavados, das ligas e metais propostos. Após 1, 4, 7, 10 e 14 dias, a atividade 
celular foi medida pelo método histoquímico MTT, ensaio dependente da redução do MTT (brometo de 3-dimetiltiazol-2,5-difeniltetrazolium) pela deidrogenase mitocondrial de células viáveis em um produto azul em forma de cristais (formazan), que pode ser avaliado por espectrofotometria (MOSMANN, 1983). Para isto, o meio de cultura dos poços foi substituído por $900 \mu \mathrm{L}$ DMEM/Ham's F12 + 100 $\mathrm{L}$ de MTT $(5 \mathrm{mg} / \mathrm{mL}$ em PBS) e as placas foram incubadas em $37^{\circ} \mathrm{C}$ durante $4 \mathrm{~h}$. Após este período, os poços foram lavados uma vez com solução salina tamponada com fosfato pH 7,4 (PBS, Gibco); 1mL de isopropanol ácido (HCl 0,04N em isopropanol) foi adicionado aos poços e estes foram agitados durante 5 minutos para solubilizar os cristais de formazan azuis. Alíquotas de $100 \mu \mathrm{L}$ de cada poço foram transferidas para placas de 96 poços. A densidade óptica foi lida em 570-650nm em espectrofotômetro ( $\mu$ Quant, Biotek, Winooski, VT) e os dados foram expressos como absorbância (A). Poços sem discos foram usados como controle da cultura.

Após 7 dias, a viabilidade celular foi avaliada lavando os poços três vezes com solução salina tamponada com fosfato $\mathrm{pH} 7,4$ (PBS, Gibco) e incubando a $37^{\circ} \mathrm{C}$ com tripsina $0,25 \%$ / EDTA 1mM (Gibco, EUA), durante 10 minutos para liberação de células aderidas ao substrato. O número total de células por poço e a porcentagem de células viáveis e nãoviáveis foram determinados após marcação com corante azul de Trypan 1\% (Sigma) na proporção 1/1 durante 5 minutos e contagem em hemocitômetro. A viabilidade celular foi expressa como porcentagem de células viáveis em relação ao número total de células cultivadas sobre os discos.

Para avaliação da morfologia celular, foram plaqueadas 3,0×10 ${ }^{4}$ células/poço em placas de 24 poços, sobre discos previamente polidos, lavados, secos, embalados e autoclavados, das ligas e metais propostos. Lamínulas plásticas tratadas para cultura de células (Thermanox® ${ }^{\circledR}$, Nalge Nunc International, NY, EUA) foram usadas como controle. A morfologia celular foi avaliada após 2, 12 e 24 horas. Para a visualização dos limites celulares 
determinados pelo citoesqueleto de actina e dos núcleos aderidos à superfície dos materiais, foram utilizados, respectivamente, faloidina conjugada com Alexa Fluor 488 (Molecular Probes, Eugene, OR, EUA) 1:200 e DAPI (4'-6-diamidino-2-fenilindole - Molecular Probes) 1:300 em água bidestilada. Após a montagem de lamínula de vidro sobre os discos, com meio de montagem antifade Prolong (Molecular Probes), as marcações foram analisadas por epiluminação em microscópio de fluorescência Leica (Wetzlar, Alemanha). Para avaliar a morfologia celular, a porcentagem de células nos estágios (I) células esféricas pequenas, (II) células esféricas maiores, (III) células esféricas arredondadas e espraiadas, isoladas ou em grupos, formando arranjos epitelióides, e (IV) células apresentando prolongamentos citoplasmáticos, foi calculada a partir da contagem de 100 células aderidas em 2, 12 e 24 horas para cada superfície, utilizando campos microscópicos selecionados aleatoriamente (40X) (RAJAMARAN et al., 1974).

Os experimentos foram realizados duas vezes. Para cada grupo experimental, os experimentos foram realizados em quintuplicata, exceto na avaliação da morfologia celular em que os experimentos foram realizados em triplicata.

\subsubsection{Caracterização microestrutural}

Para análise metalográfica, as amostras foram seccionadas ao longo da seção transversal em uma máquina automática com disco diamantado (Isomet, Buheler) e embutidas em baquelite. O lixamento úmido foi realizado com água e parafina, empregando lixas de carbeto de silício (SiC) com grana variando de 180 a 2400. O polimento foi realizado com um pano especial (OP-Chem, Struers) com ácido oxálico (5\%). Em seguida, foi realizado o ataque químico para análise da microestrutura em microscópio óptico (Epiphot 4, Nikkon). A identificação das fases foi feita por análise de difração de raios X usando um difratômetro 
Isodebyeflex 1001 - marca Seifert, da Escola de Engenharia de Lorena - USP, num intervalo angular de $2 \theta$ de 10 a $80^{\circ}$.

\subsection{ANÁLISE ESTATÍSTICA}

Os dados obtidos nos ensaios de resistência à tração, resistência à flexão, resistência à abrasão, microdureza e proliferação/viabilidade celular, foram comparados por ANOVA e teste de Tukey, usando o software SPSS 12.0 for Windows (SPSS Inc., EUA). Os dados obtidos na avaliação da morfologia celular foram comparados pela modelo de planejamento em parcelas subdivididas, usando o software SAS/STAT ${ }^{\circledR}$ (SAS Institute Inc., EUA). As diferenças foram consideradas estatisticamente significantes para $p \leq 0,05$. 
5. Resultados

5. RESULTADOS 
Os corpos-de-prova que apresentaram defeitos externos e/ou internos, detectados por exame radiográfico, não foram considerados para os ensaios. Desta forma, o exame radiográfico foi utilizado somente como um recurso para avaliar a qualidade dos corpos-deprova. Os resultados dos ensaios descritos são apresentados abaixo.

\subsection{Ensaio de resistência à tração}

Os resultados da resistência à tração demonstraram haver diferença estatisticamente significante entre os materiais testados $(p=0,004)$. A tensão na força máxima no ensaio de tração de Ti-5Ta $(364,39 \pm 38,70 \mathrm{MPa})$ foi significativamente menor do que $\mathrm{Ti}$ cp

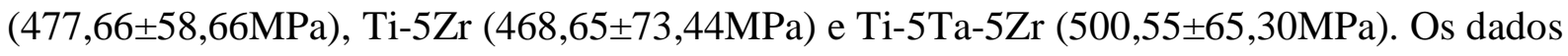
são apresentados na Figura 15.

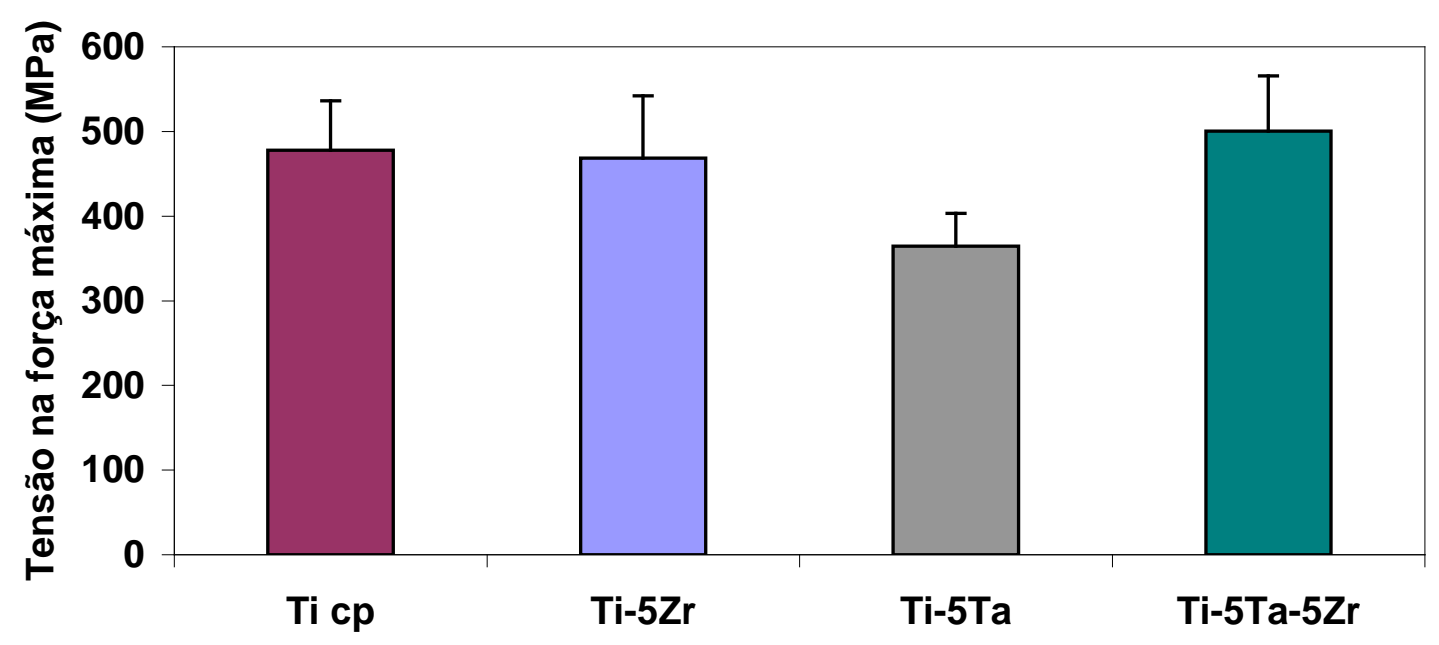

Figura 15. Resistência à tração representada pela tensão na força máxima (MPa) do Ti cp, Ti-5Zr, Ti-5Ta e Ti-5Ta-5Zr. Os dados são apresentados como média e desvio-padrão. 


\subsection{Ensaio de flexão}

Os resultados do módulo de elasticidade demonstraram que Ti cp apresentou módulo de elasticidade estatisticamente diferente de Ti-5Ta $(39,17 \pm 18,95 \mathrm{GPa})(\mathrm{p}=0,038)$, mas não houve diferença no módulo de elasticidade entre as ligas experimentais $(\mathrm{p}=0,136)$, ou entre o Ti cp $(63,88 \pm 21,16)$ e as ligas de Ti-5Zr $(57,95 \pm 17,53 \mathrm{GPa})$ e Ti-5Ta-5Zr $(55,22 \pm 17,71 \mathrm{GPa})$ $(\mathrm{p}=0,737)$. Os dados são apresentados na Figura 16.

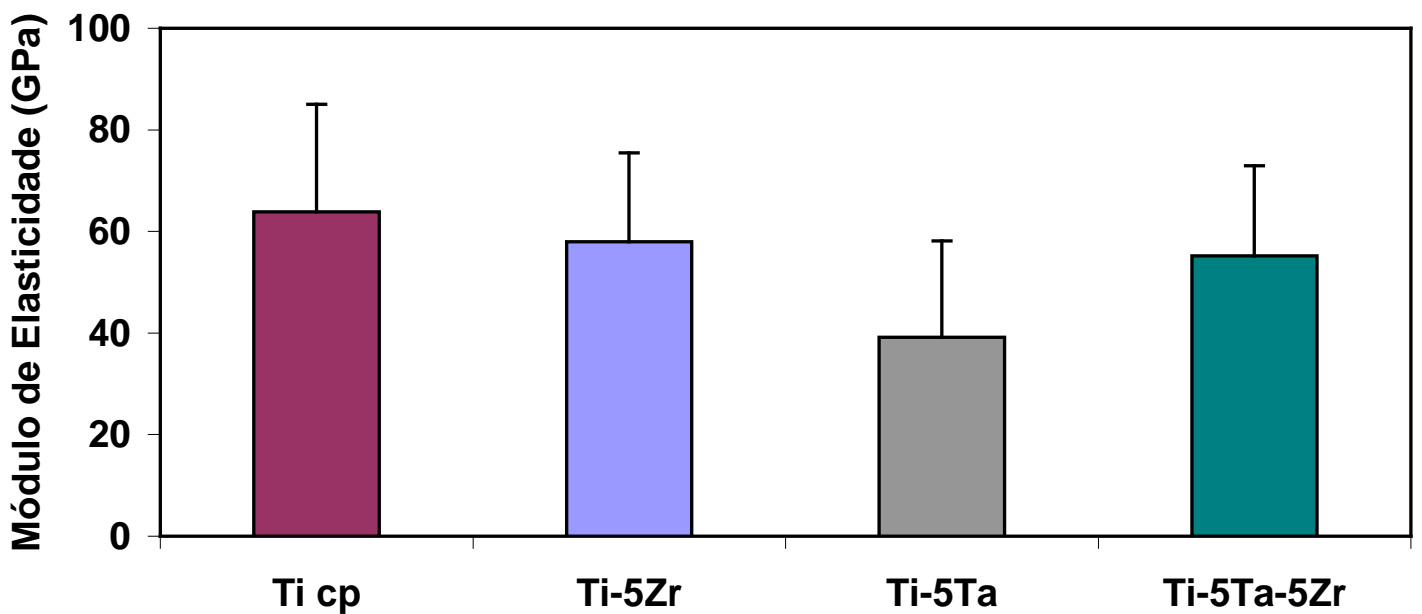

Figura 16. Módulo de elasticidade (GPa) do Ti cp, Ti-5Zr, Ti-5Ta e Ti-5Ta-5Zr. Os dados são apresentados como média e desvio-padrão. 


\subsection{Ensaio de resistência à abrasão}

Os ensaios de resistência à abrasão demonstraram que Ti cp apresentou resistência à abrasão significativamente menor $(\mathrm{p}=0,003)$ do que as ligas experimentais, uma vez que o desgaste vertical de $\mathrm{Ti}$ ср $(212,9 \pm 29,3 \mu \mathrm{m})$ foi significativamente maior do que Ti-5Zr $(155,6 \pm 16,2 \mu \mathrm{m})$, Ti-5Ta $(131,3 \pm 36,3 \mu \mathrm{m})$ e Ti-5Ta-5Zr $(137,3 \pm 55,4 \mu \mathrm{m})$. Os dados são apresentados na Figura 17.

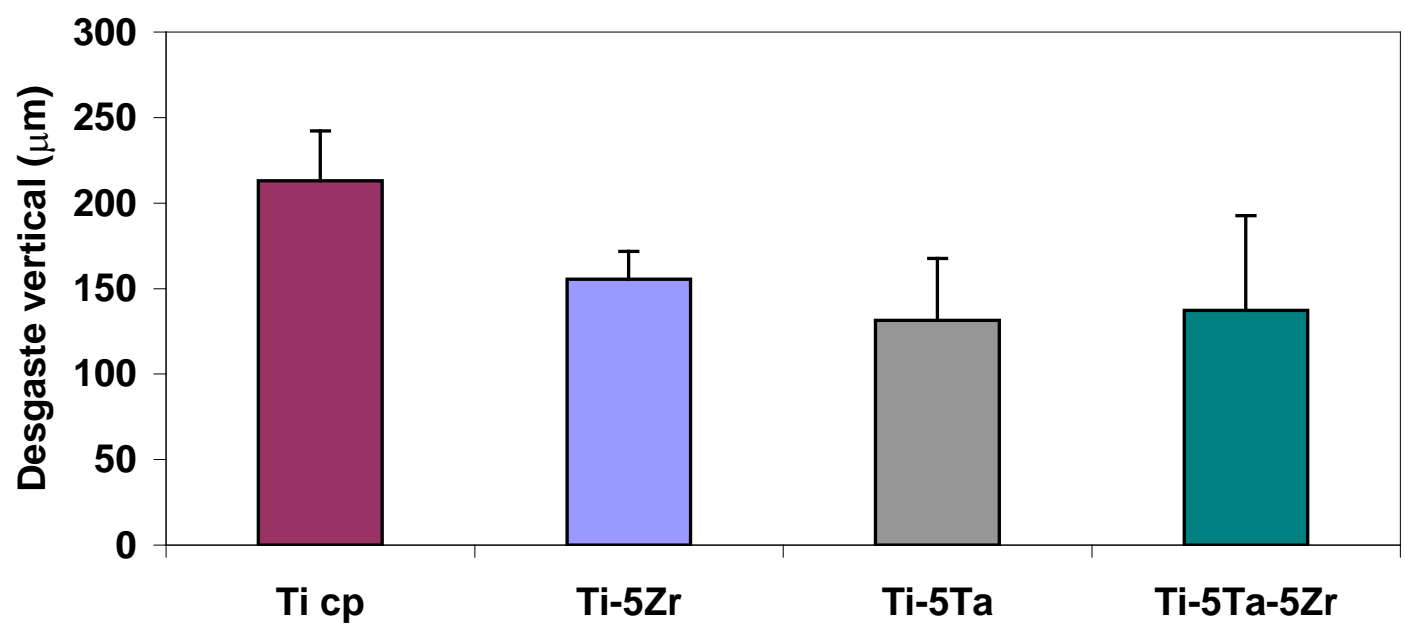

Figura 17. Resistência à abrasão representada como perda de altura vertical $(\mu \mathrm{m})$ do Ti cp, Ti-5Zr, Ti-5Ta e Ti-5Ta-5Zr. Os dados são apresentados como média e desvio-padrão. 
As imagens por microscopia eletrônica de varredura da superfície desgastada do Ti cp, Ti-5Zr, Ti-5Ta e Ti-5Ta-5Zr são apresentadas na Figura 18.
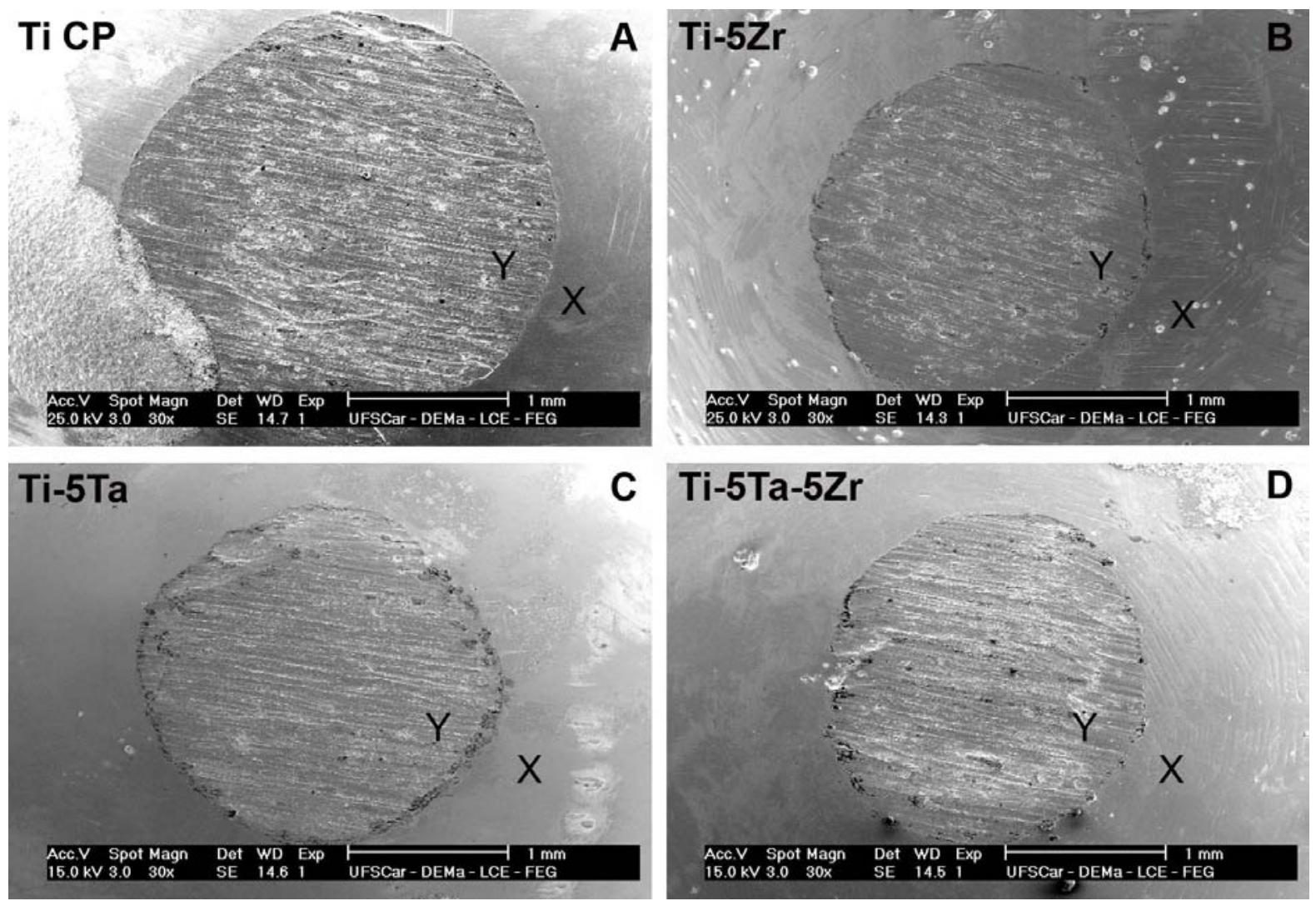

Ti-5Ta-5Zr

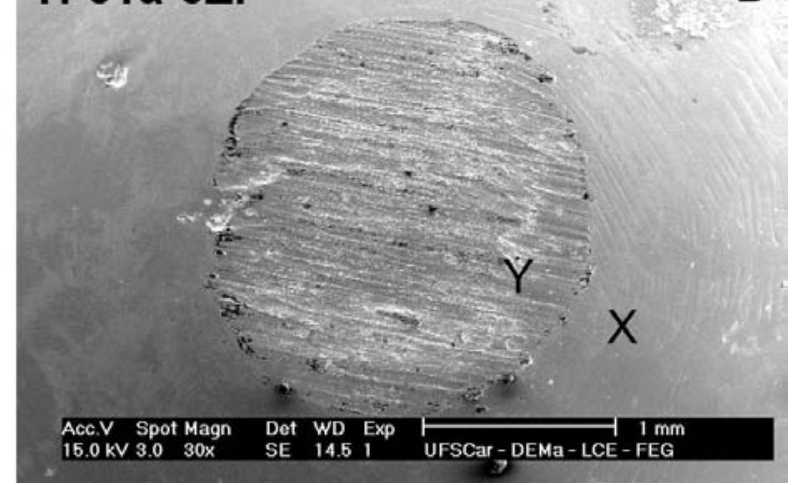

Figura 18. Microscopia eletrônica de varredura da superfície abrasionada do corpo-de-prova hemi-esférico após teste de desgaste (X-Superfície polida; e Y-Superfície desgastada). A: Ti cp; B: Ti-5Zr; C: Ti-5Ta; D: Ti-5Ta-5Zr. Aumento de 30X.

A periferia e a região central da superfície desgastada foram observadas por microscopia eletrônica de varredura em aumentos maiores. As imagens do Ti cp, Ti-5Zr, Ti5Ta e Ti-5Ta-5Zr são apresentadas, respectivamente, nas Figuras 19, 20, 21 e 22. 

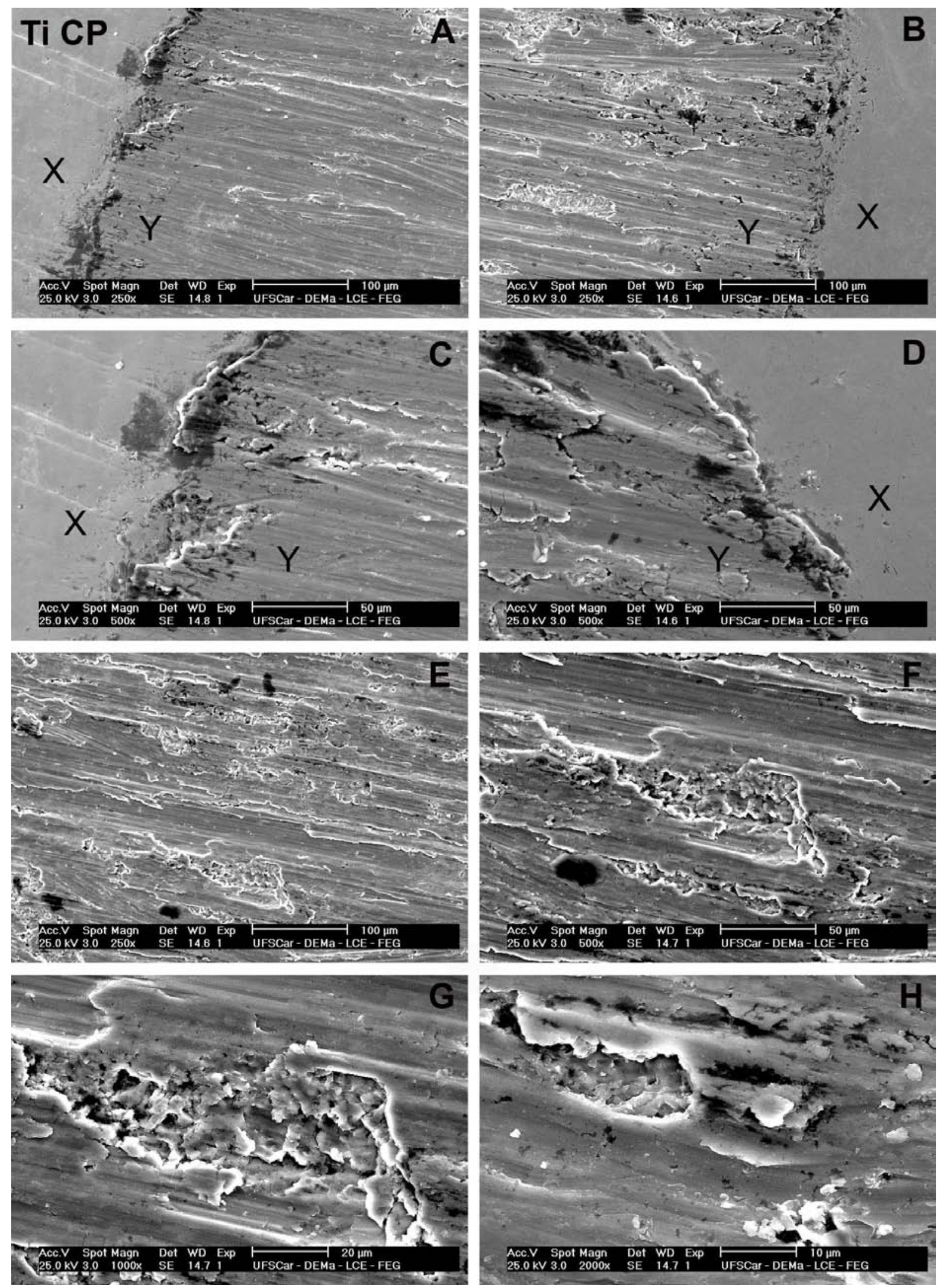

Figura 19. Microscopia eletrônica de varredura da superfície abrasionada do corpo-de-prova hemi-esférico de Ti cp A e B: Periferia da superfície abrasionada (Aumento de 250X); C e D: Periferia da superfície abrasionada (Aumento de 500X); E, F, G e H: Centro da superfície abrasionada (Aumento de 250X, 500X, 1000X e 2000X, respectivamente). X-Superfície polida; e Y-Superfície desgastada. 

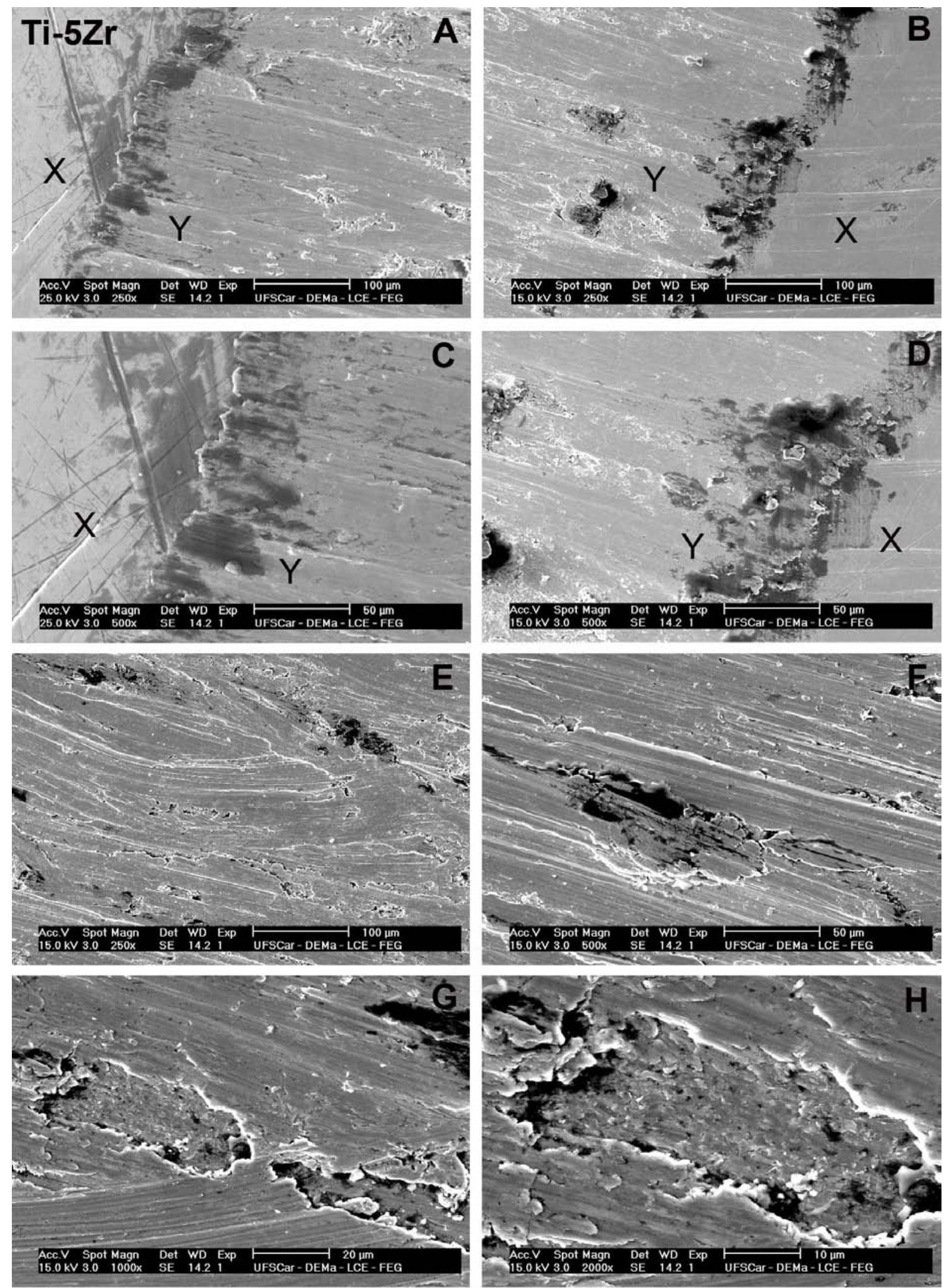

Figura 20. Microscopia eletrônica de varredura da superfície abrasionada do corpo-de-prova hemi-esférico de Ti-5Zr. A e B: Periferia da superfície abrasionada (Aumento de 250X); C e D: Periferia da superfície abrasionada (Aumento de 500X); E, F, G e H: Centro da superfície abrasionada (Aumento de 250X, 500X, 1000X e 2000X, respectivamente). X-Superfície polida; e Y-Superfície desgastada. 

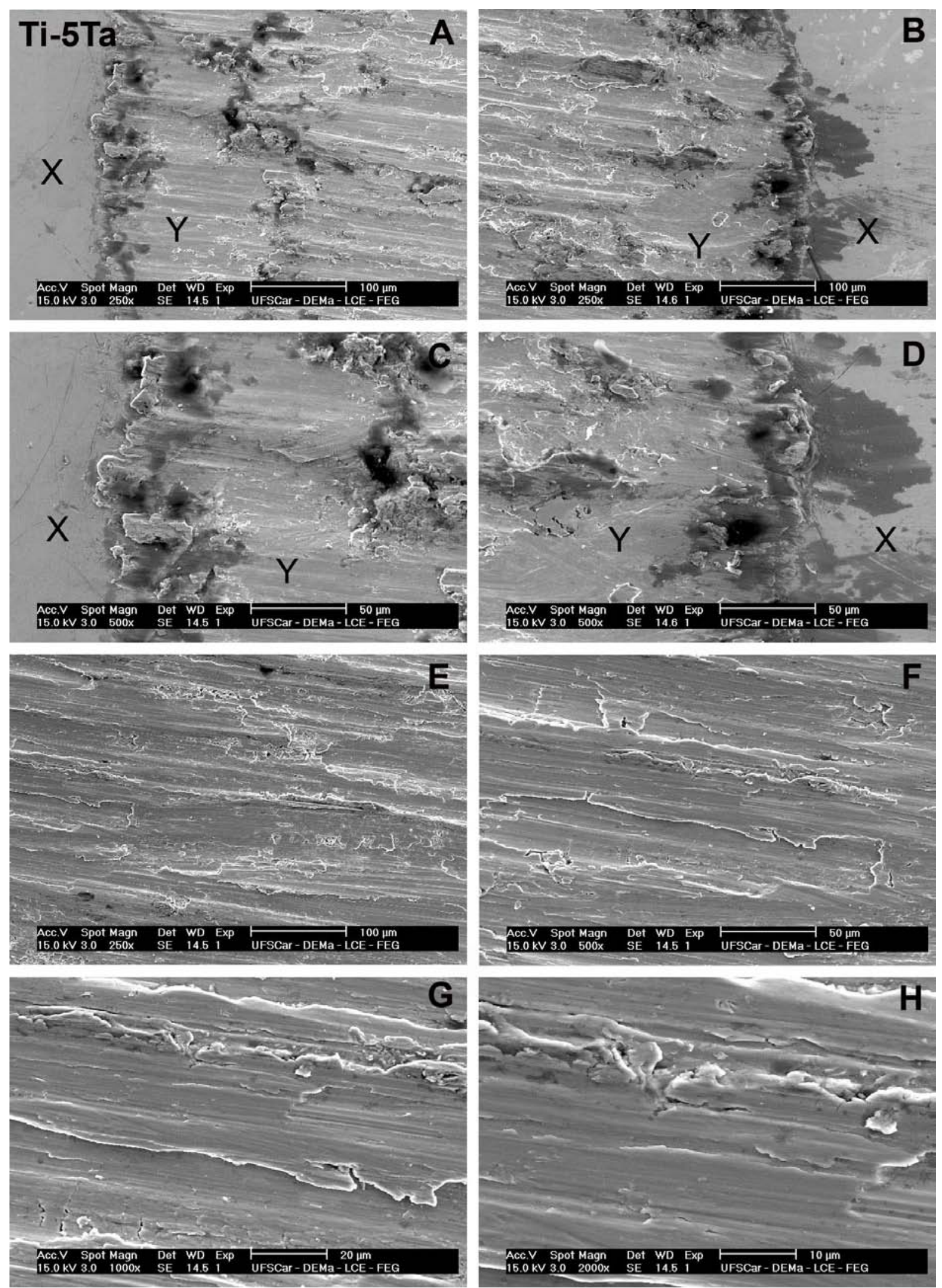

Figura 21. Microscopia eletrônica de varredura da superfície abrasionada do corpo-de-prova hemi-esférico de Ti-5Ta. A e B: Periferia da superfície abrasionada (Aumento de 250X); C e D: Periferia da superfície abrasionada (Aumento de 500X); E, F, G e H: Centro da superfície abrasionada (Aumento de 250X, 500X, 1000X e 2000X, respectivamente). X-Superfície polida; e Y-Superfície desgastada. 

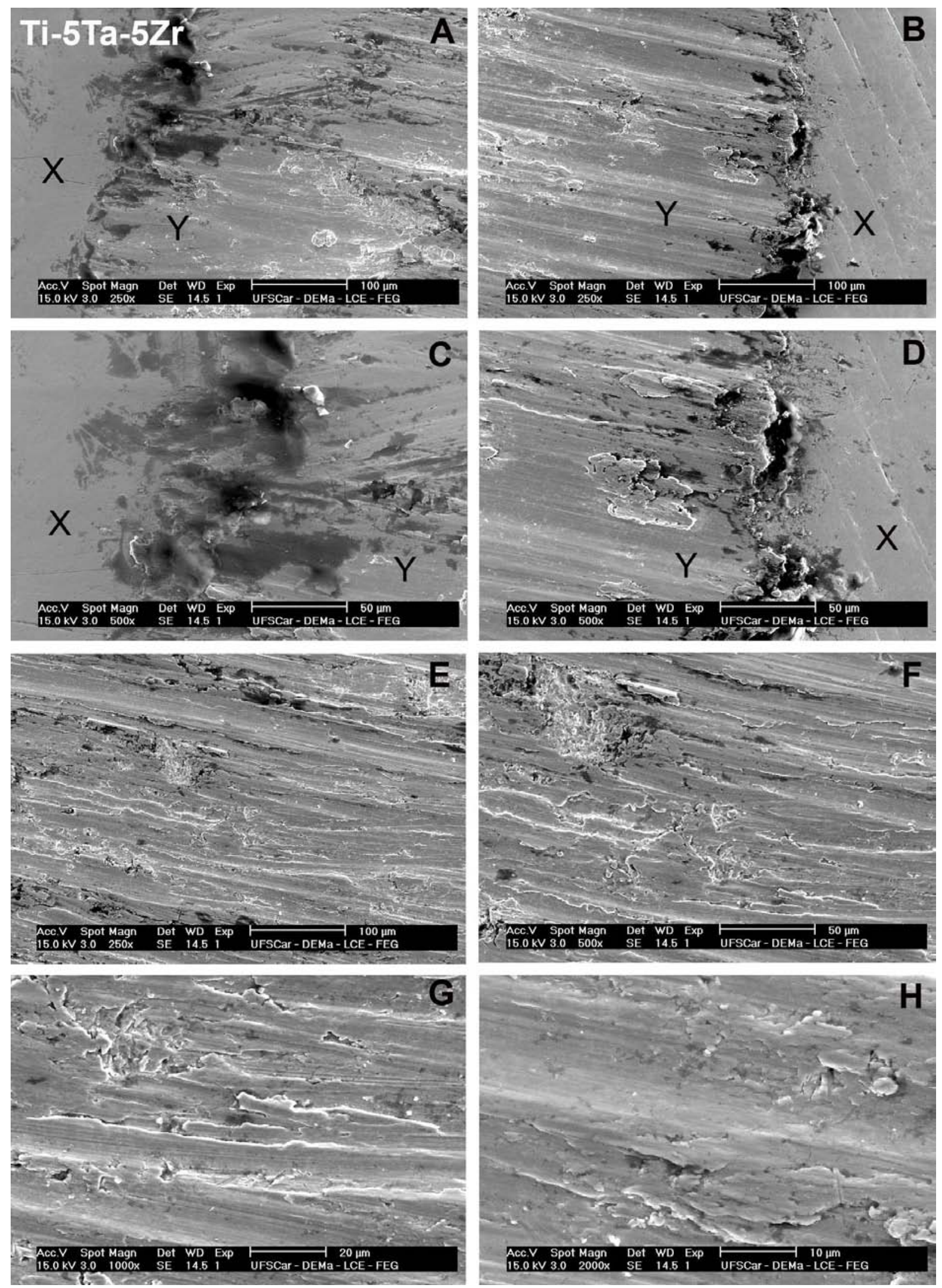

Figura 22. Microscopia eletrônica de varredura da superfície abrasionada do corpo-de-prova hemi-esférico de Ti-5Ta-5Zr. A e B: Periferia da superfície abrasionada (Aumento de 250X); C e D: Periferia da superfície abrasionada (Aumento de 500X); E, F, G e H: Centro da superfície abrasionada (Aumento de 250X, 500X, 1000X e 2000X, respectivamente). X-Superfície polida; e Y-Superfície desgastada. 


\subsection{Ensaio de microdureza}

Os resultados da microdureza Vickers demostraram haver diferença estatisticamente significante entre os materiais testados $(\mathrm{p} \leq 0,05)$. A microdureza de Ti-5Zr $(287,17 \pm 43,92 \mathrm{VHN})$ foi significativamente maior do que Ti cp $(214,83 \pm 51,25 \mathrm{VHN})$, Ti-5Ta $(213,08 \pm 39,15 \mathrm{VHN})$ e Ti-5Ta-5Zr $(199,42 \pm 39,94 \mathrm{VHN})$. Os dados são apresentados na Figura 23.

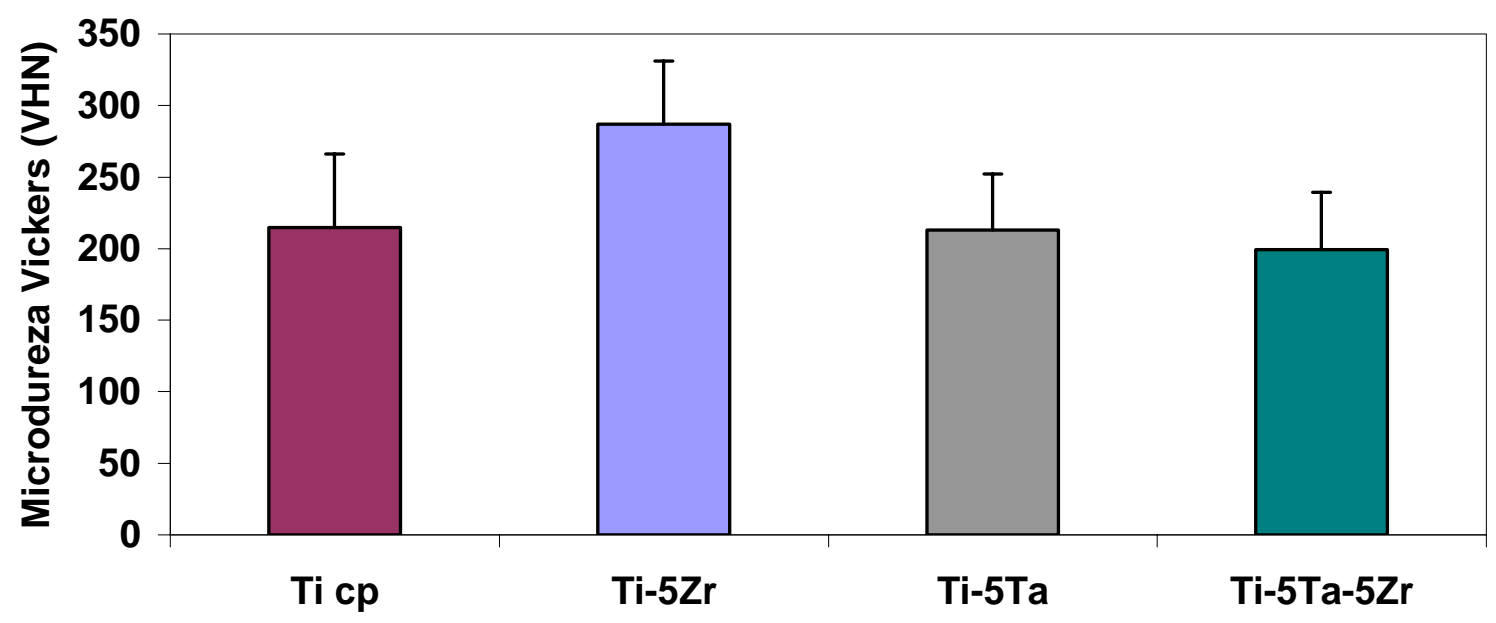

Figura 23. Microdureza Vickers (VHN) de Ti cp, Ti-5Zr, Ti-5Ta e Ti-5Ta-5Zr. Os dados são apresentados como média e desvio-padrão. 


\subsection{Teste de biocompatibilidade}

\subsubsection{Avaliação da proliferação/viabilidade celular}

No período de 24 horas não houve diferença significante entre os grupos, sendo os valores de absorbância encontrados para o Ti cp $\left(A_{M T T}=0,0176\right)$, Ti-5Zr $\left(A_{M T T}=0,0129\right)$, Ti5Ta $\left(\mathrm{A}_{\mathrm{MTT}}=0,0164\right)$ e Ti-5Ta-5Zr $\left(\mathrm{A}_{\mathrm{MTT}}=0,0156\right)$ estatisticamente semelhantes $(\mathrm{p}=0,056)$. No período de 4 dias, não houve diferença significante entre os grupos, sendo os valores de $\mathrm{A}_{\mathrm{MTT}}$ de 0,0198 para o Ti cp, 0,0246 para Ti-5Zr, 0,0280 para Ti-5Ta e 0,0275 para Ti-5Ta-5Zr $(\mathrm{p}=0,264)$. O mesmo aconteceu no período de 7 dias em que Ti cp $\left(\mathrm{A}_{\mathrm{MTT}}=0,0712\right)$, Ti-5Zr $\left(\mathrm{A}_{\mathrm{MTT}}=0,0665\right)$, Ti-5Ta $\left(\mathrm{A}_{\mathrm{MTT}}=0,0681\right)$ e Ti-5Ta-5Zr $\left(\mathrm{A}_{\mathrm{MTT}}=0,0710\right)$ foram estatisticamente semelhantes $(p=0,897)$. No período de 10 dias não houve diferença significante entre os grupos ( $(\mathrm{p}=0,231)$, sendo $\mathrm{A}_{\mathrm{MTT}}$ de 0,1193 para Ti cp, 0,1263 para Ti-5Zr, 0,1352 para Ti-5Ta e 0,1326 para Ti-5Ta-5Zr; e em 14 dias também não foram encontradas diferenças significantes $(p=0,205)$ entre Ti cp $\left(A_{M T T}=0,1399\right)$, Ti-5Zr $\left(A_{M T T}=0,1431\right)$, Ti-5Ta $\left(A_{M T T}=0,1553\right)$ e Ti5Ta-5Zr ( $\left.\mathrm{A}_{\mathrm{MTT}}=0,1508\right)$. Os dados são apresentados na Figura 24.

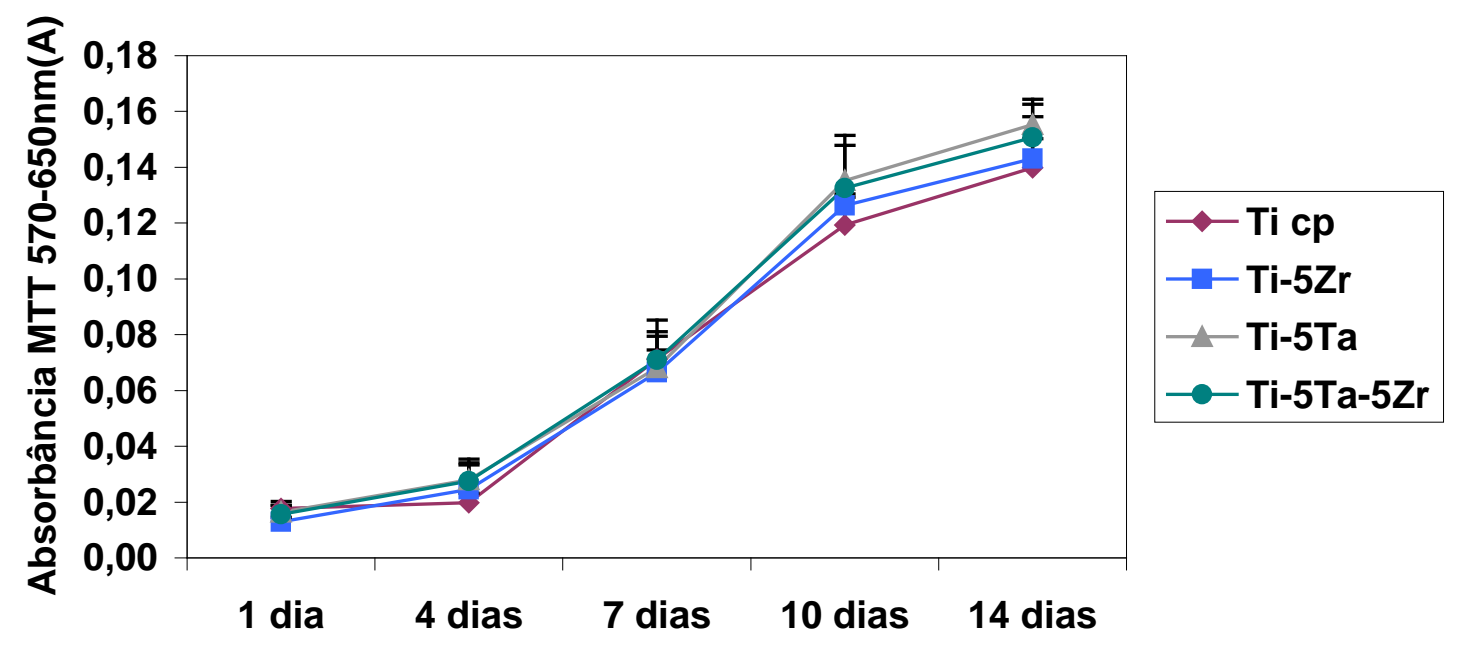

Figura 24. Proliferação/atividade celular de células SCC9 cultivadas sobre discos de Ti cp, Ti-5Zr, Ti-5Ta e Ti-5Ta-5Zr nos períodos de 1, 4, 7, 10 e 14 dias. Os dados são apresentados como média e desvio-padrão de um experimento realizado em quintuplicata. 
A porcentagem de células viáveis, evidenciadas pelo corante azul de Trypan, em relação ao número total de células cultivadas sobre os discos foi avaliada no período de 7 dias. Não houve diferença significante entre os grupos e o controle da cultura $(p=0,968)$, sendo que a porcentagem de células viáveis contadas sobre os discos foi de 72,152\% para o Ti cp, 83,133\% para Ti-5Zr, 72,857\% para Ti-5Ta, 73,75\% para Ti-5Ta-5Zr e 78,495\% para o controle da cultura. Os dados são apresentados na Figura 25.

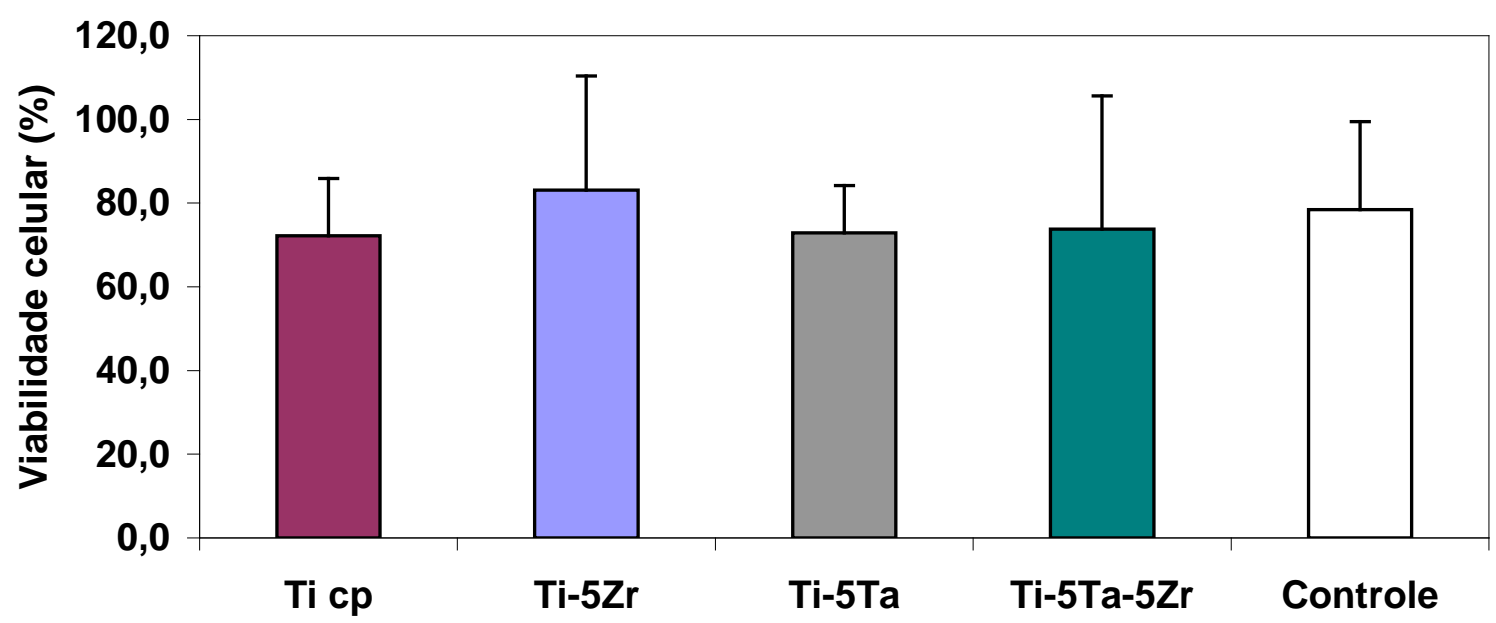

Figura 25. Porcentagem de células viáveis cultivadas sobre os discos de Ti cp, Ti-5Zr, Ti-5Ta, Ti-5Ta-5Zr e o controle da cultura no período de 7 dias. Os dados são apresentados como média e desvio-padrão de um experimento realizado em triplicata. 


\subsubsection{Avaliação da morfologia celular.}

A porcentagem de células em cada estágio foi comparada entre os grupos e o controle em cada período avaliado.

A morfologia celular foi avaliada através da visualização dos limites celulares do citoesqueleto de actina e do núcleo por epiluminação em microscópio de fluorescência. A morfologia celular foi semelhante, independente do material sobre o qual as células foram cultivadas (Figura 26 A-E). No período inicial de cultura, a maior porcentagem de células se encontrava no estágio I ou II, sendo que em I as células se apresentavam menores do que em II, indicando início de espraiamento das células. No período de 2 horas, a porcentagem de células no estágio I no controle foi estatisticamente menor do que no Ti cp, Ti-5Zr e Ti-5Ta5Zr ( $\mathrm{p} \leq 0,01)$; e no Ti-5Ta foi estatisticamente menor do que no Ti-5Zr $(\mathrm{p}=0,03)$ e Ti-5Ta-5Zr $(\mathrm{p} \leq 0,01)$, havendo ainda diferença estatística na porcentagem de células no estágio I entre Ti5Ta-5Zr e Ti cp $(p=0,04)$. Com relação à porcentagem de células no estágio II, o Ti-5Ta e o controle apresentaram maior porcentagem de células neste estágio do que Ti cp, Ti-5Ta-5Zr e Ti-5Zr ( $\leq \leq 0,05)$. Comparando a porcentagem de células no estágio III e IV, não houve diferença significativa entre os materiais testados ( $\mathrm{p}>0,05)$ (Figura 26F). 

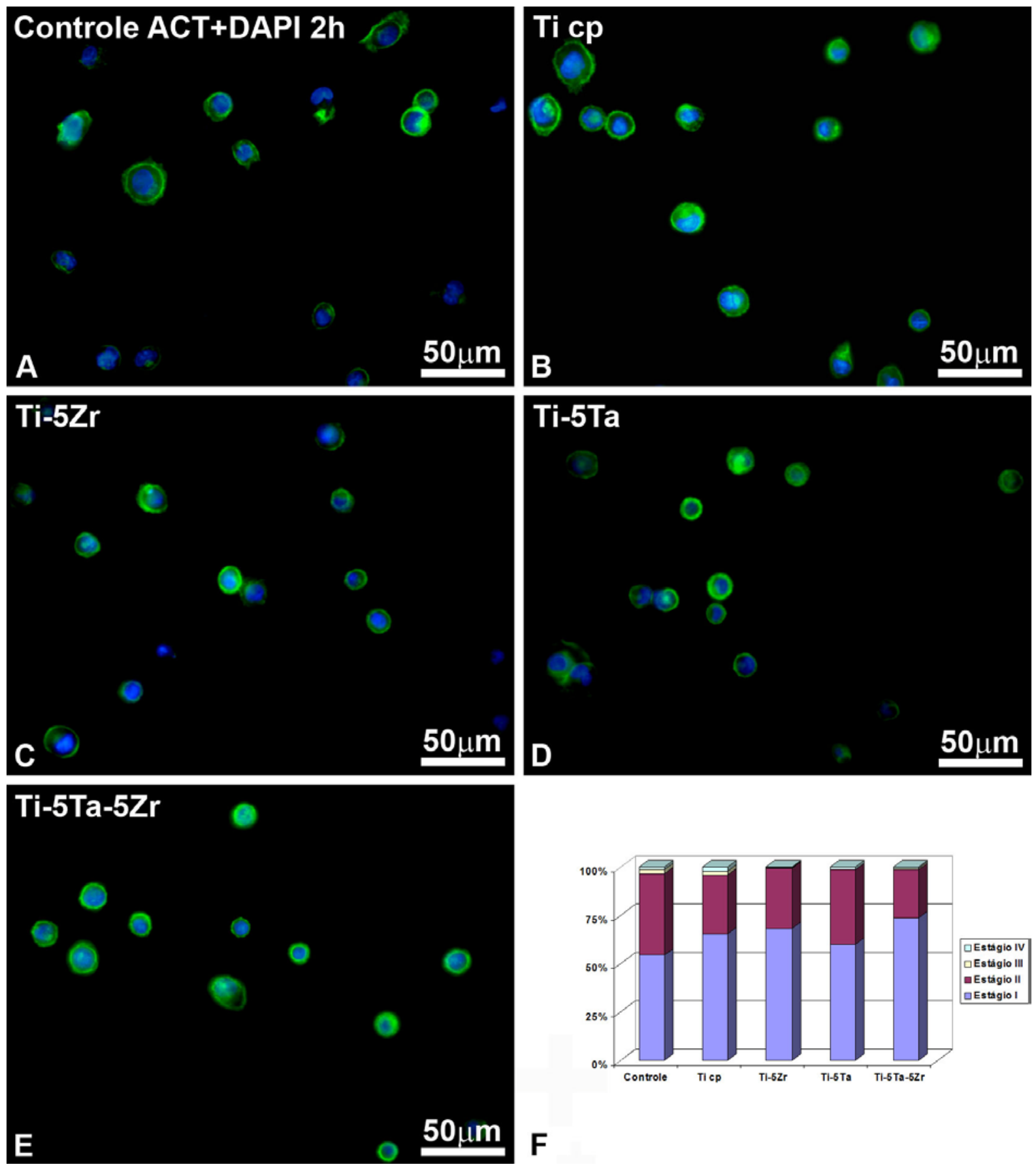

Figura 26. Marcação por fluorescência direta do citoesqueleto de actina (faloidina) e núcleo (DAPI) das células epiteliais da linhagem SCC-9 cultivadas sobre lamínula de Thermanox (A), Ti cp (B), Ti-5Zr (C), Ti-5Ta (D) e Ti-5Ta-5Zr(E) após 2 horas em cultura e proporção de células em diferentes estágios de adesão e espraiamento (F). 
No período de 12 horas, não foi encontrada diferença na morfologia das células cultivadas sobre os diferentes materiais (Figura 27 A-E), sendo que neste período, a maior porcentagem de células já se encontrava totalmente espraiada e algumas se agrupavam, dando início à formação de arranjos epitelióides; no entanto, neste período também foram observadas células arredondadas menores não totalmente espraiadas e células emitindo prolongamentos citoplasmáticos, indicando que estas células estavam em migração. Não foi encontrada diferença estatisticamente significativa na porcentagem de células no estágio I ( $p>0,05)$, mas foi encontrada diferença na porcentagem de células no estágio II e III, sendo que no estágio II a porcentagem de células na liga Ti-5Ta-5Zr foi significativamente maior do que no Ti cp e Ti-5Ta (p=0,01); e no estágio III o Ti-5Ta-5Zr apresentou menor porcentagem de células do que o Ti-5Ta ( $p=0,01)$ e Ti cp $(p=0,03)$ (Figura 27F). 


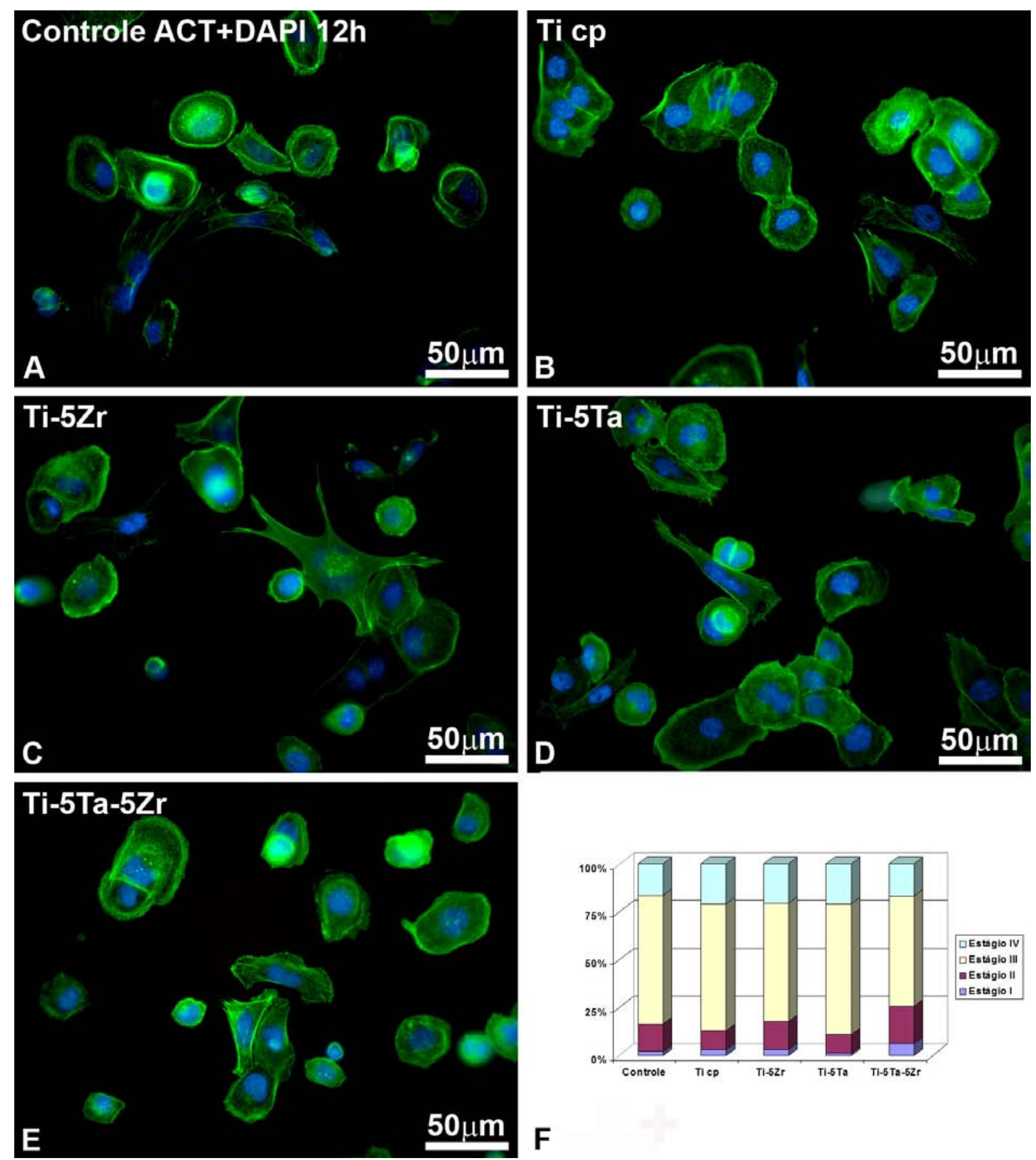

Figura 27. Marcação por fluorescência direta do citoesqueleto de actina (faloidina) e núcleo (DAPI) das células epiteliais da linhagem SCC-9 cultivadas sobre lamínula de Thermanox (A), Ti cp (B), Ti-5Zr (C), Ti-5Ta (D) e Ti-5Ta-5Zr(E) após 12 horas em cultura e proporção de células em diferentes estágios de adesão e espraiamento (F).

Após 24 horas em cultura, as células mantiveram morfologia semelhante diante dos diferentes materiais, sendo que neste período a maioria das células já se encontrava totalmente espraiada em arranjos epitelióides; e algumas apresentavam prolongamentos citoplasmáticos 
que indicam migração celular (Figura 28 A-E). No período de 24 horas não houve diferença na porcentagem de células encontradas em cada um dos estágios entre os diferentes materiais testados ( $>>0,05)$ (Figura 28F).
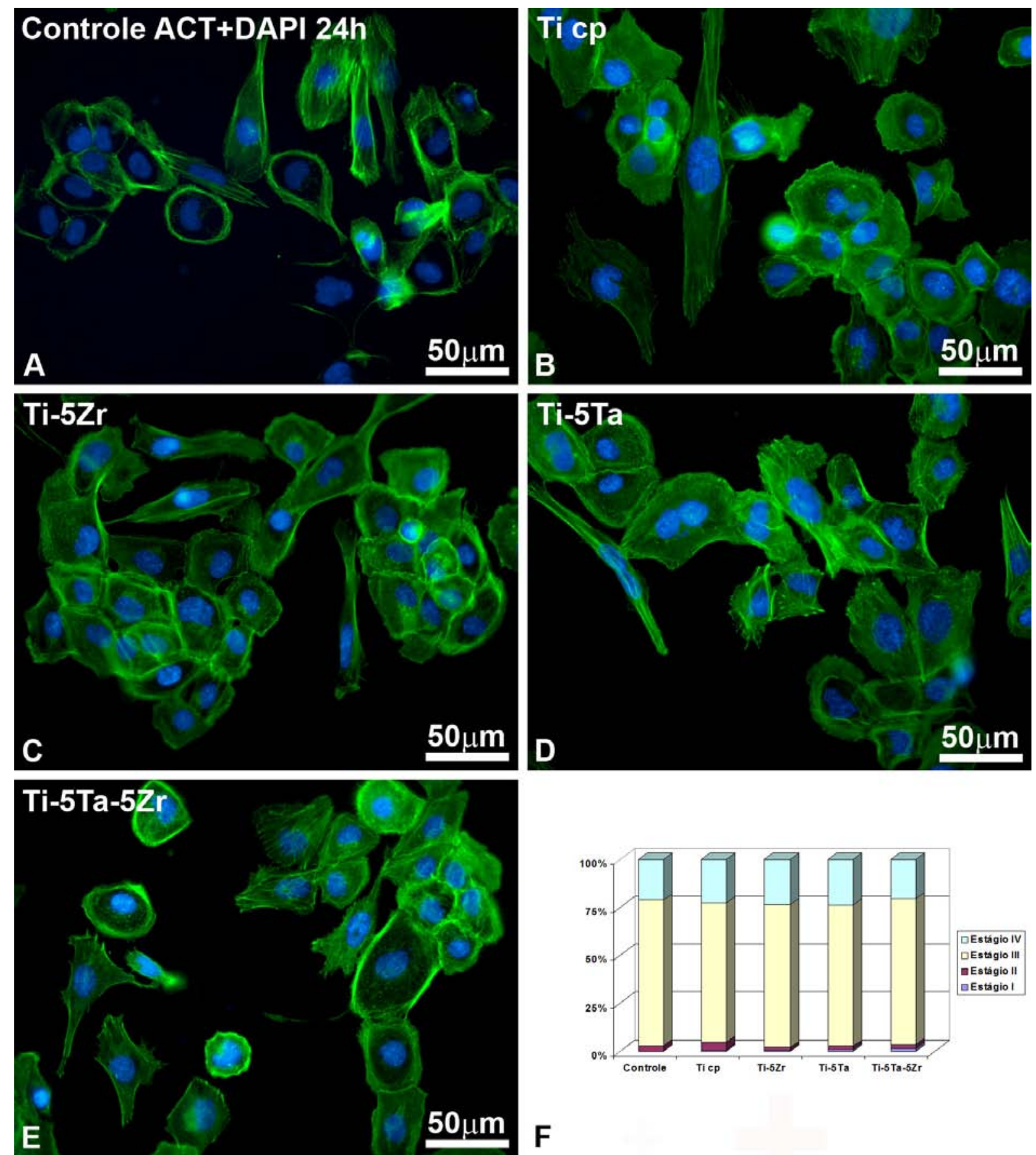

Figura 28. Marcação por fluorescência direta do citoesqueleto de actina (faloidina) e núcleo (DAPI) das células epiteliais da linhagem SCC-9 cultivadas sobre lamínula de Thermanox (A), Ti cp (B), Ti-5Zr (C), Ti-5Ta (D) e Ti-5Ta-5Zr(E) após 24 horas em cultura e proporção de células em diferentes estágios de adesão e espraiamento (F). 
A comparação da proporção de células em cada estágio, ao longo do tempo, dentro de cada grupo experimental, revelou que no controle a proporção de células em 2 horas foi estatisticamente diferente de 12 e 24 horas $(\mathrm{p} \leq 0,05)$ para todos os estágios de desenvolvimento celular, exceto para as células no estágio I $(p=0,61)$, que apresentaram porcentagens estatisticamente semelhantes nos períodos de 12 e 24 horas (Figura 29A). Para o Ti cp, a porcentagem de células em todos os estágios celulares foi estatisticamente diferente entre os períodos de 2 e 12 horas ( $\leq \leq 0,05)$; no entanto, não houve diferença entre 12 e 24 horas (p>0,05) (Figura 29B). Para o Ti-5Zr, a porcentagem de células nos estágios I, II, III e IV foi diferente no período de 2 e 12 horas ( $\leq \leq 0,05)$, enquanto nos períodos de 12 e 24 horas, não houve diferença estatística significativa entre as porcentagens de células nos estágios I $(\mathrm{p}=0,50)$ e IV $(\mathrm{p}=0,22)$, mas houve diferença nos estágios II $(\mathrm{p}<0,01)$ e III $(\mathrm{p}<0,01)$ (Figura 29C). Para o Ti-5Ta, houve diferença significativa para todos os estágios celulares entre os períodos de 2 e 12 horas ( $\mathrm{p} \leq 0,05$ ), enquanto comparações entre os períodos de 12 e 24 horas revelaram diferença significativa somente para células no estágio II $(p=0,04)$, sendo as demais semelhantes ( $>$ >0,05) (Figura 29D). Na liga Ti-5Ta-5Zr, não houve diferença significativa entre os períodos de 2 e 12 horas somente para as células em estágio II $(p=0,20)$, e comparações entre os períodos de 12 e 24 horas demonstraram haver diferença significativa nas porcentagens de células nos estágios II $(\mathrm{p}<0,01)$ e III $(\mathrm{p}<0,01)$, não havendo esta diferença nos estágio I ( $p=0,25)$ e IV ( $p=0,34)$ (Figura 29E). A comparação entre os períodos de 2 e 24 horas demonstraram haver diferença significativa da porcentagem de células em todos os estágios celulares para todos os materiais avaliados $(\mathrm{p}<0,01)$. 
A

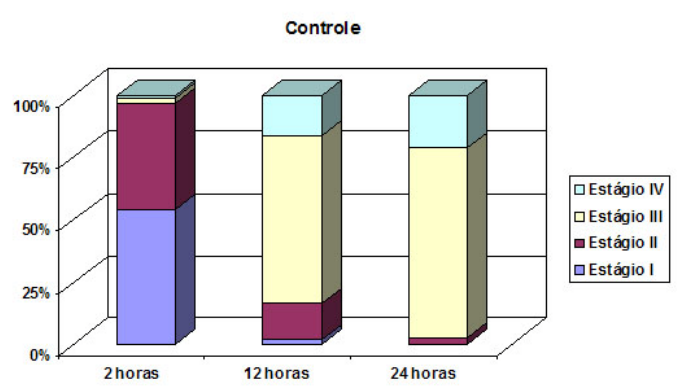

C

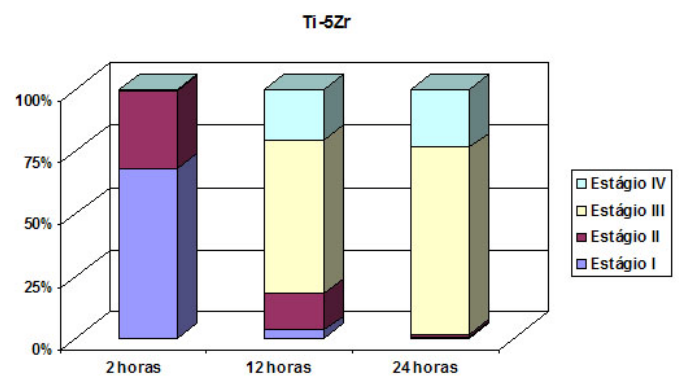

$\mathbf{E}$

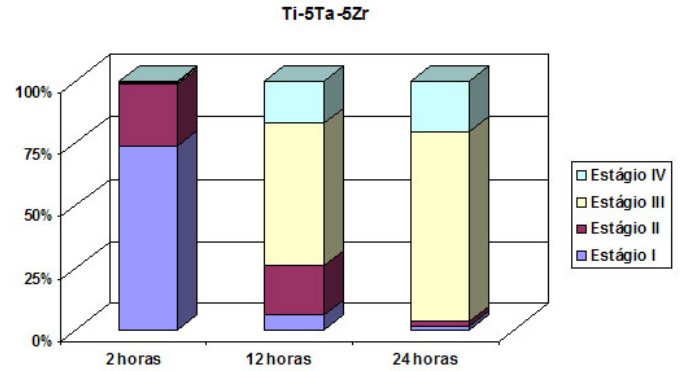

B

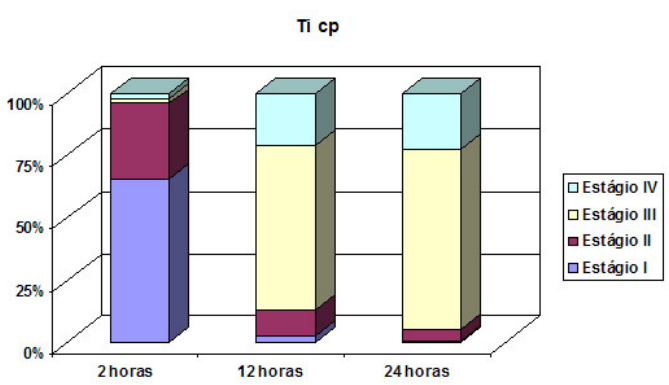

D

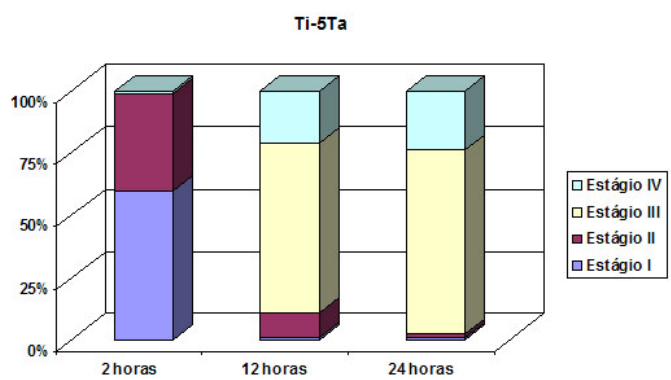

Figura 29. Proporção de células em diferentes estágios de adesão e espraiamento cultivadas sobre lamínulas de Thermanox (A), Ti cp (B), Ti-5Zr (C), Ti-5Ta (D) e Ti-5Ta-5Zr (E) após 2, 12 e 24 horas em cultura. 


\subsection{Caracterização microestrutural}

A microestrutura do Ti cp obtido após o processo de fundição da cera perdida é apresentada na Figura 30. Observa-se a formação de microestrutura do tipo feather-like com limites de grão irregulares e serrilhados, decorrente do rápido processo de resfriamento durante a fundição. O Ti cp apresenta formação de uma única fase $\alpha$.

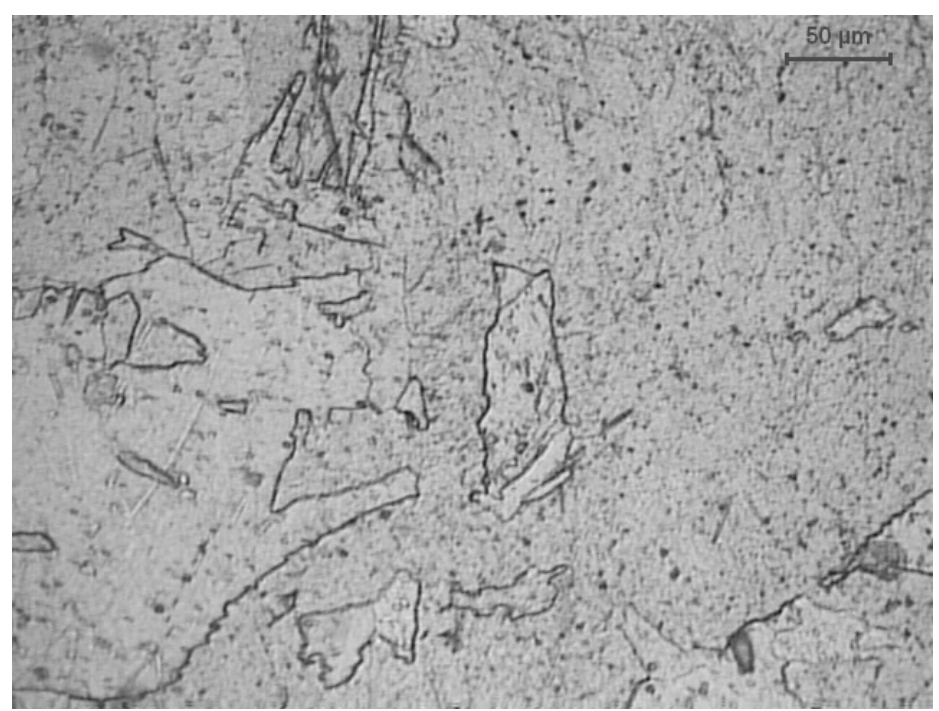

Figura 30. Microestrutura do Ti cp após fundição da cera perdida

A microestrutura da liga Ti-5Zr obtida após o processo de fundição da cera perdida é apresentada na Figura 31. Observa-se a formação das fases $\alpha$ e $\alpha$ e a formação de uma microestrutura mais fina, acicular, do tipo Widmanstätten.

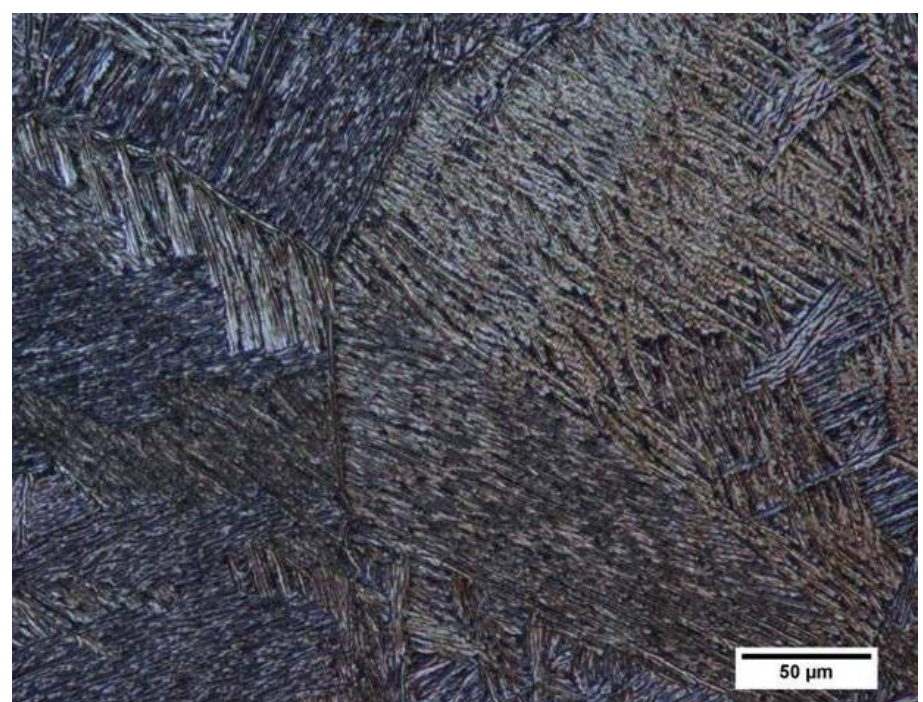

Figura 31. Microestrutura do Ti-5Zr após fundição da cera perdida 
A microestrutura da liga Ti-5Ta obtida após o processo de fundição da cera perdida é apresentada na Figura 32. Observou-se a formação de microestrutura lamelar, apresentando ranhuras grosseiras em seu arranjo associadas a outras mais finas. As fases identificadas foram $\alpha, \beta, \alpha$, е $\alpha$.

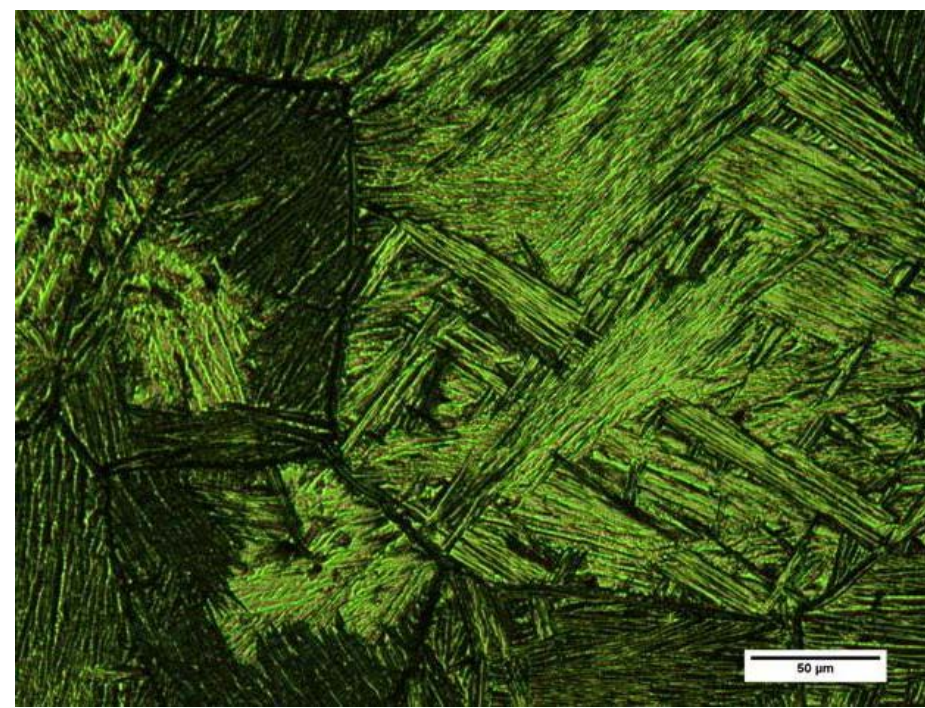

Figura 32. Microestrutura do Ti-5Ta após fundição da cera perdida.

A liga Ti-5Ta-5Zr apresentou microestrutura acicular após o processo de fundição da cera perdida, como pode ser observado na Figura 33. No entanto, esta estrutura acicular apresentou arranjo irregular. As fases identificadas foram $\alpha, \alpha^{\prime}, \alpha^{\prime \prime}$ e $\beta$.

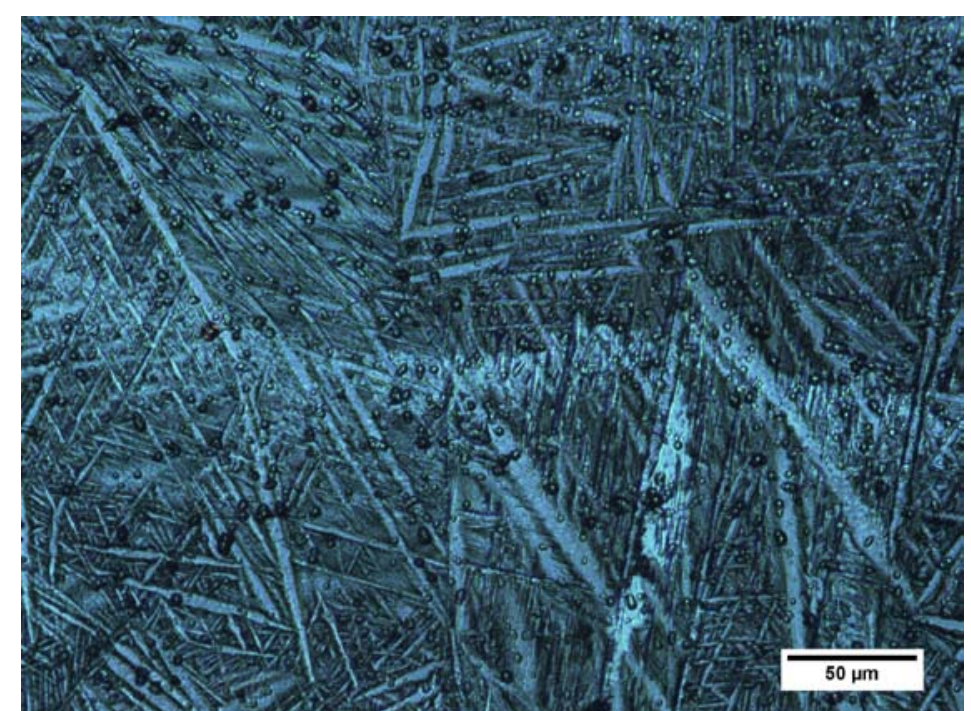

Figura 33. Microestrutura do Ti-5Ta-5Zr após fundição da cera perdida 
6. Discussão

6. DISCUSSÃO 
Novos materiais ou materiais que tenham sua composição alterada em pelo menos 5\% de seus componentes precisam ser submetidos a testes laboratoriais prévios ao uso clínico (STANFORD, 1986). Desta forma, a proposta de novas ligas à base de titânio para utilização em próteses odontológicas exige testes mecânicos e biológicos laboratoriais prévios à utilização em animais e, posteriormente, em pacientes. Através deste estudo, três ligas experimentais foram submetidas a testes mecânicos e biológicos, comparadas ao Ti cp, para avaliar a viabilidade de sua aplicação.

As ligas metálicas possuem ampla variação em suas propriedades mecânicas, por isso são classificadas em ligas de baixa e média resistência aquelas utilizadas em elementos unitários como coroas totais, inlays e onlays; e de alta e extra-alta resistência as utilizadas em estruturas metálicas de próteses parciais removíveis e infra-estruturas de próteses parciais fixas (ANUSAVICE, 2005). Assim, maiores valores de módulo de elasticidade são aconselháveis em casos de próteses mais extensas, principalmente as metalocerâmicas, em que a deflexão da infra-estrutura metálica não é aconselhável (WATAHA; MESSER, 2004).

O Ti cp apresenta rigidez moderadamente alta, caracterizada por um módulo de elasticidade de 117GPa, sendo esta rigidez comparável à do esmalte e das ligas nobres, embora seja inferior à das ligas de metais básicos, hoje comumente aplicadas em próteses (ANUSAVICE, 2005). Os resultados encontrados para o módulo de elasticidade do Ti cp (63,88GPa) foram menores do que os resultados encontrados na literatura, que estão em torno de 100GPa (HO et al., 1999; LEE; JU; CHERN LIN, 2002; KIKUCHI et al., 2003; AOKI et al., 2004; LIN; JU; CHERN LIN, 2005; SATO et al., 2005; HO et al., 2008). Tal diferença pode ser explicada pelo acabamento que os corpos-de-prova receberam antes dos testes, pois Ferenczi et al. (1998) relataram que corpos-de-prova que receberam polimento metalográfico apresentaram valores de módulo de elasticidade superior em 50GPa em relação aos corposde-prova jateados. No entanto, neste estudo os corpos-de-prova foram jateados porque o 
polimento metalográfico inviabilizaria a utilização clínica destas peças. Além disso, Lewis (1977) e Lin, Ju e Chern Lin (2005) relataram que poros superficiais ou subsuperficiais inerentes ao processo de fundição devido ao aprisionamento de gases poderiam afetar as propriedades mecânicas. Apesar de os corpos-de-prova com porosidades internas terem sido eliminados e não serem submetidos aos testes, é preciso considerar que o exame radiográfico é capaz de detectar poros visíveis macroscopicamente; no entanto, é possível que os corposde-prova apresentem microporosidades que não são detectadas macroscopicamente por exame radiográfico, mas que são observadas na superfície dos corpos-de-prova hemi-esféricos, nas imagens da microscopia eletrônica de varredura (Figura 19E e 19F).

As ligas avaliadas neste estudo apresentaram módulo de elasticidade estatisticamente semelhante ao do Ti cp, exceto a liga Ti-5Ta. O menor módulo de elasticidade da liga Ti-5Ta pode ser atribuído à presença da fase $\beta$ na microestrutura desta liga, uma vez que elementos $\beta$ estabilizadores são adicionados às ligas de titânio com o objetivo de diminuir seu módulo de elasticidade, tornando o seu uso indicado para aplicações ortopédicas, em que se busca módulo de elasticidade próximo ao do osso humano (35GPa) (GEETHA et al., 2004). Os resultados deste estudo estão de acordo com os encontrados por Ho et al. (1999) que, ao estudarem ligas binárias de Ti-Mo, encontraram valores de módulo de elasticidade inferiores aos do Ti cp, exceto para a liga com 10\% de Mo, e atribuíram estes resultados à presença da fase $\beta$ em sua microestrutura. Lee, Ju e Chern Lin (2002) também encontraram menores valores de módulo de elasticidade para as ligas binárias Ti-Nb, comparadas ao Ti cp. Gordin et al. (2004) relataram módulo de elasticidade da liga $\beta$ Ti-12Mo-5Ta inferior ao do Ti cp; e Lin, Ju e Chern Lin (2005), ao avaliar o módulo de elasticidade das ligas experimentais Ti7,5Mo e Ti-13Nb-13Zr, encontraram valores inferiores (80 e 77GPa, respectivamente) ao do Ti cp, embora os valores encontrados tenham sido superiores aos encontrados para as ligas experimentais avaliadas neste estudo. Resultados semelhantes foram relatados por Aoki et al. 
(2004) e Kikuchi, Takahashi e Okuno (2006), que observaram diminuição do módulo de elasticidade da liga Ti-6Al-4V e do Ti cp ao acrescentar $\mathrm{Cu}$, um elemento $\beta$ estabilizador. Embora a liga Ti-5Ta-5Zr tenha apresentado as mesmas fases que a liga Ti-5Ta, na Figura 33 foi observado domínio de morfologia martensítica na microestrutura da liga ternária, diferente da microestrutura da liga Ti-5Ta. Embora este estudo não tenha identificado a fração de volume em que cada uma das fases foi encontrada na microestrutura das ligas, é possível que a fração de volume de fases martensíticas instáveis na liga Ti-5Ta-5Zr tenha sido superior à da liga Ti-5Ta e esta seria a razão para a diferença encontrada no módulo de elasticidade destas duas ligas. Esta suposição pode ser confirmada pelo relato Zhou, Niinomi e Akahori (2004) que relataram que o módulo de elasticidade de uma liga é determinado pelo módulo e fração de volume de suas fases constituintes.

Niinomi (2003) avaliou o módulo de elasticidade da liga Ti-29Nb-13Ta-4,6Zr submetida a diferentes tratamentos térmicos e encontrou valores do módulo de elasticidade próximos aos encontrados para as ligas experimentais Ti-5Zr e Ti-5Ta-5Zr, apresentadas neste estudo. Além disso, os autores concluíram que esta liga foi sensível aos tratamentos térmicos, tendo seu módulo de elasticidade pós-tratamento aumentado. Zhou, Niinomi e Akahori (2004) também relataram que ligas binárias Ti-Ta eram sensíveis ao tratamento térmico, e o comportamento das ligas avaliadas (Ti-30Ta, Ti-40Ta e Ti-50Ta) variou de acordo com a temperatura utilizada no tratamento de envelhecimento. Assim, outros estudos são necessários para avaliar o comportamento das ligas testadas neste trabalho frente a diferentes tratamentos térmicos, uma vez que fases martensíticas instáveis foram identificadas em todas elas.

Embora Kikuchi et al. (2003) e Sato et al. (2005) que não tenham observado mudança no módulo de elasticidade quando $\mathrm{Cu}$ e $\mathrm{Hf}$ foram adicionados em diferentes concentrações, Zhou, Niinomi e Akahori (2004) observaram variação no módulo de elasticidade de ligas 
binárias Ti-Ta, ao variar a concentração de Ta de 10 a 80\%. Entretanto, a semelhança de resultados entre as ligas Ti-5Zr e Ti-5Ta-5Zr e o Ti cp pode ser atribuída à baixa concentração de Ta e/ou Zr adicionado à liga, uma vez que Zhou, Niinomi e Akahori (2004) observaram maior variação no módulo de elasticidade quando concentrações superiores a $10 \%$ de Ta foram adicionadas às ligas.

Diferente de outros resultados, um estudo realizado por Ho et al. (2008) avaliando ligas binárias de Ti-Zr em diferentes concentrações de Zr, relatou valores de módulo de elasticidade superiores ao do Ti cp, independente da concentração de Zr testada. Estes autores argumentam que a estrutura cristalina $\alpha$ do titânio é pouco alterada pela adição de Zr, um elemento isomorfo, e que a adição de maiores concentrações de $\mathrm{Zr}$ não alteraria as fases presentes em sua microestrutura. Neste estudo não foi encontrada diferença estatisticamente significativa entre o módulo de elasticidade da liga Ti-5Zr e do Ti cp, o que talvez possa ser explicado pela baixa concentração de Zr adicionado à liga, em comparação às concentrações utilizadas no estudo de Ho et al. (2008), que variou de 10 a 40\% de Zr.

Nos ensaios mecânicos de resistência à tração, os resultados encontrados para o Ti cp se aproximam dos encontrados por outros autores (KIKUCHI et al., 2003; AOKI et al., 2004; SATO et al., 2005) que avaliaram as propriedades mecânicas de ligas experimentais de titânio comparando-as ao Ti cp. Embora não haja estudos avaliando a resistência à tração de ligas na mesma composição deste estudo, observou-se que as ligas Ti-5Zr e Ti-5Ta-5Zr não apresentaram melhores resultados de resistência à tração do que o Ti cp, diferentemente do que outras pesquisas relataram (KIKUCHI et al., 2003; AOKI et al., 2004; LIN; JU; CHERN LIN, 2005; SATO et al., 2005; KANG et al., 2009). Sato et al. (2005) relataram que houve aumento na resistência à tração proporcional ao aumento no conteúdo de Hf que, por ser um elemento isomorfo, aumentaria a resistência e diminuiria a ductilidade da liga devido ao mecanismo de endurecimento por solução sólida. Embora a literatura afirme que o Zr também 
é um elemento isomorfo e endurecedor por solução sólida, não foram encontradas diferenças significativas entre o Ti cp e as ligas Ti-5Zr e Ti-5Ta-5Zr neste estudo, o que pode ter sido ocasionado pela baixa concentração de elementos de liga, pois Sato et al. (2005) demonstraram que em concentrações baixas, de 10\% de Hf, não houve aumento significativo da resistência à tração. Da mesma forma, Kikuchi et al. (2003) também encontraram aumento significativo na resistência à tração de ligas Ti-Cu na medida em que a concentração de Cu foi superior a 5\%, devido ao endurecimento por solução sólida e inclusão de estrutura eutetóide, diferente de Aoki et al. (2004) que observaram diminuição na resistência à tração na medida em que $\mathrm{Cu}$ foi adicionado à liga Ti-6Al-4V. Diferentemente dos resultados encontrados por Zhou, Niinomi e Akahori (2004) que observaram maiores valores de resistência à tração quando Ta foi adicionado em concentrações de 10 a 80\%, a liga Ti-5Ta apresentou resultados de resistência à tração mais baixos do que os das demais. Zhou, Niinomi e Akahori (2004) relacionam a resistência à tração de uma liga à sua microestrutura, ao tamanho dos grãos formados e às fases encontradas nesta liga. Sendo as fases identificadas nas ligas Ti-5Ta e Ti5Ta-5Zr semelhantes, a diferença de resultados pode ser atribuída à morfologia observada na microestrutura, pois as ligas contendo Zr apresentaram morfologia microestrutural dominada pela martensita, diferente da liga Ti-5Ta.

Embora alguns autores relatem a necessidade de ligas com módulo de elasticidade superior a 90GPa para elementos unitários e 180GPa para próteses extensas, neste estudo não foram encontrados valores de módulo de elasticidade superiores a 63GPa. Apesar desta diferença poder ser atribuída ao polimento aplicado aos corpos-de-prova (Ferenczi et al., 1998), é preciso considerar a dificuldade em aplicar polimento mecânico em estruturas metálicas de próteses, uma vez que problemas de adaptação poderiam surgir, principalmente nas camadas internas, que estarão em contato com as superfícies dentárias. Em relação à necessidade de módulo de elasticidade acima de 180GPa para próteses extensas, vale 
considerar que no passado estas próteses eram confeccionadas em liga de ouro tipo IV, cujo módulo de elasticidade se aproxima do módulo do Ti cp. Entretanto, as estruturas metálicas necessariamente eram mais espessas do que as estruturas confeccionadas atualmente em ligas de metais básicos, como Co-Cr e Ni-Cr. Sendo assim, estruturas em titânio e ligas de titânio poderiam ser aplicadas em próteses, desde que as estruturas fossem mais espessas. Embora as estruturas mais espessas em ouro tipo IV fossem mais pesadas, o mesmo não aconteceria nas estruturas confeccionadas em titânio, devido à baixa densidade deste metal (WATAHA, 2002). Por outro lado, o conforto dos pacientes ao utilizar estas próteses mais espessas seria um dos aspectos a ser avaliado clinicamente.

Com relação à resistência à tração, alguns autores relataram que ligas com resistência à tração superior a 300MPa são capazes de resistir à deformação permanente na maioria das situações clínicas (CRAIG; POWERS, 2004). Sendo assim, as ligas experimentais avaliadas são passíveis de aplicação clínica, ainda que os valores de resistência à tração encontrados tenham sido inferiores aos relatados por outros estudos (KIKUCHI et al., 2003; AOKI et al., 2004; SATO et al., 2005). A aplicação de tratamentos térmicos às ligas experimentais é sugerida para pesquisas futuras, com o objetivo de avaliar se as propriedades mecânicas são melhoradas frente a estes tratamentos, uma vez que Rocha et al. (2006) constataram alteração da microdureza do Ti cp e Ti-6Al-4V quando tratamentos térmicos foram empregados. Além disso, novas composições destas ligas alterando a concentração dos elementos Ta e Zr poderiam ser testadas, uma vez que a biocompatibilidade destes metais foi comprovada neste trabalho.

Segundo Ho, Ju e Chern Lin.(1999) a dureza de uma liga é atribuída a fatores como endurecimento por solução sólida, precipitação, crescimento e tamanho dos grãos, estrutura cristalina e suas fases. Neste estudo foram encontrados valores significativamente maiores de microdureza para a liga Ti-5Zr. Estes resultados estão de acordo com o estudo realizado por 
Ho et al. (2008), que ao aumentar o conteúdo de Zr em ligas binárias de Ti-Zr, observaram aumento dos valores de microdureza. Tal fato pode ser explicado pela presença de Zr, que favorece o endurecimento por solução sólida da fase $\alpha$, propiciando a formação de microestrutura mais refinada. Além disso, a presença do Zr diminui a temperatura de fusão da liga, o que facilita o processo de fundição, uma vez que a diferença de temperatura entre a liga fundida e o molde é diminuída e há um melhor preenchimento do molde, e consequentemente menos porosidades são encontradas. Resultados semelhantes foram encontrados por Kikuchi et al. (2003), Ohkubo et al. (2003) e Aoki et al. (2004), que observaram aumento dos valores de microdureza proporcional à concentração de $\mathrm{Cu}$ adicionada ao $\mathrm{Ti}$ cp e Ti-6Al-4V, respectivamente, e os primeiros atribuíram estes resultados à presença da fase intermediária $\mathrm{Ti}_{2} \mathrm{Cu}$ que origina a estrutura eutetóide. Já Sato et al. (2005) atribuem os melhores resultados da liga Ti-Hf aos mecanismos de solução sólida, afirmando que ainda que Hf seja um $\beta$ estabilizador, é um elemento pertencente ao mesmo grupo de elementos do Zr na tabela periódica e não foi identificada fase $\beta$ em sua microestrutura em nenhuma das concentrações avaliadas. Oh, Shim e Kim (2005) também atribuíram os maiores valores de microdureza das ligas Ti-Ag ao endurecimento por solução sólida e à transformação de fases de $\alpha$ para $\beta$.

Embora os valores de microdureza do Ti-5Zr e Ti cp encontrados neste estudo tenham sido maiores do que os encontrados em outros estudos (HO et al., 2008), pode-se atribuir tal diferença ao método de obtenção dos corpos-de-prova, uma vez que neste estudo os corposde-prova foram obtidos pelo método da cera perdida e a existência de uma camada endurecida, decorrente da contaminação com o oxigênio e difusão de alguns elementos do revestimento, que pode não ter sido completamente removida (AOKI et al., 2004), favoreceu tais resultados. O estudo de Ohkubo et al. (2000) demonstrou o efeito desta camada superficial na microdureza, uma vez que encontrou maiores valores de microdureza para o Ti сp e Ti-6Al-4V quando havia resquícios desta camada. Outros autores que avaliaram a 
microdureza das ligas em diferentes profundidades constataram que havia diminuição nos valores de microdureza na medida em que eram examinadas camadas mais profundas (Kikuchi et al., 2003; Aoki et al., 2004).

As ligas Ti-5Ta e Ti-5Ta-5Zr não apresentaram valores de microdureza estatisticamente diferentes do Ti cp. Embora Ho, Ju e Chern Lin.(1999) tenham afirmado que a presença da fase $\beta$ seja responsável por aumento da microdureza, comparada à presença da fase $\alpha$; e Lee, Ju e Chern Lin (2002) tenham determinado a seqüência decrescente de microdureza para cada uma das fases identificadas na microestrutura do titânio ( $\varpi>\alpha^{\prime}>\alpha^{\prime}$, $>\beta>\alpha$ ), neste estudo não foi possível identificar em que fração de volume cada uma destas fases estavam presentes nas ligas avaliadas. Estes resultados encontrados para as ligas Ti-5Ta e Ti-5Ta-5Zr diferem de vários estudos avaliando ligas com elementos $\beta$ estabilizadores, em que os valores de microdureza das ligas foram superiores aos do Ti cp (HO; JU; CHERN LIN, 1999; LEE; JU; CHERN LIN, 2002; KIKUCHI et al., 2003; AOKI et al., 2004; GORDIN et al., 2004).

Embora a resistência ao desgaste tenha sido correlacionada à dureza por alguns autores que pesquisaram a resistência ao desgaste de dentes artificiais (ABE et al., 2001; ZENG et al., 2005), em metais como o titânio, o fenômeno de desgaste está mais associado à composição da liga, que controla a formação de óxidos, e à deformação subsuperficial. Assim, em metais o desgaste tem sido pobremente correlacionado à dureza (OHKUBO et al., 2003; CHAN; KOIKE; OKABE, 2007). Apesar das dificuldades em relacionar resultados de estudos in vitro com resultados in vivo, em decorrência da variação de forças intrabucais, tempo de contato e outros fatores clínicos, como a natureza abrasiva dos alimentos, hábitos parafuncionais, força neuromuscular, pH e natureza da saliva (ELMARIA et al., 2006), estudos in vitro são necessários, principalmente quando se avalia novos materiais. Neste estudo a resistência ao desgaste foi avaliada como perda de altura em perfilômetro, uma vez 
que Heintze et al. (2006) validaram este método ao compará-lo ao dispositivo escaner a laser e ao sensor óptico que avaliava o ponto mais profundo da faceta desgastada e calculava a perda vertical e de volume. Estes autores não encontraram diferença estatística entre os três métodos, além de terem observado correlação entre perda vertical e de volume, demonstrando não haver necessidade de quantificar as duas variáveis ao se avaliar o desgaste.

Os resultados encontrados neste estudo estão de acordo com o relato de um dentista que observou maior desgaste in vivo do Ti cp do que em ligas odontológicas convencionais (KABE, 1998 apud OHKUBO et al., 2003) e com os resultados in vitro de Zhou et al. (2005), que observaram maior resistência ao desgaste para as ligas Ti-Ta do que para o Ti cp Como neste estudo foram avaliadas ligas experimentais à base de titânio, a resistência ao desgaste destas ligas foi comparada à do Ti cp e os resultados revelaram maior resistência ao desgaste das ligas experimentais. As imagens das superfícies desgastadas dos corpos-de-prova hemiesféricos ilustram o maior desgaste do Ti cp (Figura 18A) em comparação às ligas experimentais (Figuras 18B, 18C e 18D). Estes resultados estão de acordo com os encontrados por Ohkubo et al. (2003), que adicionaram diferentes concentrações de $\mathrm{Cu}$ ao Ti ср e Ti-6Al-4V e observaram menores valores de desgaste quando $\mathrm{Cu}$ era adicionado, sendo a resistência ao desgaste das ligas de Ti-6Al-4V com 4\% de $\mathrm{Cu}$ em sua composição estatisticamente superior à da liga de Ti cp contendo 3\% de Cu. Segundo Ohkubo et al. (2003) e Chan, Koike e Okabe (2007), a presença de uma estrutura eutetóide ou microstrutura com mais de uma fase são fatores que impedem a deformação plástica por dificultarem o processo de deslize de uma superfície contra a outra; consequentemente, a maior resistência ao desgaste das ligas experimentais pode ser justificada pela presença de diferentes fases, o que não foi observado no Ti cp. Além disso, o menor diâmetro do grão é apontado como responsável por maior resistência ao desgaste em ligas de ouro (Ohkubo et al., 2003) e neste estudo foi observado que as ligas experimentais apresentaram grãos melhor definidos e 
organizados do que o Ti cp, o que pode ter contribuído para a maior resistência ao desgaste, uma vez que esta organização dos grãos gerou menor tendência ao deslizamento, aumentando a resistência ao desgaste.

As imagens apresentadas na Figura 19 demonstram o aspecto do Ti cp após o teste de desgaste. Na região periférica da superfície desgastada, as imagens sugerem que o movimento de deslizamento tenha deformado o metal, sendo esta deformação identificada quando se observa o limite entre a superfície polida e a faceta desgastada (Figuras 19C e 19D). Esta deformação plástica do Ti cp é relatada por Ohkubo et al. (2003). Além disso, o movimento de deslizamento do teste remove debris da superfície do metal, tal como pode ser observado nas Figuras $19 \mathrm{G}$ e 19H. A lacuna criada no local em que os debris foram arrancados ou destacados demonstra a forma heterogêna em que são destacados do Ti cp, provavelmente em decorrência da microestrutura deste metal, que apresenta grãos mais grosseiros.

No caso da liga experimental Ti-5Zr, as imagens evidenciam característica diferente da superfície após o desgaste. As imagens sugerem que houve menor deformação superficial, como pode ser visto na periferia na superfície desgastada (Figuras 20C e 20D), diferente do que foi observado no Ti cp (Figuras 19C e 19D). Além disso, as ranhuras formadas em decorrência do movimento de deslizamento são mais superficiais do que as formadas no Ti cp, o que pode ser atribuído à microestrutura com grãos mais finos. Nas Figuras 20G e 20H é possível observar o aspecto mais fino na lacuna formada onde material foi destacado durante o teste, característico da presença do Zr (Ho et al., 2008).

As ligas experimentais Ti-5Ta (Figura 21) e Ti-5Ta-5Zr (Figura 22) apresentaram aspecto bastante semelhante. A região periférica da superfície desgastada sugere maior deformação de Ti-5Ta (Figuras 21C e 21D) e Ti-5Ta-5Zr (Figura 22C e 22D) do que o Ti-5Zr (Figura 20 C e 20D), pois a introdução da fase $\beta$ mais dúctil acomoda melhor a deformação, sendo esta deformação limitada na fase $\alpha$. Assim, a característica destas ligas na superfície 
desgastada é afetada pelas fases presentes em sua microestrutura (SEAGLE; YU; GIANGIORDANO, 1999).

Além disso, a Figura 18B evidencia os microporos superficiais formados na superfície da liga Ti-5Zr, principalmente na superfície polida. Segundo Seagle, Yu, Giangiordano (1999), quanto maior a concentração de elementos $\beta$ estabilizadores e diminuição de $\alpha$, menor será a susceptibilidade da liga à formação de porosidades. As imagens da superfície desgastada das ligas Ti-5Ta (Figuras 21E e 21F) evidenciam esta característica da liga $\beta$. Embora a liga Ti-5Ta-5Zr não tenha apresentado porosidade superficial (Figuras 22E e 22F), a superfície desgastada é ligeiramente diferente daquela da liga Ti-5Ta, sugerindo maior tendência ao destacamento de debris e menor tendência à deformação. Entretanto, as Figuras 19F e 20F demonstram o efeito da fase $\alpha$ na porosidade dos metais, uma vez que no Ti cp e na liga Ti-5Zr não foi identificada fase $\beta$.

Embora alguns autores tenham relacionado a resistência ao desgaste de ligas de titânio à presença de microestrutura do tipo $\alpha, \beta$ ou $\alpha+\beta$ e componentes intermetálicos (CHAN; KOIKE; OKABE, 2007), neste estudo não foi encontrada diferença entre as ligas experimentais, ainda que a liga Ti-5Zr tenha sido caracterizada por fase $\alpha$ e $\alpha$ ' e as ligas Ti5Ta e Ti-5Ta-5Zr por $\alpha, \alpha^{\prime}, \alpha$ e $\beta$. Ainda que a literatura tenha relatado resistência ao desgaste melhorada em ligas $\alpha$, $\alpha+\beta$ e $\beta$ endurecida por precipitação; e pobre resistência ao desgaste em ligas $\beta$, cuja dureza e ductilidade são menores, não foram encontradas diferenças entre as ligas experimentais neste estudo. Além disso, este estudo demonstrou que não se pode associar a resistência ao desgaste à dureza, pois a liga experimental que apresentou maior microdureza não apresentou resistência à abrasão significativamente maior do que as demais. 
Ainda que alguns autores questionem a preocupação com o desgaste de restaurações por não haver evidências de que o desgaste oclusal possa levar à disfunção da articulação temporo-mandibular, dor muscular e problemas periodontais (SELIGMAN et al., 1988 apud HEINTZE et al., 2006), Niinomi (2003) alerta para a necessidade de diminuir ao máximo o desgaste dos materiais metálicos utilizados como biomateriais porque os debris formados podem alterar a citotoxicidade. Além disso, Heintze (2006) alerta para o risco de ingestão ou inalação dos debris desgastados que podem levar à alteração de tecidos e células.

Dentre os requisitos de um material para que seja utilizado no corpo humano estão a biocompatibilidade e a resistência à corrosão, ressaltando a relação existente entre elas, uma vez que a liberação de íons metálicos de uma liga decorrente do processo de corrosão em meio biológico, pode ocasionar reações nos tecidos circundantes (SCHMALZ; GARHAMMER, 2002). O Ti cp é um material biocompatível, o que tem aumentado o seu uso na prática odontológica. Entretanto, neste estudo foram avaliadas ligas experimentais à base de titânio, tendo sido adicionados o Ta e o Zr a este metal. A biocompatibilidade das ligas foi avaliada através da viabilidade e da morfologia celular. Os resultados da viabilidade celular não demonstraram diferença entre o Ti cp e as ligas experimentais em qualquer dos períodos avaliados, o que comprova a biocompatibilidade destas ligas. Estes resultados comprovam a biocompatibilidade in vitro de metais como o $\mathrm{Ta}$ e o $\mathrm{Zr}$ ao serem utilizados como elementos de ligas, o que está de acordo com os estudos realizado por Okazaki et al. (1998), Eisenbarth et al. (2004), que relataram bons resultados nos testes de biocompatibilidade in vitro para estes metais, ainda que os últimos relatassem a menor resistência à corrosão do Zr.

Segundo Oliveira et al. (2005) a adição de Nb e Ti ao Zr aumenta a sua resistência à corrosão em soluções que simulam o meio fisiológico por levar à formação de filmes de óxidos que são capazes de resistir ao ataque inclusive de íons cloreto. Sendo assim, o fato do Zr estar associado ao Ti na liga experimental Ti-5Zr justifica sua biocompatibilidade, pois é 
possível que a camada de óxidos formada em sua superfície iniba a resposta citotóxica. Afirmações semelhantes são relatadas na literatura por Oh, Shim e Kim (2005) e Kang et al. (2009), que justificam a ausência de citotoxicidade de ligas Ti-Ag e Ti-Ag-Cu, respectivamente, em decorrência de uma fina camada de óxidos formada espontaneamente na superfície da liga, ainda que a Ag seja reconhecida como agente citotóxico.

Os resultados encontrados para as ligas experimentais avaliadas estão de acordo com os resultados encontrados por Prigent et al. (1998) e Zhou et al. (2005), que relataram a biocompatibilidade da liga Ti-5Ta em cultura de células; e os encontrados por Berg et al. (2008), que relataram biocompatibilidade da liga Ti-15Zr após uso clínico de coroas confeccionadas com esta liga e acompanhamento durante 3 anos. Koike et al. (2007) atribuíram a biocompatibilidade de diversas ligas experimentais de titânio à camada de óxidos formada nestas ligas, que protege as células dos elementos tóxicos que poderiam ser solubilizados, e Zhou et al. (2005) relataram que o filme passivo $\mathrm{Ta}_{2} \mathrm{O}_{5}$ formado sobre a superfície de ligas binárias Ti-Ta é mais resistente à corrosão e solubilização de metais do que $\mathrm{TiO}_{2}$ formado na superfície do Ti cp e outras ligas de titânio.

Além disso, a avaliação da morfologia das células cultivadas sobre o Ti cp, as ligas experimentais avaliadas e o Thermanox, que é um material cuja superfície é reconhecida por favorecer o cultivo das células, revelou mudança da morfologia celular nas primeiras 24 horas. Neste período as células evoluíram de uma morfologia arredondada, característica de células em processo de adesão, para células arredondadas maiores, espraiadas e agrupadas em arranjos epitelióides. Esta mudança da morfologia celular nas primeiras 24 horas foi semelhante em todas as superfícies sobre as quais as células foram cultivadas. Embora comparações entre os materiais nos períodos avaliados revelassem alguma diferença na proporção de células nos diferentes estágios, esta diferença é representativa de uma possível diferença de velocidade de evolução das células em cultura sobre os diferentes materiais; 
entretanto, esta diferença não interfere na biocompatibilidade dos materiais em períodos maiores que 4 dias. A análise estatística dos dados revelou que no período de 2 horas, as ligas Ti-5Zr e Ti-5Ta-5Zr apresentaram mais células no estágio I e menos células no estágio II do que o controle e as demais ligas; enquanto em período de 12 horas, a liga Ti-Ta-Zr apresentou mais células no estágio II e menos no estágio III do que o controle, o Ti cp e Ti-5Ta. Estes resultados sugerem que nos períodos iniciais da cultura de células, as ligas contendo $\mathrm{Zr}$ apresentem evolução mais lenta do que as demais; entretanto, esta diferença desaparece com o tempo, constatando a biocompatibilidade das ligas experimentais em cultura de células epiteliais.

O Zr, por ser um elemento isomorfo, não é responsável por estabilizar nenhuma fase nem alterar a temperatura de transformação. Sendo assim, a liga Ti-5Zr apresentou em sua microestrutura as fases $\alpha$ e $\alpha^{\prime}$. Como na composição da liga não há nenhum elemento $\beta$ estabilizador, a microestrutura apresentaria fase $\alpha$; no entanto, após fundição por cera perdida foi observada também a fase $\alpha$ ' que, segundo Lee, Ju e Chern Lin (2002), apresenta estrutura cristalina hexagonal distorcida, decorrente do processo de resfriamento da liga (AHMED; RACK, 1998). A microestrutura da liga Ti-5Zr deste estudo difere da apresentada por Ho et al.(2008), que avaliaram a microestrutura de ligas binárias Ti-Zr em diferentes concentrações de Zr e em nenhuma delas identificaram a fase $\alpha^{\prime}$. A diferença da microestrutura pode ser decorrente do processo de fundição por cera perdida.

No caso da liga Ti-5Ta, a adição do Ta, que é um elemento $\beta$ estabilizador, levou à introdução da fase $\beta$. No entanto, em ligas binárias Ti-Ta a microestrutura é sensível ao conteúdo de Ta, e somente ligas com conteúdo acima de 60\% de Ta estabilizaram somente a fase $\beta$ (ZHOU; NIINOMI; AKAHORI, 2004). Neste estudo foram identificadas as fases $\alpha, \beta$, $\alpha$ e $\alpha^{\prime \prime}$ na liga Ti-5Ta, sendo que as fases $\alpha$ e $\alpha$ " são observadas a partir da matriz $\beta$, como conseqüência do processo de resfriamento, uma vez que a formação de $\alpha$ ' e $\alpha$ ” depende da 
composição e da velocidade de resfriamento. Em virtude da baixa concentração de Ta, a microestrutura desta liga não é caracterizada somente por fase $\beta$, apresentando também a fase $\alpha$. Além disso, as fases $\alpha$ e $\alpha$ " foram identificadas devido o processo de resfriamento que não possibilitou a formação unicamente das fases estáveis $\alpha$ e $\beta$. Tal fato pode ser comprovado pelo trabalho de Zhou, Niinomi e Akahori (2004) que observaram decomposição da martensita $\alpha$ ”, em $\alpha$ e $\beta$ (fases estáveis) em ligas binárias Ti-Ta, após tratamento de envelhecimento. Este resultado também está de acordo com os de Ho et al. (1999), que afirmaram que o mínimo de $10 \%$ de elementos $\beta$ estabilizadores seria necessário para que ligas binárias Ti-Mo estabilizassem somente a fase $\beta$ em temperatura ambiente.

Com relação à liga Ti-5Ta-5Zr, o arranjo irregular observado em sua microestrutura se assemelha ao encontrado na liga Ti-40Ta estudada por Zhou, Niinomi e Akahori (2004), em que foi observada microestrutura acicular com arranjo de tamanho irregular. Semelhante à liga Ti-5Ta, a concentração de Ta não foi suficiente para estabilizar a fase $\beta$ em temperatura ambiente e o processo de resfriamento é responsável pela identificação das fases $\alpha$ ' e $\alpha$ ”. Entretanto, a microestrutura parece ser dominada por morfologia martensítica, o que pode ter sido favorecido pela presença do Zr.

Os resultados demonstram que o processo de fundição odontológica pelo método da cera perdida levou à formação das fases instáveis $\alpha$ e $\alpha$ ” nas três ligas avaliadas, o que pode ser atribuído ao processo de resfriamento destes metais, uma vez que a diferença de temperatura entre o metal fundido e o molde não possibilitou a formação das fases estáveis. Como há fases instáveis nestas ligas, é possível submetê-las a tratamentos de envelhecimento para que se decomponham em outras fases. Sabendo que estes tratamentos podem alterar as propriedades mecânicas de uma liga (ZHOU; NIINOMI; AKAHORI; 2004), outros estudos são necessários para avaliar o efeito destes tratamentos nas propriedades mecânicas das ligas avaliadas. 
Ainda que não tenha sido o objetivo deste estudo avaliar a facilidade ao fundir estas ligas pelo método da cera perdida para aplicação odontológica, foi possível observar que a liga Ti-5Zr apresentou fundições como menos porosidades internas do que as demais. Sendo esta uma das dificuldades inerentes ao processo de fundição do titânio (CHAI; STEIN, 1995; SYVERUD; HERO, 1995; AOKI, 1996 apud AOKI et al., 2004; WATANABE et al., 1997), outros estudos são sugeridos para comparar a qualidade das fundições do Ti cp e destas ligas avaliadas, quantificando as porosidades internas e a adaptação marginal de coroas confeccionadas nestes metais. 
7. Conclusão

7. CONCLUSÃO 
Os resultados deste estudo sugerem que as ligas estudadas apresentam potencial para futuras aplicações em próteses dentárias, uma vez que:

- suas propriedades biológicas foram semelhantes ao $\mathrm{Ti}$ cp, comprovado pela proliferação, viabilidade e morfologia celular;

- e suas propriedades mecânicas, como resistência à abrasão, microdureza e resistência à tração foram satisfatórias, ainda que o módulo de elasticidade possa e deva ser melhorado. 
${ }^{2} \mathrm{ABE}$, Y. et al. An in vitro wear study of posterior denture tooth materials on human enamel. Journal of Oral Rehabilitation, v. 28, p. 407-412. 2001.

AHMED, T.; RACK, H.J. Phase transformations during cooling in $\alpha+\beta$ titanium alloys. Materials Science and Engineering, v. A243, p. 206-211. 1998.

ALVES, A.P.R. Preparação de materiais compósitos in situ a partir de ligas eutéticas nos sistemas Nb-Al-Ti e Nb-Al-Cr. 1998. 124 f. Tese (Doutorado em Materiais) - Faculdade de Engenharia Mecânica, Universidade Estadual de Campinas, Campinas, 1998.

ALVES, A.P.R. et al. A study on corrosion resistance of the Ti-10Mo experimental alloy after different processing methods. Materials Science and Engineering, v. C24, p.693-696. 2004.

ANKEM, S.; GREENE, C.A. Recent developmentes in microstructure/property relationships of beta titanium alloys. Material Science and Engineering, v. A263, p. 127-131. 1999.

ANUSAVICE, K.J. Philips, materiais dentários. 11ed. Rio de Janeiro: Elsevier, 2005. 764p.

AOKI, T. et al. Mechanical properties of cast Ti-6Al-4V-XCu alloys. Journal of Oral Rehabilitation, v.31, p.1109-1114. 2004.

ASTM, Standart Specification for titanium and titanium alloy strip, E -8M.

BERG, E. et al. Three-year split-mouth randomized clinical comparison between crowns fabricated in a titanium-zirconium and a gold-palladium alloy. International Journal of Prosthodontics, v.21, p.312-318. 2008.

CALLISTER Jr., W.D. Materials Science and Engineering: an Introduction, 3 ed. Estados Unidos: John Wiley \& Sons, 1994.

CANAY, S. et al. Evaluation of titanium in oral conditions and its eletrochemical corrosion behaviour, Journal of Oral Rehabilitation, v.25, p.759-764, 1998.

CHAI, T.I.; STEIN, R.S. Porosity and accuracy of multiple-unit titanium casting. Journal of Prosthetic Dentistry, v.9, p.534-540, 1995.

CHAN, K.S.; KOIKE, M.; OKABE, T. Modeling wear of cast Ti alloys. Acta Biomaterialia, v.3, p.383-389. 2007.

CHRAPONSKI, J.; SZKLINIARZ, W. Quantitative metallography of two-phase titanium alloys. Materials Characterization, v. 46, p. 149-154. 2001.

CRAIG, R.G.; POWERS, J.M. Materiais dentários restauradores. 11 ed. São Paulo: Livraria Editora Santos, 2004. 704p.

DONACHIE Jr., M. J. Titanium a technical guide. ASM International, 1989.

${ }^{2}$ Associação Brasileira de Normas Técnicas (ABNT) - NBR 6023 
EISENBARTH, E. et al. Biocompatibility of b-stabilizing elements of titanium alloys. Biomaterials, v.25, p.5705-5713. 2004.

ELMARIA, A. et al. An evaluation of wear when enamel is opposed by various ceramic materials and gold. Journal of Prosthetic Dentistry, v. 96, p.345-353. 2006.

FARIA, A.C.L. et al. In vitro cytotoxicity of dental alloys and cpTi obtained by casting. Journal of Biomedical Materials Research - Part B - Applied Biomaterials, v.85, n.2, p.504-508. 2008.

FARIA, A.C.L. et al. Effect of temperature variation on the cytotoxicity of dental alloys and titanium obtained by casting. Journal of Applied Oral Science, (aceito para publicação).

FERENCZI, A.M. et al. Casted titanium for dental applications: an XPS and SEM study. Biomaterials, v. 19, p.1513-1515. 1998.

GEETHA, M. et al. Influence of microstructure and alloying elements on corrosion behavior of Ti-13Nb-13Zr alloy. Corrosion Science, v.46, n.4, p.877-892, Apr. 2004.

GORDIN, D.M. et al. Development of a b-type Ti-12Mo-5Ta alloy for biomedical applications: cytocompatibility and metallurgical aspects. Journal of Materials Science: Materials in Medicine, v.15, p.885-891. 2004.

HAAG, P.; NILNER, K. Questions and answers on titanium-ceramic dental restorative systems: a literature study. Quintessence International, v. 38, p. 7.e5-13. 2007.

HAO, Y.L.; LI, S.J.; SUN, S.Y.; YANG, R. Effect of Zr and Sn on Young's modulus and superelasticity of Ti-Nb-based alloys. Materials Science and Engineering A, v.441, p.112118. 2006.

HEINTZE, S.D. How to qualify and validate wear simulation devices and methods. Dental Materials, v. 22, p. 712-734. 2006.

HEINTZE, S.D. et al. A comparison of three different methods for the quantification of the in vitro wear of dental materials. Dental Materials, v.22, p.1051-1062. 2006.

HENSTEN-PETTERSEN A. Casting alloys: side-effects. Advances in Dental Research, v.6, p.38-43, 1992.

HERO, H.; SYVERUD, M.; WAARLI, M. Mold filling and porosity in castings of titanium. Dental Materials, v. 9, p.15-18. 1993.

HO, W. F.; JU, C. P.; CHERN LIN, J. H. Structure and properties of cast binary Ti-Mo alloys. Biomaterials, v. 20, p. 2115-2122. 1999.

HO, W.F.; CHEN, W.K.; WU, S.C.; HSU, H.C. Structure, mechanical properties, and grindability of dental Ti-Zr alloys. Journal of Materials Science: Materials in Medicine, v.19, p.3179-3186. 2008. 
KADOKAWA, A.; SUZUKI, S.; TANAKA, T. Wear evaluation of porcelain opposing gold, composite resin and enamel. Journal of Prosthetic Dentistry, v.96, p.258-265. 2006.

KANG, D.K. et al. Properties of experimental titanium-silver-copper alloys for dental applications. Journal of Biomedical Materials Research Part B: Applied Biomaterials, v. xx, p. xx-xx. 2009. (DOI: 10.1002/jbm.b.31305)

KHAN, M.A.; WILLIAMS, R.L.; WILLIAMS, D.F. In vitro corrosion and wear of titanium alloys in the biological environment. Biomaterials, v.17, p.2117-2126. 1996.

KIKUCHI, M. et al. Mechanical properties and microstructures of cast Ti-Cu alloys. Dental Materials, v. 19, p. 174-181. 2003.

KIKUCHI, M.; TAKAHASHI, M.; OKUNO, O. Elastic moduli of cast Ti-Au, Ti-Ag, and Ti$\mathrm{Cu}$ alloys. Dental Materials, v.22, p.641-646. 2006.

KOBAYASHI, E et al. Mechanical properties of the binary titanium-zirconium alloys and their potential for biomedical materials. Journal of Biomedical Materials Research, v. 29, n.8, p. 943-950. 1995.

KOBAYASHI, E. et al. Influence of aging heat treatment on mechanical properties of biomedical $\mathrm{Ti}-\mathrm{Zr}$ based ternary alloys containing niobium. Journal of Materials Science: Materials in Medicine, v. 9, p. 625-630. 1998.

KOIKE, M. et al. Initial cytotoxicity of novel titanium alloys. Journal of Biomedical Materials Research Part B: Applied Biomaterials, v.83B, p.327-331. 2007.

KURODA, D. et al. Design and mechanical properties of new $\beta$ type titanium alloys for implant materials. Materials Science and Engineering, v. A243, p. 244-249. 1998.

LAMBRECHTS, P. et al. How to simulate wear? Overview of existing methods. Dental Materials, v.22, p.693-701. 2006.

LAUTENSCHLAGER, E.P.; MONAGHAN, P. Titanium and titanium alloys as dental materials. International Dental Journal, v.43, p.245-253, 1993.

LEE, C.M.; JU, C.P.; CHERN LIN, J.H. Structure-property relationship of cast Ti-Nb alloys. Journal of Oral Rehabilitation, v.29, p.314-322. 2002.

LEWIS, A.J. The effect of variations in the technique of metal fusion on the development of internal porosity in cast structures. Australian Dental Journal, v. 22, p. 357-359. 1977.

LIN, D.J. et al. Structure and properties of Ti-7,5Mo-xFe alloys. Biomaterials, v. 23. p. 17231730. 2002.

LIN, C.H.; JU, C.P.; CHERN LIN, J.H.C. A comparison of the fatigue behavior of cast Ti7,5Mo with cp titanium, Ti-6Al-4V and Ti-13Nb-13Zr alloys. Biomaterials, v. 26, p.28992907. 2005. 
LONG, M.; RACK, H.J. Titanium alloys in total joint replacement - a materials science perspective. Biomaterials, v. 19, p. 1621-1639. 1998.

LOW, D. et al. Thermal expansion of titanium casting. Journal of Oral Rehabilitation, v. 28, p. 239-242. 2001.

McLEAN, J. W. The metal-ceramic restoration. Dental Clinics of North America, v. 27, n. 4, p. 747-761.1983.

MOSMANN, T. Rapid colorimetric assay for cellular growth and survival: application to proliferation and cytotoxicity assays. Journal of Immunological Methods, v. 65, p. 55-63. 1983.

NIINOMI, M. Mechanical properties of biomedical titanium alloys. Materials Science and Engineering, v. A242, p. 231-236. 1998.

NIINOMI, M. Fatigue performance and cytotoxicity of low rigidity titanium alloy, Ti-29Nb13Ta-4,6Zr. Biomaterials, v. 24, p.2673-2683. 2003.

OH, K.T.; SHIM, H.M.; KIM, K.N. Properties of titanium-silver alloys for dental application. Journal of Biomedical Materials Research Part B: Applied Biomaterials, v.74B, p.649658. 2005.

OHKUBO, C. et al. The machinability of cast titanium and Ti-6Al-4V. Biomaterials, v.21, p.421-428. 2000.

OHKUBO, C. et al. Wear resistance of experimental Ti-Cu alloys. Biomaterials, v. 24, p.3377-3381. 2003.

OHKUBO, C.; HANATANI, S.; HOSOI, T. Present status of titanium removable dentures - a review of the literature. Journal of Oral Rehabilitation, v.35, p.706-714. 2008.

OHLMANN, B. et al. Clinical wear of posterior metal-free polymer crowns - One-year results from a randomized clinical trial. Journal of Dentistry, v.35, n.3, p.246-252. 2007.

OKABE, T.; HERO, H. The use of titanium in dentistry. Cells Materials, v.5, p.211-230, 1995.

OKABE, T. et al. The present status of dental titanium casting. Journal of Metals, v.50, p.2429, 1998.

OKAZAKI, Y. et al. Corrosion resistance, mechanical properties, corrosion fatigue strength and cytocompatibility of new Ti alloys without Al and V. Biomaterials, v.19, p.1197-1215. 1998.

OLIVEIRA, N.T.C. et al. Eletrochemical studies on zirconium and its biocompatible alloys Ti-50Zr at.\% and Zr-2,5Nb wt.\% in simulated physiologic media. Journal of Biomedical Materials Research, v. 74A, p.397-407. 2005. 
OUCHI, C. et al. Effects of ultra-high purification and addition of interstitial elements on properties of pure titanium and titanium alloy. Materials Science and Engineering. A243, p. 186-195, 1998.

PRIGENT, H. et al. Evaluation of the biocompatibility of titanium-tantalum alloy versus titanium. Journal of Biomedical Materials Research, v.39, p.200-206. 1998.

RAJARAMAN, R. et al. A scanning electron microscopy study of cell adhesion and spreading in vitro. Experimental Cell Research, v. 88, p. 327-339. 1974.

RICCIARDI COPPEDÊ, A. et al. Effect of repeated torque/mechanical loading cycles on two different abutment types in implants with internal tapered connections: an in vitro study. Clinical Oral Implants Research, v.xx, p. XX-Xx. 2009. (DOI:10.1111/g.16000501.2008.01690.x).

ROCHA, S.S. et al. Vickers hardness of cast commercially pure titanium and Ti-6Al-4V alloy submitted to heat treatments. Brazilian Dental Journal, v.17, p.126-129. 2006.

SATO, H. et al. Mechanical properties of cast Ti-Hf alloys. Journal of Biomedical Materials Research Part B: Applied Biomaterials, v.72B, p.362-367. 2005.

SCHMALZ, G. Concepts in biocompatibility testing of dental restorative materials. Clinical Oral Investigations, v.1, p.154-162. 1997.

SCHMALZ, G.; GARHAMMER, P. Biological interactions of dental cast alloys with oral tissues. Dental Materials, v.18, p.396-406. 2002.

SEAGLE, S.R.; YU, K.O.; GIANGIORDANO, S. Considerations in processing titanium. Materials Science and Engineering. v. A263, p. 237-242. 1999.

SHIMPO, H. Effect of arm design and chemical polishing on retentive force of cast titanium alloy clasps. Journal of Prosthodontics, v.17, p.300-307. 2007.

SMITH. F.W. Structure and Properties of Engineering Alloys. McGraw-Hill, Inc., p. 433486, 1993.

STANFORD, J.W. Recommendations for determining biocompatibility and safety for the clinical use of metals in dentistry. International Dental Journal, v.36, p.45-48. 1986.

SUZUKI, S. et al. In vitro wear of indirect composite restoratives. Journal of Prosthetic Dentistry, v.88, p.431-436. 2002.

SYVERUD, M.; HERO, H. Mold filling of Ti castings using investments with different gas permeability. Dental Materials, v.11, p.14-18, jan. 1995.

TAKAHASHI, H.; MIYAZAKI, T.; KAWAWA, T. Accuracy of titanium cast crowns obtained from calcia base mold. Clinical Materials, v. 16, n.3, p.155-160. 1994.

WANG, R.R.; FENTON, A. Titanium for prosthodontics applications: a review of the literature. Quintessence International, v. 27, p.401-408, 1996. 
WATAHA, J.C. et al. Effect of pH on element release from dental casting alloys. Journal of Prosthetic Dentistry, v.80, n. 6, p. 691-8, Dec. 1998.

WATAHA, J.C. Biocompatibility of dental casting alloys: a review. Journal of Prosthetic Dentistry, v.83, p.223-234. 2000.

WATAHA, J.C. Alloys for prosthodontics restorations. Journal of Prosthetic Dentistry, v. 87, n. 4, p. 351-363, Apr. 2002.

WATAHA, J.C.; MESSER, R.L. Casting alloys. Dental Clinics of North America, v.48, p.499-512, 2004.

WATANABE, I. et al. Effect of pressure difference on the quality of titanium casting. Journal of Dental Research, v.76, p.773-779. 1997.

WATANABE, K. et al. Casting behavior of titanium alloys in a centrifugal casting machine. Biomaterials, v.24, p.1737-1743. 2003.

WATANABE, I. et al. Cytotoxicity of commercial and novel binary titanium alloys with and without a surface-reaction layer. Journal of Oral Rehabilitation, v.31, p.185-189. 2004.

WEISS, I.; SEMIATIN, S.L. Thermomechanical processing of alpha titanium alloys - an overview. Materials Science and Engineering, A263, p. 243-256. 1999.

WHITTERS, C. J. et al. Dental materials: 1997 literature review. Journal of Dentistry, v. 27, p. 401-435. 1999.

YAMADA, M. An overview on the development of titanium alloys for non-aerospace application in Japan. Materials Science and Engineering, v. A213, p. 8-15. 1996.

ZENG, J. et al. In vitro wear resistance of three types of composite denture teeth. Journal of Prosthetic Dentistry, v.94, p. 453-457. 2005.

ZHOU, Y.L.; NIINOMI, M.; AKAHORI, T. Effects of Ta content on Young's modulus and tensile properties of binary Ti-Ta alloys for biomedical applications. Materials Science and Engineering, v. A371, p.283-290. 2004.

ZHOU, Y.L.; NIINOMI, M.; AKAHORI, T. Decomposition of martensite $\alpha$ ' during aging treatments and resulting mechanical properties of Ti-Ta alloys. Materials Science and Engineering, v. A384, p.92-101. 2004.

ZHOU, Y.L. et al. Corrosion resistance and biocompatibility of Ti-Ta alloys for biomedical applications. Materials Science and Engineering, v. A398, p.28-36. 2005. 
ANEXO A - Resultados da tensão na força máxima (MPa) obtidos em ensaio de resistência à tração

\begin{tabular}{ccccc}
\hline & Ti $\mathbf{~ p}$ & Ti-5Zr & Ti-5Ta & Ti-5Ta-5Zr \\
\hline \hline 1 & 453,31 & 348,80 & 307,21 & 529,91 \\
2 & 468,86 & 505,56 & 326,18 & 531,68 \\
3 & 543,81 & 513,69 & 401,96 & 504,78 \\
4 & 545,66 & 548,11 & 395,57 & 535,76 \\
5 & 392,26 & 479,74 & 374,41 & 531,96 \\
6 & 462,08 & 415,97 & 380,99 & 369,23 \\
\hline Média & $\mathbf{4 7 7 , 6 6}$ & $\mathbf{4 6 8 , 6 5}$ & $\mathbf{3 6 4 , 3 9}$ & $\mathbf{5 0 0 , 5 5}$ \\
DP & $\mathbf{5 8 , 6 6}$ & $\mathbf{7 3 , 4 4}$ & $\mathbf{3 8 , 7 0}$ & $\mathbf{6 5 , 3 0}$ \\
\hline \hline
\end{tabular}

ANEXO B - Curva força x deformação dos corpos-de-prova de Ti cp submetidos a ensaio de tração

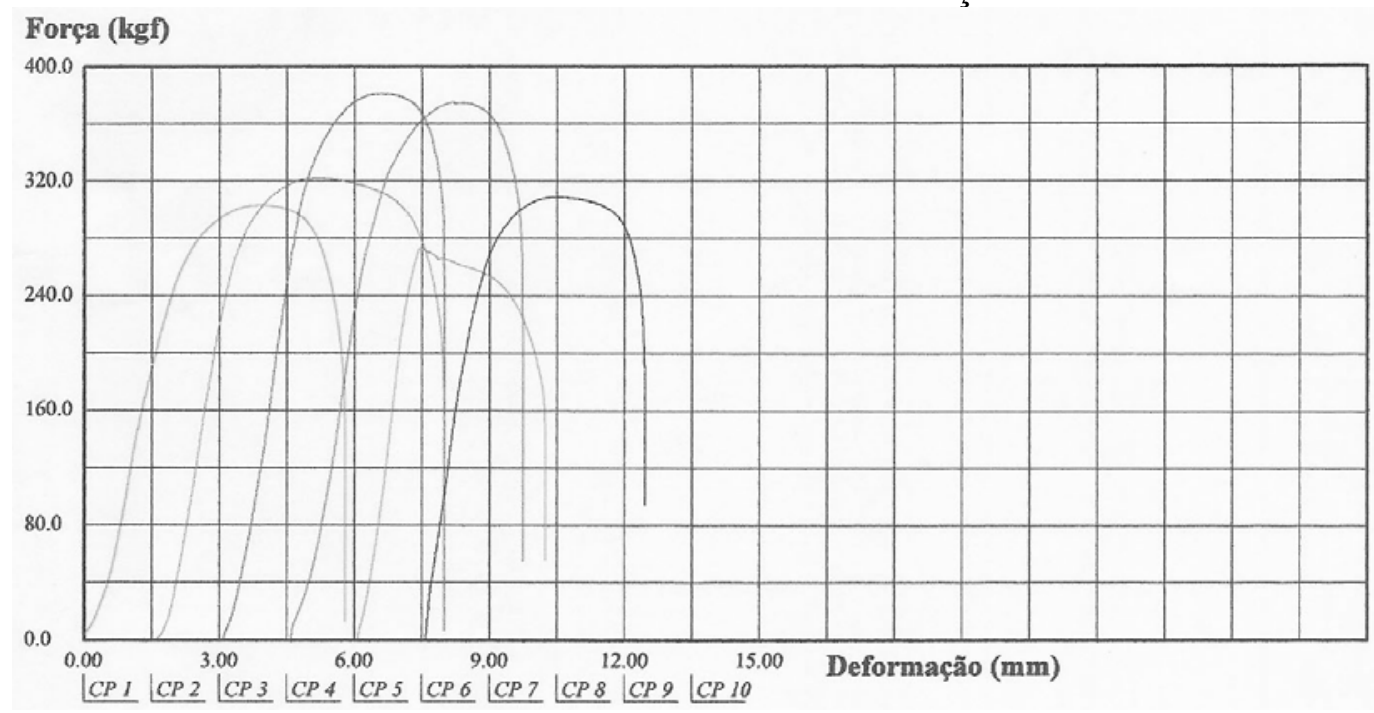

ANEXO C - Curva força x deformação dos corpos-de-prova de Ti-5Zr submetidos a ensaio de tração

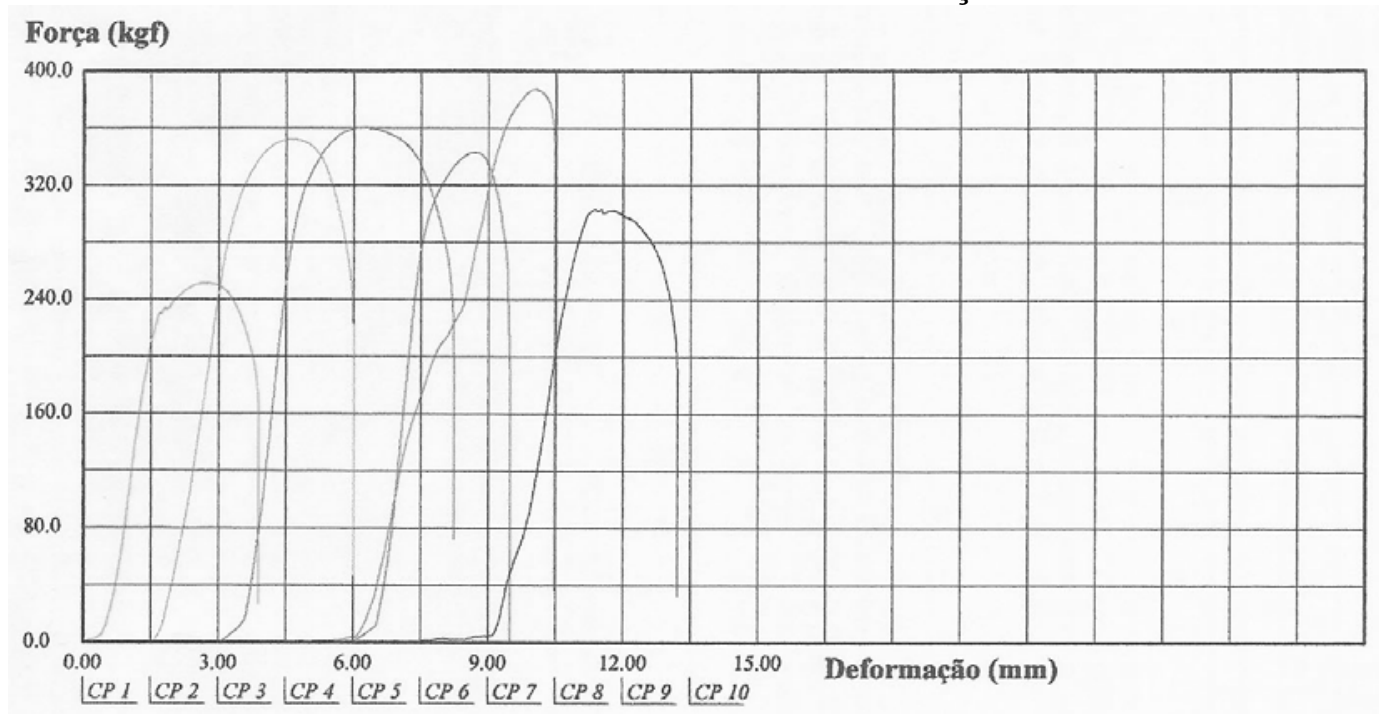


ANEXO D - Curva força x deformação dos corpos-de-prova de Ti-5Ta submetidos a ensaio de tração

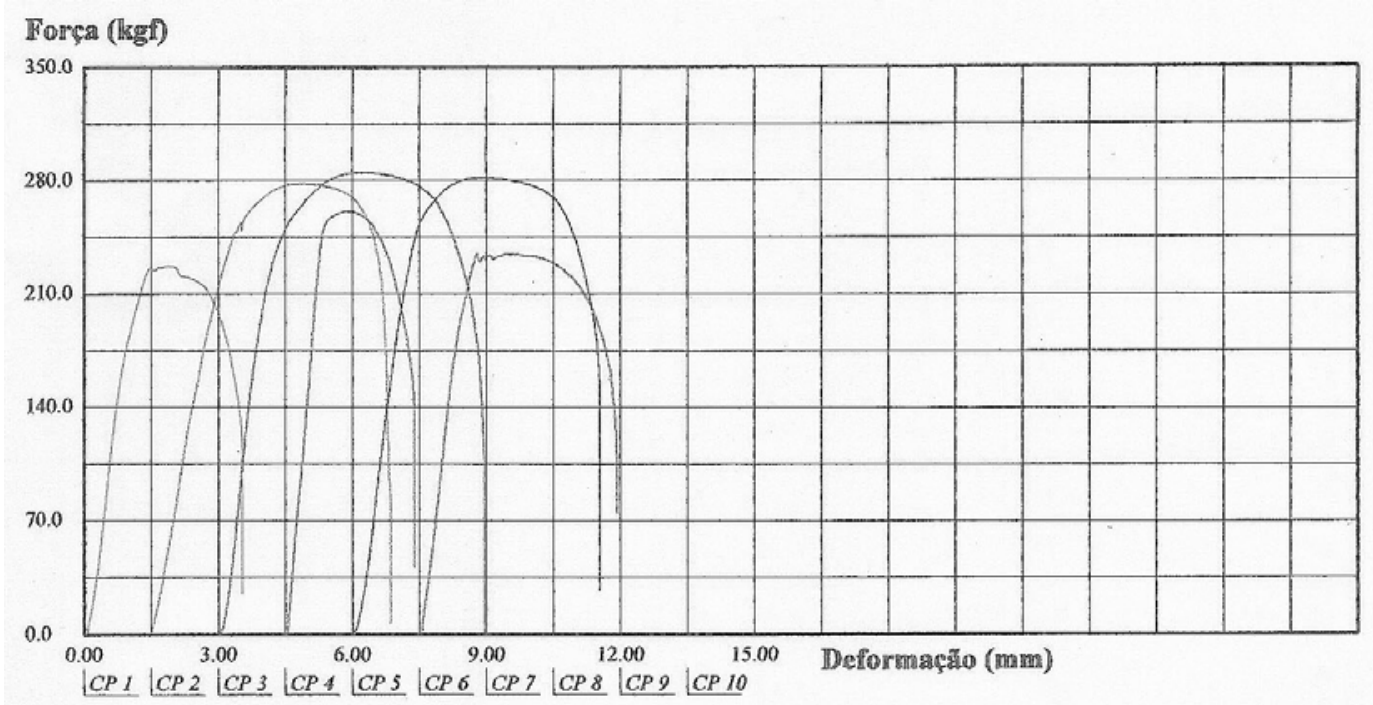

ANEXO E - Curva força x deformação dos corpos-de-prova de Ti-5Ta-5Zr submetidos a ensaio de tração

Força (kgf)

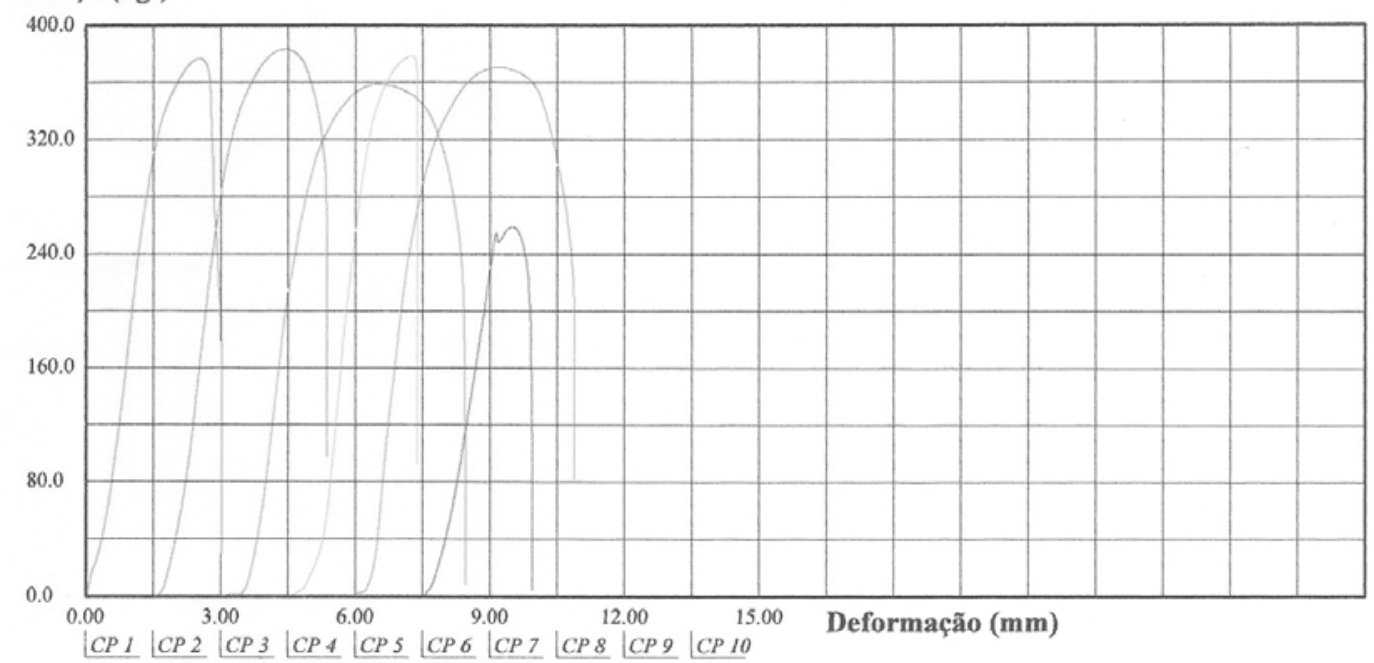

ANEXO F - Análise de Variância para resultados de tensão na força máxima obtidos em ensaio de resistência à tração

\begin{tabular}{cccccc}
\hline & $\begin{array}{c}\text { Sum of } \\
\text { Squares }\end{array}$ & df & $\begin{array}{c}\text { Mean } \\
\text { Square }\end{array}$ & $F$ & Sig. \\
\hline $\begin{array}{c}\text { Between } \\
\text { Groups }\end{array}$ & 65799,283 & 3 & 21933,094 & 6,011 &, 004 \\
\hline Within Groups & 72982,584 & 20 & 3649,129 & & \\
\hline Total & 138781,866 & 23 & & & \\
\hline
\end{tabular}


ANEXO G - Teste de Tukey para resultados de tensão na força máxima obtidos em ensaio de resistência à tração

\begin{tabular}{|c|c|c|c|c|}
\hline & & \multirow{2}{*}{$\mathrm{N}$} & \multicolumn{2}{|c|}{ Subset for alpha $=.05$} \\
\hline & & & 1 & 2 \\
\hline \multirow{5}{*}{$\begin{array}{l}\text { Tukey } \\
\text { HSD(a) }\end{array}$} & Ti-Ta & 6 & 364,3867 & \\
\hline & $\mathrm{Ti}-\mathrm{Zr}$ & 6 & & 468,6450 \\
\hline & Ti cp & 6 & & 477,6633 \\
\hline & Ti-Ta-Zr & 6 & & 500,5533 \\
\hline & Sig. & & 1,000 & ,797 \\
\hline
\end{tabular}

ANEXO H - Resultados do módulo de elasticidade (GPa) obtidos em ensaio de flexão

\begin{tabular}{ccccc}
\hline & Ti $\mathbf{~ p}$ & Ti-Zr & Ti-Ta & Ti-Ta-Zr \\
\hline \hline 1 & 78,93 & 38,14 & 60,36 & 75,43 \\
2 & 31,10 & 55,38 & 40,25 & 72,69 \\
3 & 42,86 & 39,21 & 27,49 & 37,68 \\
4 & 79,56 & 64,31 & 24,47 & 71,00 \\
5 & 81,10 & 47,72 & 24,59 & 53,92 \\
6 & 86,88 & 94,03 & 70,98 & 38,26 \\
7 & 78,29 & 71,89 & 20,79 & 32,83 \\
8 & 74,57 & 64,48 & 37,81 & 78,56 \\
9 & 43,06 & 40,67 & 21,96 & 50,61 \\
10 & 42,42 & 63,70 & 63,01 & 41,27 \\
\hline Média & $\mathbf{6 3 , 8 8}$ & $\mathbf{5 7 , 9 5}$ & $\mathbf{3 9 , 1 7}$ & $\mathbf{5 5 , 2 2}$ \\
DP & $\mathbf{2 1 , 1 6}$ & $\mathbf{1 7 , 5 3}$ & $\mathbf{1 8 , 9 5}$ & $\mathbf{1 7 , 7 1}$ \\
\hline
\end{tabular}

ANEXO I - Análise de Variância para resultados do módulo de elasticidade (GPa) obtidos em ensaio de flexão

\begin{tabular}{cccccc}
\hline & $\begin{array}{c}\text { Sum of } \\
\text { Squares }\end{array}$ & df & $\begin{array}{c}\text { Mean } \\
\text { Square }\end{array}$ & $F$ & Sig. \\
\hline $\begin{array}{c}\text { Between } \\
\text { Groups }\end{array}$ & 3345,684 & 3 & 1115,228 & 3,125 &, 038 \\
\hline Within Groups & 12848,823 & 36 & 356,912 & & \\
\hline Total & 16194,507 & 39 & & & \\
\hline
\end{tabular}

ANEXO J - Teste de Tukey para resultados do módulo de elasticidade (GPa) obtidos em ensaio de flexão

\begin{tabular}{ccccc}
\hline & & \multirow{2}{*}{$N$} & \multicolumn{2}{c}{ Subset for alpha $=.05$} \\
\cline { 4 - 5 } & & & \multicolumn{1}{c}{1} & 2 \\
\hline \multirow{3}{*}{ Tukey } & Ti-Ta & 10 & 39,1710 & \\
HSD(a) & Ti-Ta-Zr & 10 & 55,2250 & 55,2250 \\
& Ti-Zr & 10 & 57,9530 & 57,9530 \\
& Ti cp & 10 & & 63,8770 \\
\cline { 2 - 5 } & Sig. & &, 136 &, 737 \\
\hline
\end{tabular}


ANEXO K - Resultados de perda de altura vertical $(\mu \mathrm{m})$ obtidos em teste de abrasão de 2 corpos

\begin{tabular}{ccccc}
\hline & Ti cp & Ti-5Zr & Ti-5Ta & Ti-5Ta-5Zr \\
\hline \hline 1 & 211,0 & 161,0 & 94,0 & 244,0 \\
2 & 155,5 & 142,5 & 134,0 & 114,0 \\
3 & 225,5 & 142,5 & 82,5 & 141,5 \\
4 & 232,0 & 172,0 & 147,5 & 131,5 \\
5 & 220,0 & 139,5 & 177,0 & 97,0 \\
6 & 233,5 & 176,0 & 153,0 & 95,5 \\
\hline Média & $\mathbf{2 1 2 , 9}$ & $\mathbf{1 5 5 , 6}$ & $\mathbf{1 3 1 , 3}$ & $\mathbf{1 3 7 , 3}$ \\
DP & $\mathbf{2 9 , 3}$ & $\mathbf{1 6 , 2}$ & $\mathbf{3 6 , 3}$ & $\mathbf{5 5 , 4}$ \\
\hline \hline
\end{tabular}

ANEXO L - Análise de Variância para resultados de perda de altura vertical $(\mu \mathrm{m})$ obtidos em teste de abrasão de 2 corpos

\begin{tabular}{cccccc}
\hline & $\begin{array}{c}\text { Sum of } \\
\text { Squares }\end{array}$ & df & $\begin{array}{c}\text { Mean } \\
\text { Square }\end{array}$ & F & Sig. \\
\hline $\begin{array}{c}\text { Between } \\
\text { Groups }\end{array}$ & 25845,833 & 3 & 8615,278 & 6,425 &, 003 \\
\hline Within Groups & 26816,667 & 20 & 1340,833 & & \\
\hline Total & 52662,500 & 23 & & & \\
\hline
\end{tabular}

ANEXO M - Teste de Tukey para resultados de perda de altura vertical $(\mu \mathrm{m})$ obtidos em teste de abrasão de 2 corpos

\begin{tabular}{ccccc}
\hline & & \multirow{2}{*}{$N$} & \multicolumn{2}{c}{ Subset for alpha $=.05$} \\
\cline { 4 - 5 } & & & \multicolumn{2}{c}{1} \\
\hline & Ti-Ta & 6 & 130,0000 & \\
Tukey & Ti-Ta-Zr & 6 & 136,6667 & \\
HSD(a) & Ti-Zr & 6 & 155,0000 & 155,0000 \\
& Ti cp & 6 & & 213,3333 \\
\cline { 2 - 5 } & Sig. & &, 644 &, 054 \\
\hline
\end{tabular}

ANEXO N - Resultados de microdureza (VHN)

\begin{tabular}{ccccc}
\hline & Ti $\mathbf{~ p}$ & Ti-Zr & Ti-Ta & Ti-Ta-Zr \\
\hline \hline 1 & 145 & 232 & 295 & 135 \\
2 & 209 & 251 & 174 & 188 \\
3 & 182 & 349 & 211 & 270 \\
4 & 320 & 343 & 190 & 171 \\
5 & 240 & 253 & 195 & 249 \\
6 & 219 & 312 & 204 & 217 \\
7 & 183 & 335 & 171 & 155 \\
8 & 192 & 250 & 238 & 183 \\
9 & 170 & 308 & 259 & 213 \\
10 & 260 & 277 & 204 & 166 \\
11 & 280 & 308 & 169 & 228 \\
12 & 178 & 228 & 247 & 218 \\
\hline Média & $\mathbf{2 1 4 , 8 3}$ & $\mathbf{2 8 7 , 1 7}$ & $\mathbf{2 1 3 , 0 8}$ & $\mathbf{1 9 9 , 4 2}$ \\
DP & $\mathbf{5 1 , 2 5}$ & $\mathbf{4 3 , 9 2}$ & $\mathbf{3 9 , 1 5}$ & $\mathbf{3 9 , 9 4}$ \\
\hline
\end{tabular}


ANEXO O - Análise de Variância para resultados de microdureza (VHN)

\begin{tabular}{cccccc}
\hline & $\begin{array}{c}\text { Sum of } \\
\text { Squares }\end{array}$ & df & $\begin{array}{c}\text { Mean } \\
\text { Square }\end{array}$ & F & Sig. \\
\hline $\begin{array}{c}\text { Between } \\
\text { Groups }\end{array}$ & 56544,083 & 3 & 18848,028 & 9,813 &, 000 \\
\hline Within Groups & 84509,167 & 44 & 1920,663 & & \\
\hline Total & 141053,250 & 47 & & & \\
\hline
\end{tabular}

ANEXO P - Teste de Tukey para resultados de microdureza (VHN)

\begin{tabular}{ccccc}
\hline & Materiais & \multirow{2}{*}{} & \multicolumn{2}{c}{ Subset for alpha $=.05$} \\
\cline { 4 - 5 } & & & \multicolumn{2}{c}{1} \\
& Ti-Ta-Zr & 12 & 199,4167 & \\
Tukey & Ti-Ta & 12 & 213,0833 & \\
HSD(a) & Ti cp & 12 & 214,8333 & \\
& Ti-Zr & 12 & & 287,1667 \\
\cline { 2 - 5 } & Sig. & &, 824 & 1,000 \\
\hline
\end{tabular}

ANEXO Q - Resultados de absorbância (A) obtidos pelo método histoquímico MTT nos períodos de 1, 4, 7, 10 e 14 dias

\begin{tabular}{ccccccc}
\hline & & MTT 24h & MTT 4d & MTT 7d & MTT 10d & MTT 14d \\
\hline Ti cp & 1 & 0,014 & 0,017 & 0,060 & 0,108 & 0,125 \\
Ti cp & 2 & 0,021 & 0,025 & 0,069 & 0,128 & 0,138 \\
Ti cp & 3 & 0,018 & 0,018 & 0,079 & 0,132 & 0,154 \\
Ti cp & 4 & 0,019 & 0,021 & 0,079 & 0,113 & 0,143 \\
Ti cp & 5 & 0,016 & 0,018 & 0,069 & 0,116 & 0,140 \\
\hline Ti-Zr & 6 & 0,010 & 0,036 & 0,078 & 0,126 & 0,152 \\
Ti-Zr & 7 & 0,014 & 0,025 & 0,068 & 0,127 & 0,166 \\
Ti-Zr & 8 & 0,014 & 0,029 & 0,065 & 0,122 & 0,131 \\
Ti-Zr & 9 & 0,014 & 0,010 & 0,055 & 0,124 & 0,135 \\
Ti-Zr & 10 & 0,013 & 0,023 & 0,067 & 0,133 & 0,132 \\
\hline Ti-Ta & 11 & 0,013 & 0,033 & 0,071 & 0,149 & 0,163 \\
Ti-Ta & 12 & 0,014 & 0,020 & 0,073 & 0,140 & 0,164 \\
Ti-Ta & 13 & 0,019 & 0,030 & 0,038 & 0,129 & 0,151 \\
Ti-Ta & 14 & 0,017 & 0,032 & 0,082 & 0,117 & 0,152 \\
Ti-Ta & 15 & 0,018 & 0,026 & 0,077 & 0,143 & 0,147 \\
\hline Ti-Ta-Zr & 16 & 0,011 & 0,030 & 0,067 & 0,163 & 0,159 \\
Ti-Ta-Zr & 17 & 0,017 & 0,017 & 0,056 & 0,134 & 0,157 \\
Ti-Ta-Zr & 18 & 0,019 & 0,038 & 0,080 & 0,119 & 0,159 \\
Ti-Ta-Zr & 19 & 0,013 & 0,029 & 0,081 & 0,115 & 0,127 \\
Ti-Ta-Zr & 20 & 0,017 & 0,023 & 0,070 & 0,133 & 0,153 \\
\hline Controle & 21 & 0,032 & 0,071 & 0,170 & 0,300 & 0,316 \\
Controle & 22 & 0,033 & 0,063 & 0,156 & 0,325 & 0,278 \\
Controle & 23 & 0,034 & 0,062 & 0,157 & 0,361 & 0,284 \\
Controle & 24 & 0,040 & 0,064 & 0,176 & 0,322 & 0,305 \\
\hline
\end{tabular}


ANEXO R - Análise de Variância para os resultados de absorbância (A) obtidos pelo método histoquímico MTT no período de 1 dia

\begin{tabular}{cccccc}
\hline & $\begin{array}{c}\text { Sum of } \\
\text { Squares }\end{array}$ & df & $\begin{array}{c}\text { Mean } \\
\text { Square }\end{array}$ & F & Sig. \\
\hline $\begin{array}{c}\text { Between } \\
\text { Groups }\end{array}$ &, 000 & 3 &, 000 & 3,109 &, 056 \\
\hline Within Groups &, 000 & 16 &, 000 & & \\
\hline Total &, 000 & 19 & & & \\
\hline
\end{tabular}

ANEXO S - Teste de Tukey para os resultados de absorbância (A) obtidos pelo método histoquímico MTT no período de 1 dia

\begin{tabular}{ccccc}
\hline & & \multirow{2}{*}{$N$} & \multicolumn{2}{c}{ Subset for alpha $=.05$} \\
\cline { 3 - 5 } & & & 1 & 2 \\
\hline \multirow{3}{*}{ Tukey } & Ti-Zr & 5 &, 0129 & \\
HSD(a) & Ti-Ta-Zr & 5 &, 0156 &, 0156 \\
& Ti-Ta & 5 &, 0164 &, 0164 \\
& Ti cp & 5 & &, 0176 \\
\cline { 2 - 5 } & Sig. & &, 173 &, 592 \\
\hline
\end{tabular}

ANEXO T - Análise de Variância para os resultados de absorbância (A) obtidos pelo método histoquímico MTT no período de 4 dias

\begin{tabular}{cccccc}
\hline & $\begin{array}{c}\text { Sum of } \\
\text { Squares }\end{array}$ & df & $\begin{array}{c}\text { Mean } \\
\text { Square }\end{array}$ & F & Sig. \\
\hline $\begin{array}{c}\text { Between } \\
\text { Groups }\end{array}$ &, 000 & 3 &, 000 & 1,455 &, 264 \\
\hline Within Groups &, 001 & 16 &, 000 & & \\
\hline Total &, 001 & 19 & & & \\
\hline
\end{tabular}

ANEXO U - Teste de Tukey para os resultados de absorbância (A) obtidos pelo método histoquímico MTT no período de 4 dias

\begin{tabular}{cccc}
\hline & & $N$ & Subset for alpha $=.05$ \\
\cline { 3 - 4 } & & & 1 \\
\hline \multirow{5}{*}{ Tukey HSD(a) } & Ti cp & 5 &, 0198 \\
& Ti-Zr & 5 &, 0246 \\
& Ti-Ta-Zr & 5 &, 0275 \\
& Ti-Ta & 5 &, 0280 \\
\cline { 2 - 4 } & Sig. & &, 281 \\
\hline
\end{tabular}

ANEXO V - Análise de Variância para os resultados de absorbância (A) obtidos pelo método histoquímico MTT no período de 7 dias

\begin{tabular}{cccccc}
\hline & $\begin{array}{c}\text { Sum of } \\
\text { Squares }\end{array}$ & df & $\begin{array}{c}\text { Mean } \\
\text { Square }\end{array}$ & F & Sig. \\
\hline $\begin{array}{c}\text { Between } \\
\text { Groups }\end{array}$ &, 000 & 3 &, 000 &, 197 &, 897 \\
\hline Within Groups &, 002 & 16 &, 000 & & \\
\hline Total &, 002 & 19 & & & \\
\hline
\end{tabular}


ANEXO W - Teste de Tukey para os resultados de absorbância (A) obtidos pelo método histoquímico MTT no período de 7 dias

\begin{tabular}{cccc}
\hline & & $N$ & \multicolumn{2}{c}{ Subset for alpha $=.05$} \\
\cline { 3 - 4 } & & & 1 \\
\hline \multirow{4}{*}{ Tukey } & Ti-Zr & 5 &, 0665 \\
HSD(a) & Ti-Ta & 5 &, 0681 \\
& Ti-Ta-Zr & 5 &, 0710 \\
& Ti cp & 5 &, 0712 \\
\cline { 2 - 4 } & Sig. & &, 915 \\
\hline
\end{tabular}

ANEXO X - Análise de Variância para os resultados de absorbância (A) obtidos pelo método histoquímico MTT no período de 10 dias

\begin{tabular}{cccccc}
\hline & $\begin{array}{c}\text { Sum of } \\
\text { Squares }\end{array}$ & df & $\begin{array}{c}\text { Mean } \\
\text { Square }\end{array}$ & $\mathrm{F}$ & Sig. \\
\hline $\begin{array}{c}\text { Between } \\
\text { Groups }\end{array}$ &, 001 & 3 &, 000 & 1,589 &, 231 \\
\hline Within Groups &, 003 & 16 &, 000 & & \\
\hline Total &, 003 & 19 & & & \\
\hline
\end{tabular}

ANEXO Y - Teste de Tukey para os resultados de absorbância (A) obtidos pelo método histoquímico MTT no período de 10 dias

\begin{tabular}{cccc}
\hline & & $N$ & \multicolumn{2}{c}{ Subset for alpha $=.05$} \\
\cline { 3 - 4 } & & & 1 \\
\hline \multirow{4}{*}{ Tukey } & Ti cp & 5 &, 1193 \\
HSD(a) & Ti-Zr & 5 &, 1263 \\
& Ti-Ta-Zr & 5 &, 1326 \\
& Ti-Ta & 5 &, 1352 \\
\cline { 2 - 4 } & Sig. & &, 230 \\
\hline
\end{tabular}

ANEXO Z - Análise de Variância para os resultados de absorbância (A) obtidos pelo método histoquímico MTT no período de 14 dias

\begin{tabular}{cccccc}
\hline & $\begin{array}{c}\text { Sum of } \\
\text { Squares }\end{array}$ & df & $\begin{array}{c}\text { Mean } \\
\text { Square }\end{array}$ & F & Sig. \\
\hline $\begin{array}{c}\text { Between } \\
\text { Groups }\end{array}$ &, 001 & 3 &, 000 & 1,711 &, 205 \\
\hline Within Groups &, 002 & 16 &, 000 & & \\
\hline Total &, 003 & 19 & & & \\
\hline
\end{tabular}


ANEXO AA - Teste de Tukey para os resultados de absorbância (A) obtidos pelo método histoquímico MTT no período de 14 dias

\begin{tabular}{lllrr}
\hline & & & \multicolumn{2}{c}{ Subset for alpha $=.05$} \\
\cline { 4 - 5 } & & & & 1 \\
\hline Tukey & Ti cp & 5 & 1399 \\
HSD(a) & Ti-Zr & 5 &, 1431 \\
& Ti-Ta-Zr & 5 &, 1508 \\
& Ti-Ta & 5 &, 1553 \\
\cline { 4 - 5 } & Sig. & &, 221 \\
\hline
\end{tabular}

ANEXO AB - Resultados de viabilidade celular expresso como \% de células viáveis no período 7 dias

\begin{tabular}{cccccc}
\hline & Ti cp & Ti-Zr & Ti-Ta & Ti-Ta-Zr & Controle \\
\hline 1 & 83,544 & 79,518 & 64,286 & 97,500 & 77,419 \\
2 & 75,949 & 112,048 & 68,571 & 86,250 & 58,065 \\
3 & 56,962 & 57,831 & 85,714 & 37,500 & 100,000 \\
\hline Média & $\mathbf{7 2 , 1 5 2}$ & $\mathbf{8 3 , 1 3 3}$ & $\mathbf{7 2 , 8 5 7}$ & $\mathbf{7 3 , 7 5 0}$ & $\mathbf{7 8 , 4 9 5}$ \\
DP & $\mathbf{1 3 , 6 9 2}$ & $\mathbf{2 7 , 2 8 9}$ & $\mathbf{1 1 , 3 3 9}$ & $\mathbf{3 1 , 8 9 3}$ & $\mathbf{2 0 , 9 8 8}$ \\
\hline
\end{tabular}

ANEXO AC - Análise de Variância para resultados de viabilidade celular expresso como \% de células viáveis no período 7 dias

\begin{tabular}{cccccc}
\hline & $\begin{array}{c}\text { Sum of } \\
\text { Squares }\end{array}$ & df & $\begin{array}{c}\text { Mean } \\
\text { Square }\end{array}$ & $\mathrm{F}$ & Sig. \\
\hline $\begin{array}{c}\text { Between } \\
\text { Groups }\end{array}$ & 2,538 & 4 &, 634 &, 329 &, 852 \\
\hline Within Groups & 19,294 & 10 & 1,929 & & \\
\hline Total & 21,832 & 14 & & & \\
\hline
\end{tabular}

ANEXO AD - Teste de Tukey para resultados de viabilidade celular expresso como \% de células viáveis no período 7 dias

\begin{tabular}{ccc}
\hline & $N$ & Subset for alpha $=.05$ \\
\cline { 3 - 3 } Ti Ta & 3 & 1 \\
Ti cp & 3 & 4,8887 \\
Ti Ta Zr & 3 & 4,3890 \\
Ti Zr & 3 & 4,4443 \\
Controle & 3 & 5,6110 \\
\hline Sig. & & 5,1667 \\
\hline
\end{tabular}


ANEXO AE - Porcentagem de células nos diferentes estágios de desenvolvimento no período de 2 horas

I - Células redondas pequenas
II- Células redondas maiores
III- Células espraiadas
IV- Células em migração

\begin{tabular}{|c|c|c|c|c|}
\hline Discos $2 h$ & $\mathbf{I}$ & II & III & IV \\
\hline Controle 1 & 51,49 & 44,55 & 0,99 & 2,97 \\
\hline Controle 2 & 60,00 & 36,00 & 3,00 & 1,00 \\
\hline Controle 3 & 51,40 & 45,79 & 2,80 & 0,00 \\
\hline Média & 54,30 & 42,12 & 2,26 & 1,32 \\
\hline DP & 4,94 & 5,33 & 1,11 & 1,51 \\
\hline Ticp 1 & 53,85 & 39,56 & 1,10 & 5,49 \\
\hline Ticp 2 & 63,27 & 31,63 & 4,08 & 1,02 \\
\hline Ticp 3 & 79,80 & 19,19 & 1,01 & 0,00 \\
\hline Média & 65,64 & 30,13 & 2,06 & 2,17 \\
\hline DP & 13,14 & 10,27 & 1,75 & 2,92 \\
\hline Ti-Zr 1 & 59,41 & 39,60 & 0,00 & 0,99 \\
\hline Ti-Zr 2 & 71,56 & 27,52 & 0,92 & 0,00 \\
\hline Ti-Zr 3 & 74,29 & 25,71 & 0,00 & 0,00 \\
\hline Média & 68,42 & 30,95 & 0,31 & 0,33 \\
\hline DP & 7,92 & 7,55 & 0,53 & 0,57 \\
\hline Ti-Ta 1 & 61,11 & 38,89 & 0,00 & 0,00 \\
\hline Ti-Ta 2 & 51,00 & 48,00 & 0,00 & 1,00 \\
\hline Ti-Ta 3 & 67,96 & 29,13 & 0,00 & 2,91 \\
\hline Média & 60,02 & 38,67 & 0,00 & 1,30 \\
\hline DP & 8,53 & 9,44 & 0,00 & 1,48 \\
\hline Ti-Ta-Zr 1 & 74,26 & 23,76 & 1,98 & 0,00 \\
\hline Ti-Ta-Zr 2 & 75,49 & 24,51 & 0,00 & 0,00 \\
\hline Ti-Ta-Zr 3 & 71,90 & 25,62 & 0,83 & 1,65 \\
\hline Média & 73,88 & 24,63 & 0,94 & 0,55 \\
\hline DP & 1,82 & 0,93 & 0,99 & 0,95 \\
\hline
\end{tabular}


ANEXO AF - Porcentagem de células nos diferentes estágios de desenvolvimento no período de 12 horas

I - Células redondas pequenas

II- Células redondas maiores

III- Células espraiadas

IV- Células em migração

\begin{tabular}{|c|c|c|c|c|}
\hline Discos 12h & $\mathrm{I}$ & II & III & IV \\
\hline Controle 1 & 2,38 & 11,90 & 68,25 & 17,46 \\
\hline Controle 2 & 0,93 & 17,76 & 61,68 & 19,63 \\
\hline Controle 3 & 2,63 & 14,04 & 71,05 & 12,28 \\
\hline Média & 1,98 & 14,57 & 67,00 & 16,46 \\
\hline DP & 0,92 & 2,96 & 4,81 & 3,77 \\
\hline Ticp 1 & 3,15 & 6,30 & 70,87 & 19,69 \\
\hline Ticp 2 & 3,48 & 11,30 & 60,87 & 24,35 \\
\hline Ticp 3 & 2,34 & 12,50 & 66,41 & 18,75 \\
\hline Média & 2,99 & 10,03 & 66,05 & 20,93 \\
\hline DP & 0,58 & 3,29 & 5,01 & 3,00 \\
\hline Ti-Zr 1 & 6,25 & 11,61 & 65,18 & 16,96 \\
\hline Ti-Zr 2 & 0,79 & 19,84 & 55,56 & 23,81 \\
\hline Ti-Zr 3 & 2,40 & 12,80 & 64,00 & 20,80 \\
\hline Média & 3,15 & 14,75 & 61,58 & 20,52 \\
\hline DP & 2,80 & 4,45 & 5,25 & 3,43 \\
\hline Ti-Ta 1 & 1,64 & 12,30 & 63,11 & 22,95 \\
\hline Ti-Ta 2 & 0,00 & 11,82 & 62,73 & 25,45 \\
\hline Ti-Ta 3 & 1,90 & 4,76 & 79,05 & 14,29 \\
\hline Média & 1,18 & 9,63 & 68,30 & 20,90 \\
\hline DP & 1,03 & 4,22 & 9,31 & 5,86 \\
\hline Ti-Ta-Zr 1 & 2,50 & 16,67 & 57,50 & 23,33 \\
\hline Ti-Ta-Zr 2 & 4,90 & 14,71 & 66,67 & 13,73 \\
\hline Ti-Ta-Zr 3 & 10,71 & 27,68 & 48,21 & 13,39 \\
\hline Média & 6,04 & 19,68 & 57,46 & 16,82 \\
\hline DP & 4,22 & 6,99 & 9,23 & 5,65 \\
\hline
\end{tabular}


ANEXO AG - Porcentagem de células nos diferentes estágios de desenvolvimento no período de 24 horas

I - Células redondas pequenas

II- Células redondas maiores

III- Células espraiadas

IV- Células em migração

\begin{tabular}{|c|c|c|c|c|}
\hline $\begin{array}{l}\text { Discos } \\
24 h\end{array}$ & 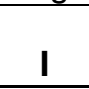 & II & III & IV \\
\hline Controle 1 & 0,00 & 2,65 & 76,11 & 21,24 \\
\hline Controle 2 & 0,00 & 1,60 & 80,80 & 17,60 \\
\hline Controle 3 & 0,00 & 4,42 & 70,80 & 24,78 \\
\hline Média & 0,00 & 2,89 & 75,90 & 21,21 \\
\hline DP & 0,00 & 1,43 & 5,00 & 3,59 \\
\hline Ticp 1 & 1,59 & 2,38 & 76,19 & 19,84 \\
\hline Ticp 2 & 0,00 & 2,42 & 70,16 & 27,42 \\
\hline Ticp 3 & 0,85 & 7,69 & 70,94 & 20,51 \\
\hline Média & 0,81 & 4,16 & 72,43 & 22,59 \\
\hline DP & 0,79 & 3,06 & 3,28 & 4,19 \\
\hline Ti-Zr 1 & 0,00 & 2,54 & 72,88 & 24,58 \\
\hline Ti-Zr 2 & 0,75 & 0,00 & 78,20 & 21,05 \\
\hline Ti-Zr 3 & 0,78 & 1,56 & 72,66 & 25,00 \\
\hline Média & 0,51 & 1,37 & 74,58 & 23,54 \\
\hline DP & 0,44 & 1,28 & 3,14 & 2,17 \\
\hline Ti-Ta 1 & 2,01 & 0,67 & 73,83 & 23,49 \\
\hline Ti-Ta 2 & 0,00 & 3,48 & 80,00 & 16,52 \\
\hline Ti-Ta 3 & 0,83 & 0,83 & 66,67 & 31,67 \\
\hline Média & 0,95 & 1,66 & 73,50 & 23,89 \\
\hline DP & 1,01 & 1,58 & 6,67 & 7,58 \\
\hline Ti-Ta-Zr 1 & 0,66 & 0,66 & 77,48 & 21,19 \\
\hline Ti-Ta-Zr 2 & 0,68 & 0,68 & 79,59 & 19,05 \\
\hline Ti-Ta-Zr 3 & 3,42 & 4,27 & 70,94 & 21,37 \\
\hline Média & 1,59 & 1,87 & 76,01 & 20,54 \\
\hline DP & 1,59 & 2,08 & 4,51 & 1,29 \\
\hline
\end{tabular}


ANEXO AG - Comparação da porcentagem de células em cada estágio de desenvolvimento entre os materiais e entre os tempos

\begin{tabular}{|c|c|c|c|c|}
\hline \multirow{2}{*}{ Comparações } & \multirow{2}{*}{ Estimativa média da diferença } & \multirow{2}{*}{ P-Valor } & \multicolumn{2}{|c|}{ IC 95\% } \\
\hline & & & LI & LS \\
\hline (Tempo 12 -24)I Ti-Ta & 0,23 & 0,95 & $-7,43$ & 7,90 \\
\hline (Tempo 12 -24)I Ti-Ta-Zr & 4,45 & 0,25 & $-3,21$ & 12,12 \\
\hline (Tempo 12 -24)I Ti-Zr & 2,64 & 0,50 & $-5,03$ & 10,30 \\
\hline (Tempo 12 -24)I Ticp & 2,18 & 0,58 & $-5,49$ & 9,84 \\
\hline (Tempo 12 -24)I controle & 1,98 & 0,61 & $-5,68$ & 9,65 \\
\hline (Tempo 12 -24)II Ti-Ta & 7,96 & 0,04 & 0,30 & 15,63 \\
\hline (Tempo 12 -24)II Ti-Ta-Zr & 17,81 & $<0,01$ & 10,15 & 25,48 \\
\hline (Tempo 12 -24)II Ti-Zr & 13,38 & $<0,01$ & 5,72 & 21,05 \\
\hline (Tempo 12 -24)II Ticp & 5,87 & 0,13 & $-1,79$ & 13,54 \\
\hline (Tempo 12 -24)II controle & 11,67 & $<0,01$ & 4,01 & 19,34 \\
\hline (Tempo 12 -24)III Ti-Ta & $-5,20$ & 0,18 & $-12,87$ & 2,46 \\
\hline (Tempo 12 -24)III Ti-Ta-Zr & $-18,54$ & $<0,01$ & $-26,21$ & $-10,88$ \\
\hline (Tempo 12 -24)III Ti-Zr & $-13,00$ & $<0,01$ & $-20,66$ & $-5,33$ \\
\hline (Tempo 12 -24)III Ticp & $-6,38$ & 0,10 & $-14,05$ & 1,28 \\
\hline (Tempo 12 -24)III controle & $-8,90$ & 0,02 & $-16,57$ & $-1,24$ \\
\hline (Tempo 12 -24)IV Ti-Ta & $-3,00$ & 0,44 & $-10,66$ & 4,67 \\
\hline (Tempo 12 -24)IV Ti-Ta-Zr & $-3,72$ & 0,34 & $-11,38$ & 3,95 \\
\hline (Tempo 12 -24)IV Ti-Zr & $-3,02$ & 0,44 & $-10,68$ & 4,65 \\
\hline (Tempo 12 -24)IV Ticp & $-1,66$ & 0,67 & $-9,33$ & 6,00 \\
\hline (Tempo 12 -24)IV controle & $-4,75$ & 0,22 & $-12,42$ & 2,91 \\
\hline (Tempo 12 -2)I Ti-Ta & $-58,84$ & $<0,01$ & $-66,51$ & $-51,18$ \\
\hline (Tempo 12 -2)I Ti-Ta-Zr & $-67,84$ & $<0,01$ & $-75,51$ & $-60,18$ \\
\hline (Tempo 12 -2)I Ti-Zr & $-65,27$ & $<0,01$ & $-72,93$ & $-57,60$ \\
\hline (Tempo 12 -2)I Ticp & $-62,65$ & $<0,01$ & $-70,31$ & $-54,98$ \\
\hline (Tempo 12 -2)I controle & $-52,31$ & $<0,01$ & $-59,98$ & $-44,65$ \\
\hline (Tempo 12 -2)II Ti-Ta & $-29,05$ & $<0,01$ & $-36,71$ & $-21,38$ \\
\hline (Tempo 12 -2)II Ti-Ta-Zr & $-4,95$ & 0,20 & $-12,61$ & 2,72 \\
\hline (Tempo 12 -2)II Ti-Zr & $-16,20$ & $<0,01$ & $-23,86$ & $-8,53$ \\
\hline (Tempo 12 -2)II Тіср & $-20,09$ & $<0,01$ & $-27,76$ & $-12,43$ \\
\hline (Tempo 12 -2)II controle & $-27,55$ & $<0,01$ & $-35,22$ & $-19,89$ \\
\hline (Tempo 12 -2)III Ti-Ta & 68,30 & $<0,01$ & 60,63 & 75,96 \\
\hline (Tempo 12 -2)III Ti-Ta-Zr & 56,52 & $<0,01$ & 48,86 & 64,19 \\
\hline (Tempo 12 -2)III Ti-Zr & 61,27 & $<0,01$ & 53,61 & 68,94 \\
\hline (Tempo 12 -2)III Ticp & 63,98 & $<0,01$ & 56,32 & 71,65 \\
\hline (Tempo 12 -2)III controle & 64,73 & $<0,01$ & 57,07 & 72,40 \\
\hline (Tempo 12 -2)IV Ti-Ta & 19,59 & $<0,01$ & 11,93 & 27,26 \\
\hline (Tempo 12 -2)IV Ti-Ta-Zr & 16,27 & $<0,01$ & 8,60 & 23,93 \\
\hline (Tempo 12 -2)IV Ti-Zr & 20,19 & $<0,01$ & 12,53 & 27,86 \\
\hline (Tempo 12 -2)IV Ticp & 18,76 & $<0,01$ & 11,09 & 26,42 \\
\hline (Tempo 12 -2)IV controle & 15,13 & 0,00 & 7,47 & 22,80 \\
\hline (Tempo 24 -2)I Ti-Ta & $-59,08$ & $<0,01$ & $-66,74$ & $-51,41$ \\
\hline (Tempo 24 -2)I Ti-Ta-Zr & $-72,30$ & $<0,01$ & $-79,96$ & $-64,63$ \\
\hline
\end{tabular}


(Tempo 24 -2)I Ti-Zr

(Tempo 24 -2)I Ticp

(Tempo 24 -2)I controle

(Tempo 24 -2)II Ti-Ta

(Tempo 24 -2)II Ti-Ta-Zr

(Tempo 24 -2)II Ti-Zr

(Tempo 24 -2)II Ticp

(Tempo 24 -2)II controle

(Tempo 24 -2)III Ti-Ta

(Tempo 24 -2)III Ti-Ta-Zr

(Tempo 24 -2)III Ti-Zr

(Tempo 24 -2)III Ticp

(Tempo 24 -2)III controle

(Tempo 24 -2)IV Ti-Ta

(Tempo 24 -2)IV Ti-Ta-Zr

(Tempo 24 -2)IV Ti-Zr

(Tempo 24 -2)IV Ticp

(Tempo 24 -2)IV controle

(TiTa - TiTaZr)12h I

(TiTa - TiZr)12h I

(TiTa - Ticp)12h I

(TiTa - cont)12h I

(TiTaZr - TiZr)12h I

(TiTaZr - Ticp)12h I

(TiTaZr - cont)12h I

(TiZr - Ticp)12h I

(TiZr - cont)12h I

(Ticp - cont)12h I

(TiTa - TiTaZr)24h I

(TiTa - TiZr)24h I

(TiTa - Ticp)24h I

(TiTa - cont)24h I

(TiTaZr - TiZr)24h I

(TiTaZr - Ticp)24h I

(TiTaZr - cont)24h I

(TiZr - Ticp)24h I

(TiZr - cont)24h I

(Ticp - cont)24h I

(TiTa - TiTaZr)2h I

(TiTa - TiZr)2h I

(TiTa - Ticp)2h I

(TiTa - cont)2h I

(TiTaZr - TiZr)2h I

(TiTaZr - Ticp)2h I

(TiTaZr - cont)2h I

(TiZr - Ticp)2h I
$-67,91$

$-64,82$

$-54,30$

$-37,01$

$-22,76$

$-29,58$

$-25,96$

$-39,22$

73,50

75,07

74,27

70,37

73,64

22,59

19,98

23,21

20,42

19,88

$-4,86$

$-1,97$

$-1,81$

$-0,80$

2,89

3,05

4,06

0,16

1,17

1,01

$-0,64$

0,44

0,13

0,95

1,08

0,77

1,59

$-0,30$

0,51

0,81

$-13,86$

$-8,39$

$-5,61$

5,73

5,47

8,25

19,59

2,78

$\begin{array}{ccc}<0,01 & -75,57 & -60,24 \\ <0,01 & -72,49 & -57,16 \\ <0,01 & -61,96 & -46,63 \\ <0,01 & -44,68 & -29,35 \\ <0,01 & -30,42 & -15,09 \\ <0,01 & -37,24 & -21,91 \\ <0,01 & -33,63 & -18,30 \\ <0,01 & -46,89 & -31,56 \\ <0,01 & 65,83 & 81,16 \\ <0,01 & 67,40 & 82,73 \\ <0,01 & 66,61 & 81,94 \\ <0,01 & 62,70 & 78,03 \\ <0,01 & 65,97 & 81,30 \\ <0,01 & 14,92 & 30,25 \\ <0,01 & 12,32 & 27,65 \\ <0,01 & 15,55 & 30,88 \\ <0,01 & 12,75 & 28,08 \\ <0,01 & 12,22 & 27,55 \\ 0,21 & -12,52 & 2,81 \\ 0,61 & -9,63 & 5,70 \\ 0,64 & -9,47 & 5,86 \\ 0,84 & -8,47 & 6,86 \\ 0,46 & -4,77 & 10,56 \\ 0,43 & -4,62 & 10,71 \\ 0,30 & -3,61 & 11,72 \\ 0,97 & -7,51 & 7,82 \\ 0,76 & -6,50 & 8,83 \\ 0,80 & -6,66 & 8,67 \\ 0,87 & -8,30 & 7,03 \\ 0,91 & -7,23 & 8,10 \\ 0,97 & -7,53 & 7,80 \\ 0,81 & -6,72 & 8,61 \\ 0,78 & -6,59 & 8,74 \\ 0,84 & -6,89 & 8,44 \\ 0,68 & -6,08 & 9,25 \\ 0,94 & -7,97 & 7,36 \\ 0,90 & -7,15 & 8,18 \\ 0,83 & -6,85 & 8,48 \\ <0,01 & -21,52 & -6,19 \\ 0,03 & -16,06 & -0,73 \\ 0,15 & -13,28 & 2,05 \\ 0,14 & -1,94 & 13,39 \\ 0,16 & -2,20 & 13,13 \\ 0,04 & 0,58 & 15,91 \\ 04 & 11,92 & 27,25 \\ & -4,88 & 10,45\end{array}$




\begin{tabular}{|c|c|c|c|c|}
\hline (TiZr - cont)2h I & 14,12 & $<0,01$ & 6,46 & 21,79 \\
\hline (Ticp - cont)2h I & 11,34 & $<0,01$ & 3,68 & 19,01 \\
\hline (TiTa - TiTaZr)12h II & $-10,06$ & 0,01 & $-17,72$ & $-2,39$ \\
\hline (TiTa - TiZr)12h II & $-5,12$ & 0,19 & $-12,79$ & 2,54 \\
\hline (TiTa - Ticp)12h II & $-0,41$ & 0,92 & $-8,07$ & 7,26 \\
\hline (TiTa - cont)12h II & $-4,94$ & 0,20 & $-12,61$ & 2,72 \\
\hline (TiTaZr - TiZr)12h II & 4,93 & 0,20 & $-2,73$ & 12,60 \\
\hline (TiTaZr - Ticp)12h II & 9,65 & 0,01 & 1,98 & 17,31 \\
\hline (TiTaZr - cont)12h II & 5,12 & 0,19 & $-2,55$ & 12,78 \\
\hline (TiZr - Ticp)12h II & 4,72 & 0,23 & $-2,95$ & 12,38 \\
\hline (TiZr - cont)12h II & 0,18 & 0,96 & $-7,48$ & 7,85 \\
\hline (Ticp - cont)12h II & $-4,53$ & 0,24 & $-12,20$ & 3,13 \\
\hline (TiTa - TiTaZr)24h II & $-0,21$ & 0,96 & $-7,88$ & 7,45 \\
\hline (TiTa - TiZr)24h II & 0,29 & 0,94 & $-7,37$ & 7,96 \\
\hline (TiTa - Tiср)24h II & $-2,50$ & 0,52 & $-10,17$ & 5,16 \\
\hline (TiTa - cont)24h II & $-1,23$ & 0,75 & $-8,90$ & 6,43 \\
\hline (TiTaZr - TiZr)24h II & 0,50 & 0,90 & $-7,16$ & 8,17 \\
\hline (TiTaZr - Ticp)24h II & $-2,29$ & 0,55 & $-9,96$ & 5,37 \\
\hline (TiTaZr - cont)24h II & $-1,02$ & 0,79 & $-8,69$ & 6,64 \\
\hline (TiZr - Ticp)24h II & $-2,80$ & 0,47 & $-10,46$ & 4,87 \\
\hline (TiZr - cont)24h II & $-1,52$ & 0,69 & $-9,19$ & 6,14 \\
\hline (Ticp - cont)24h II & 1,27 & 0,74 & $-6,39$ & 8,94 \\
\hline (TiTa - TiTaZr)2h II & 14,04 & $<0,01$ & 6,38 & 21,71 \\
\hline (TiTa - TiZr)2h II & 7,72 & 0,05 & 0,06 & 15,39 \\
\hline (TiTa - Ticp)2h II & 8,54 & 0,03 & 0,88 & 16,21 \\
\hline (TiTa - cont)2h II & $-3,44$ & 0,38 & $-11,11$ & 4,22 \\
\hline (TiTaZr - TiZr)2h II & $-6,32$ & 0,11 & $-13,98$ & 1,35 \\
\hline (TiTaZr - Ticp)2h II & $-5,50$ & 0,16 & $-13,16$ & 2,17 \\
\hline (TiTaZr - cont)2h II & $-17,49$ & $<0,01$ & $-25,15$ & $-9,82$ \\
\hline (TiZr - Ticp)2h II & 0,82 & 0,83 & $-6,85$ & 8,48 \\
\hline (TiZr - cont)2h II & $-11,17$ & $<0,01$ & $-18,83$ & $-3,50$ \\
\hline (Ticp - cont)2h II & $-11,99$ & $<0,01$ & $-19,65$ & $-4,32$ \\
\hline (TiTa - TiTaZr)12h III & 10,84 & 0,01 & 3,17 & 18,50 \\
\hline (TiTa - TiZr)12h III & 6,72 & 0,09 & $-0,95$ & 14,38 \\
\hline (TiTa - Ticp)12h III & 2,25 & 0,56 & $-5,42$ & 9,91 \\
\hline (TiTa - cont)12h III & 1,30 & 0,74 & $-6,36$ & 8,97 \\
\hline (TiTaZr - TiZr)12h III & $-4,12$ & 0,29 & $-11,78$ & 3,55 \\
\hline (TiTaZr - Ticp)12h III & $-8,59$ & 0,03 & $-16,25$ & $-0,92$ \\
\hline (TiTaZr - cont)12h III & $-9,54$ & 0,02 & $-17,20$ & $-1,87$ \\
\hline (TiZr - Ticp)12h III & $-4,47$ & 0,25 & $-12,13$ & 3,20 \\
\hline (TiZr - cont)12h III & $-5,42$ & 0,16 & $-13,08$ & 2,25 \\
\hline (Ticp - cont)12h III & $-0,95$ & 0,81 & $-8,61$ & 6,72 \\
\hline (TiTa - TiTaZr)24h III & $-2,51$ & 0,52 & $-10,17$ & 5,16 \\
\hline (TiTa - TiZr)24h III & $-1,08$ & 0,78 & $-8,75$ & 6,58 \\
\hline (TiTa - Ticp)24h III & 1,07 & 0,78 & $-6,60$ & 8,73 \\
\hline (TiTa - cont)24h III & $-2,40$ & 0,54 & $-10,07$ & 5,26 \\
\hline
\end{tabular}


(TiTaZr - TiZr)24h III

(TiTaZr - Ticp)24h III

(TiTaZr - cont)24h III

(TiZr - Ticp)24h III

(TiZr - cont)24h III

(Ticp - cont)24h III

(TiTa - TiTaZr)2h III

(TiTa - TiZr)2h III

(TiTa - Ticp)2h III

(TiTa - cont)2h III

(TiTaZr - TiZr)2h III

(TiTaZr - Ticp)2h III

(TiTaZr - cont)2h III

(TiZr - Ticp)2h III

(TiZr - cont)2h III

(Ticp - cont)2h III

(TiTa - TiTaZr)12h VI

(TiTa - TiZr)12h VI

(TiTa - Ticp)12h VI

(TiTa - cont)12h VI

(TiTaZr - TiZr)12h VI

(TiTaZr - Ticp)12h VI

(TiTaZr - cont)12h VI

(TiZr - Ticp)12h VI

(TiZr - cont)12h VI

(Ticp - cont)12h VI

(TiTa - TiTaZr)24h VI

(TiTa - TiZr)24h VI

(TiTa - Ticp)24h VI

(TiTa - cont)24h VI

(TiTaZr - TiZr)24h VI

(TiTaZr - Ticp)24h VI

(TiTaZr - cont)24h VI

(TiZr - Ticp)24h VI

(TiZr - cont)24h VI

(Ticp - cont)24h VI

(TiTa - TiTaZr)2h VI

(TiTa - TiZr)2h VI

(TiTa - Ticp)2h VI

(TiTa - cont)2h VI

(TiTaZr - TiZr)2h VI

(TiTaZr - Ticp)2h VI

(TiTaZr - cont)2h VI

(TiZr - Ticp)2h VI

(TiZr - cont)2h VI

(Ticp - cont)2h VI
1,43

3,57

0,10

2,15

$-1,32$

$-3,47$

$-0,94$

$-0,31$

$-2,06$

$-2,26$

0,63

$-1,13$

$-1,33$

$-1,76$

$-1,96$

$-0,20$

4,08

0,37

$-0,03$

4,44

$-3,71$

$-4,11$

0,36

$-0,40$

4,07

4,47

3,36

0,35

1,30

2,69

$-3,01$

$-2,06$

$-0,67$

0,95

2,34

1,39

0,75

0,97

$-0,87$

$-0,02$

0,22

$-1,62$

$-0,77$

$-1,84$

$-0,99$

0,85 $\begin{array}{lll}0,71 & -6,24 & 9,09\end{array}$

$0,36 \quad-4,09 \quad 11,24$

$0,98 \quad-7,56 \quad 7,77$

$0,58 \quad-5,52 \quad 9,81$

$0,73 \quad-8,99 \quad 6,34$

$0,37 \quad-11,14 \quad 4,19$

$0,81 \quad-8,60 \quad 6,73$

$0,94 \quad-7,97 \quad 7,36$

$0,60 \quad-9,73 \quad 5,60$

$0,56 \quad-9,93 \quad 5,40$

$0,87 \quad-7,04 \quad 8,29$

$0,77 \quad-8,79 \quad 6,54$

$0,73 \quad-8,99 \quad 6,34$

$0,65 \quad-9,42 \quad 5,91$

$0,61 \quad-9,62 \quad 5,71$

$0,96 \quad-7,87 \quad 7,46$

$0,29 \quad-3,59 \quad 11,74$

$0,92 \quad-7,29 \quad 8,04$

$0,99 \quad-7,70 \quad 7,63$

$0,25 \quad-3,22 \quad 12,11$

$0,34 \quad-11,37 \quad 3,96$

$0,29 \quad-11,78 \quad 3,55$

$0,93 \quad-7,30 \quad 8,03$

$0,92 \quad-8,07 \quad 7,26$

$0,30 \quad-3,60 \quad 11,73$

$0,25 \quad-3,19 \quad 12,14$

$0,39 \quad-4,31 \quad 11,02$

$0,93 \quad-7,32 \quad 8,01$

$0,74 \quad-6,36 \quad 8,97$

$0,49 \quad-4,98 \quad 10,35$

$0,44 \quad-10,67 \quad 4,66$

$0,60 \quad-9,72 \quad 5,61$

$0,86 \quad-8,34 \quad 6,99$

$0,81 \quad-6,71 \quad 8,62$

$0,55 \quad-5,33 \quad 10,00$

$0,72 \quad-6,28 \quad 9,05$

$0,85 \quad-6,91 \quad 8,42$

$0,80 \quad-6,69 \quad 8,64$

$0,82 \quad-8,53 \quad 6,80$

$1,00 \quad-7,68 \quad 7,65$

$0,95 \quad-7,44 \quad 7,89$

$0,68 \quad-9,29 \quad 6,04$

$0,84 \quad-8,44 \quad 6,89$

$0,64 \quad-9,51 \quad 5,82$

$0,80 \quad-8,66 \quad 6,67$

$0,83 \quad-6,82 \quad 8,51$ 
ANEXO AH - Difractograma de raios-X da liga Ti-5Zr após fundição odontológica

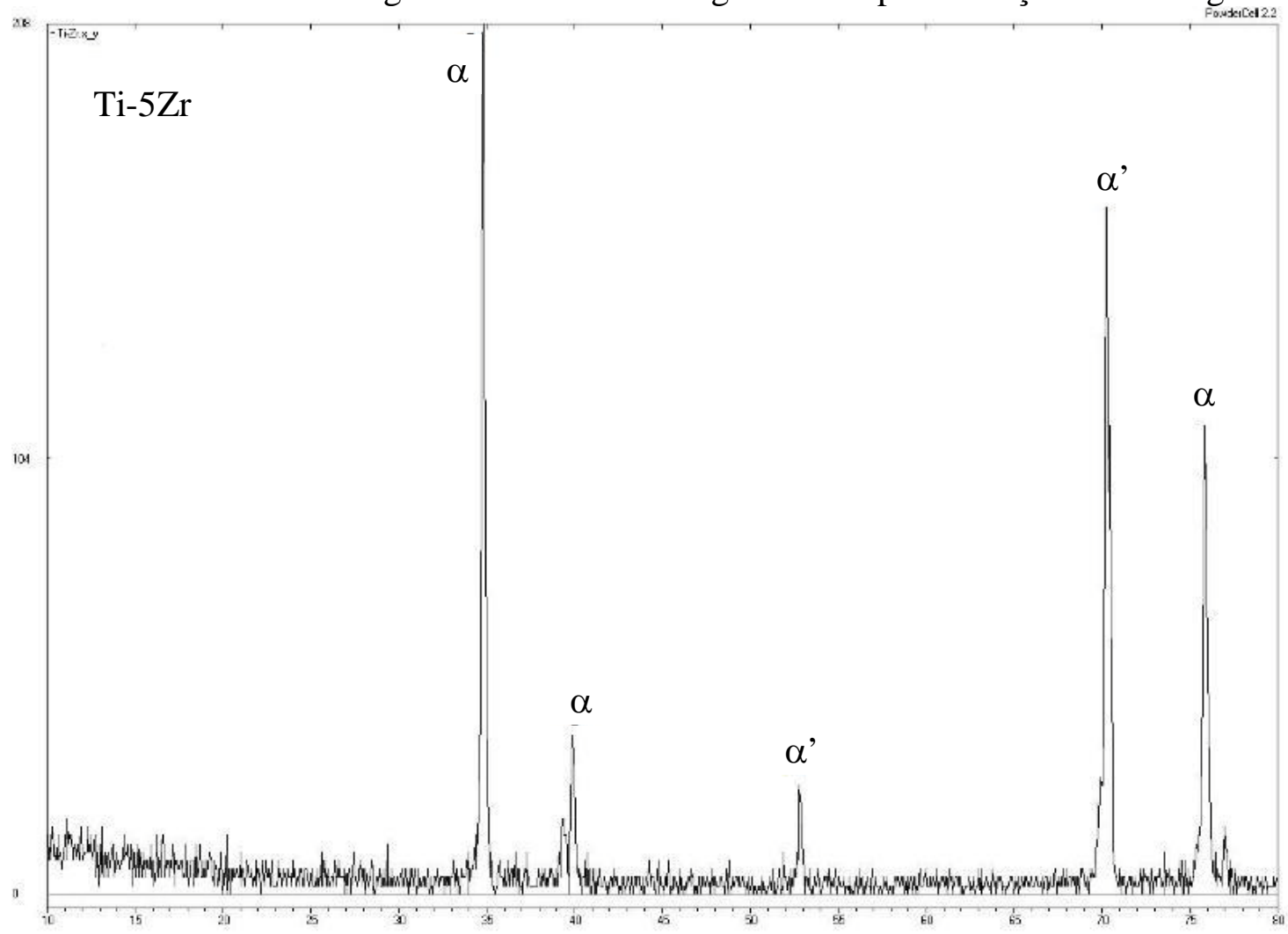

ANEXO AI - Difractograma de raios-X da liga Ti-5Ta após fundição odontológica

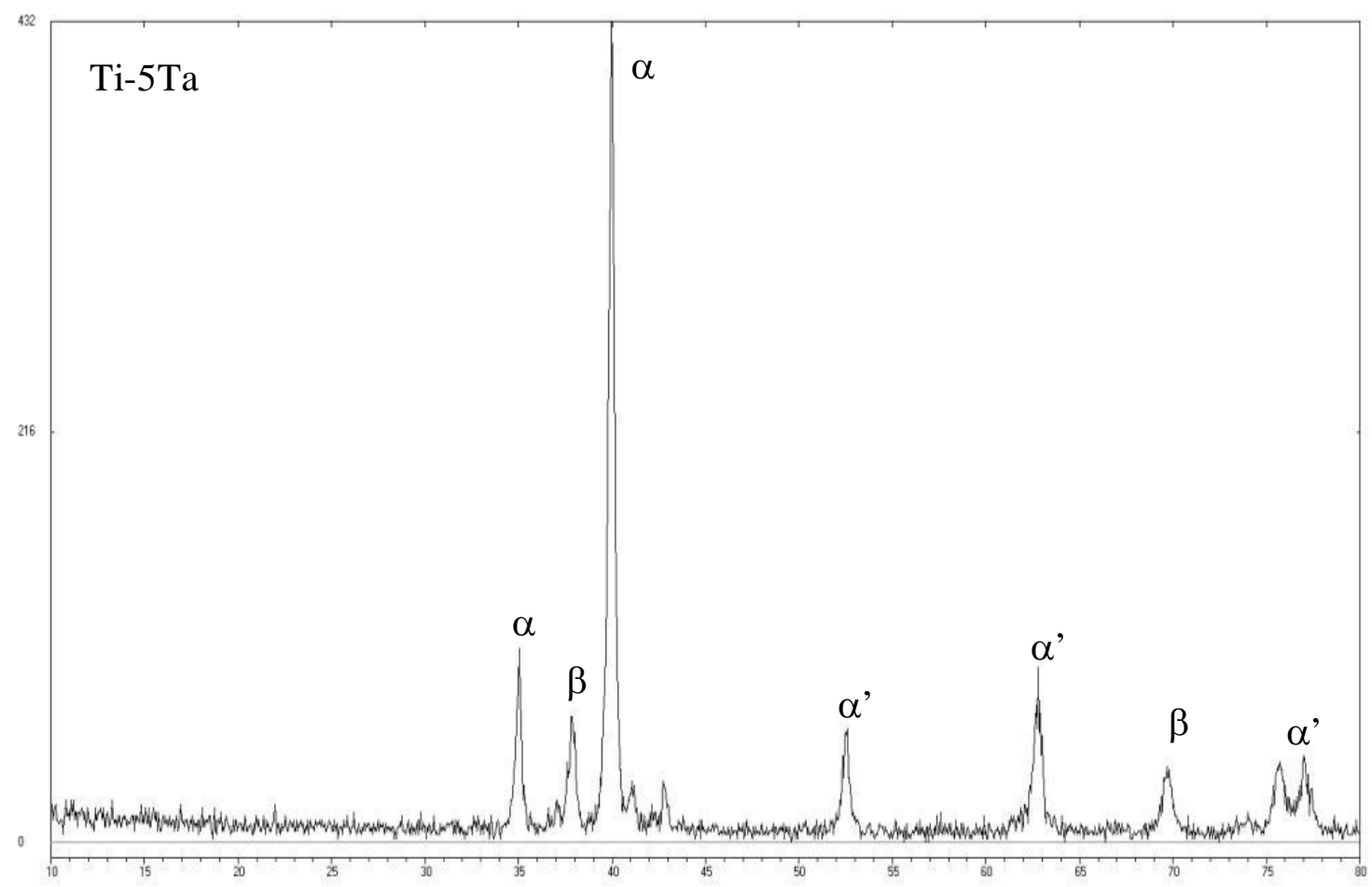


ANEXO AJ - Difractograma de raios-X da liga Ti-5Ta-5Zr após fundição odontológica

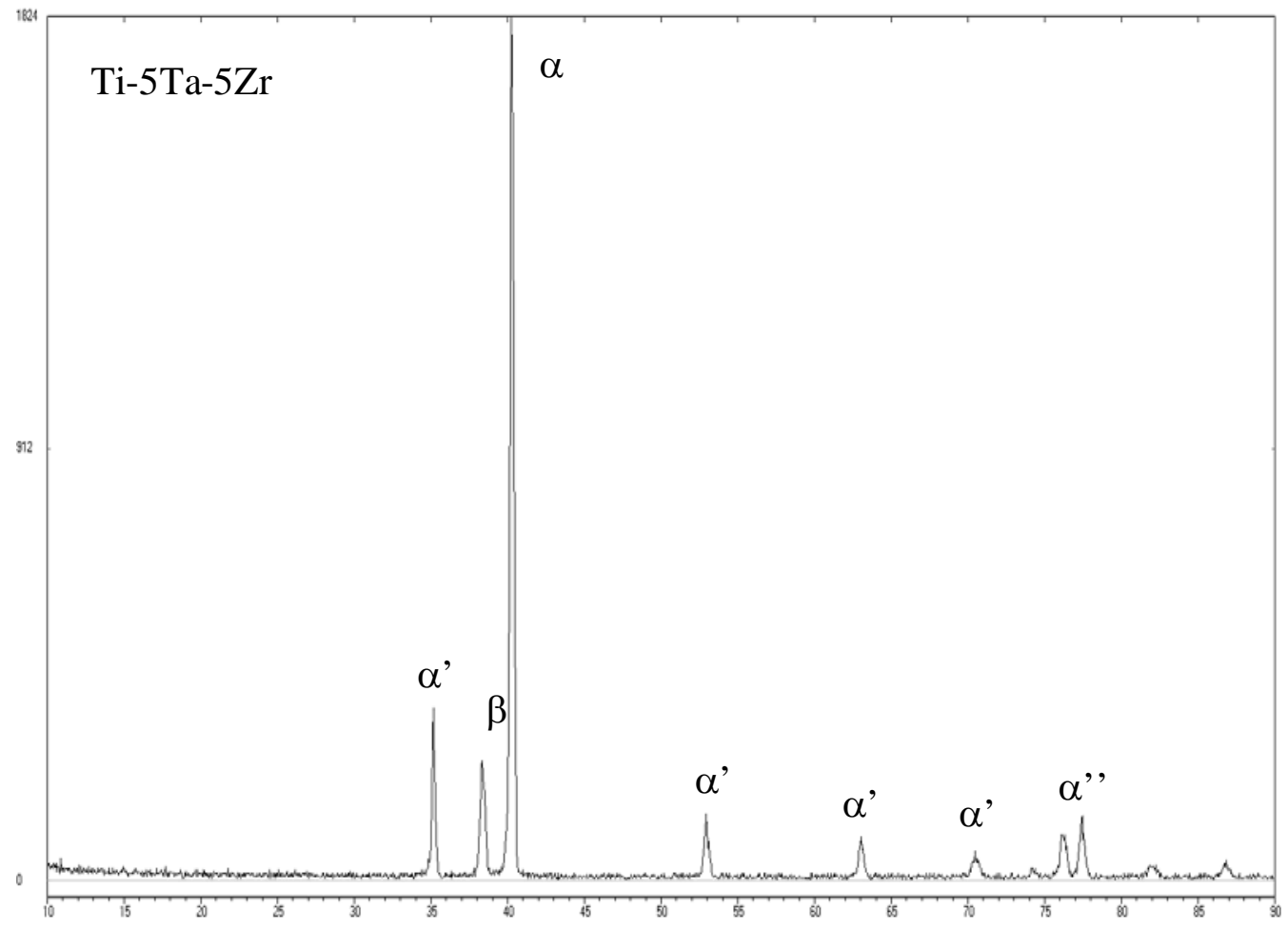

